\title{
The Incomplete Glutathione Puzzle: Just Guessing at Numbers and Figures?
}

\author{
Marcel Deponte
}

\author{
The phoenicians invented money—but why so little? \\ (Johann Nestroy) \\ Mother Nature invented glutathione-but why so much?
}

\begin{abstract}
Significance: Glutathione metabolism is comparable to a jigsaw puzzle with too many pieces. It is supposed to comprise (i) the reduction of disulfides, hydroperoxides, sulfenic acids, and nitrosothiols, (ii) the detoxification of aldehydes, xenobiotics, and heavy metals, and (iii) the synthesis of eicosanoids, steroids, and iron-sulfur clusters. In addition, glutathione affects oxidative protein folding and redox signaling. Here, I try to provide an overview on the relevance of glutathione-dependent pathways with an emphasis on quantitative data.

Recent Advances: Intracellular redox measurements reveal that the cytosol, the nucleus, and mitochondria contain very little glutathione disulfide and that oxidative challenges are rapidly counterbalanced. Genetic approaches suggest that iron metabolism is the centerpiece of the glutathione puzzle in yeast. Furthermore, recent biochemical studies provide novel insights on glutathione transport processes and uncoupling mechanisms.

Critical Issues: Which parts of the glutathione puzzle are most relevant? Does this explain the high intracellular concentrations of reduced glutathione? How can iron-sulfur cluster biogenesis, oxidative protein folding, or redox signaling occur at high glutathione concentrations? Answers to these questions not only seem to depend on the organism, cell type, and subcellular compartment but also on different ideologies among researchers.

Future Directions: A rational approach to compare the relevance of glutathione-dependent pathways is to combine genetic and quantitative kinetic data. However, there are still many missing pieces and too little is known about the compartment-specific repertoire and concentration of numerous metabolites, substrates, enzymes, and transporters as well as rate constants and enzyme kinetic patterns. Gathering this information might require the development of novel tools but is crucial to address potential kinetic competitions and to decipher uncoupling mechanisms to solve the glutathione puzzle. Antioxid. Redox Signal. 27, 1130-1161.
\end{abstract}

Keywords: glutathione, concentration, compartmentalization, kinetics, rate constant, function

\section{Introduction and Scope}

G LUTATHIONE IS A MAJOR THIOL CURRENCY and pivotal adapter molecule in metabolism. In contrast to traditional theories on nonenzymatic redox buffering, glutathione exerts multiple functions far beyond the maintenance of a reducing intracellular milieu (60). The versatility of glutathione metabolism is reflected by at least five nonrelated protein folds that have been optimized for glutathione interaction and catalysis in the course of evolution. These

Department of Parasitology, Ruprecht-Karls University, Heidelberg, Germany.

(C) Marcel Deponte, 2017; Published by Mary Ann Liebert, Inc. This article is available under the Creative Commons License CC-BY-NC (http://creativecommons.org/licenses/by-nc/4.0). This license permits non-commercial use, distribution and reproduction in any medium, provided the original work is properly cited. Permission only needs to be obtained for commercial use and can be done via RightsLink. 
Table 1. Overview of Glutathione-Dependent EnZymes

\begin{tabular}{|c|c|c|c|}
\hline Protein & Fold and family & Glutathione-dependent function ${ }^{\mathrm{a}}$ & Refs. \\
\hline GR & $\begin{array}{l}\text { Pyridine nucleotide } \\
\text { disulfide oxidoreductase } \\
\text { family }\end{array}$ & $\begin{array}{l}\mathrm{NADPH}+\mathrm{H}^{+}+\mathrm{GSSG} \rightarrow 2 \mathrm{GSH}+\mathrm{NADP}^{+} \\
\text {- Link the NADPH pool with the thiol/disulfide pool } \\
\text { - Reduce GSSG and maintain high GSH concentrations }\end{array}$ & (60) \\
\hline $\mathrm{Grx}^{\mathrm{b}}$ & Thioredoxin superfamily & $\begin{array}{l}\text { - Catalyze thiol/disulfide exchange reactions } \\
\text { (e.g., deglutathionylations or the reduction } \\
\text { of ribonucleotide reductase) } \\
\text { - Contribute to iron-sulfur cluster biosynthesis } \\
\text { - Play a regulatory role in iron and redox metabolism }\end{array}$ & $\begin{array}{c}(56,60,65,97 \\
163,214)\end{array}$ \\
\hline $\mathrm{PDI}^{\mathrm{b}}$ & Thioredoxin superfamily & $\begin{array}{l}\text { - Catalyze thiol/disulfide exchange reactions during } \\
\text { oxidative protein folding in the endoplasmic reticulum } \\
\text { - Reduce misfolded substrates of the ERAD pathway } \\
\text { - Act as redox regulator of other proteins }\end{array}$ & $\begin{array}{l}(8,36,209) \\
286)\end{array}$ \\
\hline $\mathrm{GPx}^{\mathrm{b}}$ & Thioredoxin superfamily & $\begin{array}{l}\mathrm{ROOH}+2 \mathrm{R}^{\prime} \mathrm{SH} \rightarrow \mathrm{R}^{\prime} \mathrm{SS} S^{\prime} \mathrm{R}+\mathrm{ROH}+\mathrm{H}_{2} \mathrm{O} \\
\text { - Reduce and detoxify hydroperoxides using Trx and/or GSH } \\
\text { - Act as redox sensor in signal transduction cascades }\end{array}$ & $\begin{array}{l}(34,35,60 \\
273)\end{array}$ \\
\hline $\operatorname{Prx}^{\mathrm{b}}$ & Thioredoxin superfamily & $\begin{array}{l}\mathrm{ROOH}+2 \mathrm{R}^{\prime} \mathrm{SH} \rightarrow \mathrm{R}^{\prime} \mathrm{SS} S^{\prime} \mathrm{R}+\mathrm{ROH}+\mathrm{H}_{2} \mathrm{O} \\
\text { - Reduce hydroperoxides using Trx, Grx, and/or GSH } \\
\text { - Act as redox sensor in signal transduction cascades }\end{array}$ & $\begin{array}{c}(34,60,113, \\
238)\end{array}$ \\
\hline $\mathrm{GST}^{\mathrm{b}}$ & $\begin{array}{l}\text { Thioredoxin superfamily } \\
\quad \text { (or DsbA-like }^{\mathrm{d}} \text { ) }\end{array}$ & $\begin{array}{l}\text { - Conjugate and detoxify drugs, xenobiotics, etc. } \\
\text { - Reduce hydroperoxides and/or disulfides } \\
\text { - Catalyze isomerizations (e.g., during } \\
\text { Phe/Tyr-degradation or steroid and eicosanoid metabolism) } \\
\text { - Exert regulatory functions by protein-protein interaction }\end{array}$ & $(30,60,117)$ \\
\hline MAPEG $^{\mathrm{b}}$ & $\begin{array}{l}\text { MAPEG domain- } \\
\text { like fold }\end{array}$ & $\begin{array}{l}\text { Membrane-associated proteins with divergent functions in } \\
\text { eicosanoid and glutathione metabolism: } \\
\text { - Catalyze conjugations and (hydro)peroxide reductions } \\
\text { - Catalyze eicosanoid isomerization and conversions }\end{array}$ & $(60,135,176)$ \\
\hline Glo1 & $\begin{array}{l}\text { Vicinal oxygen chelate } \\
\text { superfamily }\end{array}$ & $\begin{array}{l}\text { - Convert and detoxify 2-oxoaldehydes (isomerase step) } \\
\text { - Can have regulatory or unknown functions }\end{array}$ & $\begin{array}{l}(60,61,129, \\
256,270)\end{array}$ \\
\hline $\mathrm{Glo}^{\mathrm{b}}$ & $\begin{array}{l}\beta \text {-lactamase fold } \\
\text { binuclear metallo- } \\
\text { hydrolase family }\end{array}$ & $\begin{array}{l}\text { - Convert and detoxify 2-oxoaldehydes (thioesterase step) } \\
\text { - Hydrolyze alternative non-glutathione thioesters } \\
\text { - Can have regulatory or unknown functions }\end{array}$ & $\begin{array}{l}(60,61,129, \\
256,270)\end{array}$ \\
\hline GSNOR $^{\mathrm{e}}$ & $\begin{array}{l}\text { Alcohol dehydrogenase } \\
\text { fold }\end{array}$ & $\begin{array}{l}\text { - Catalyze the } \mathrm{NAD}^{+} \text {-dependent oxidation of formaldehyde } \\
\text { - Catalyze the NADH-dependent reduction of GSNO } \\
\text { - Might have regulatory functions }\end{array}$ & $(24,173,260)$ \\
\hline
\end{tabular}

${ }^{\text {a}}$ Physiological functions can differ significantly among isoforms and organisms.

${ }^{\mathrm{b}}$ Organisms often harbor several isoforms of these proteins.

${ }^{\mathrm{c}}$ The relevance of GSH and GSSG for these processes is not fully understood.

${ }^{\mathrm{d}}$ The $\alpha$-helical domain of kappa class GST is inserted and not fused to the Trx domain.

eIdentical to class III alcohol dehydrogenase (ADH5) or GSH-dependent formaldehyde dehydrogenase.

${ }^{\mathrm{f}} \mathrm{A}$ similar activity was reported for NADPH-dependent human carbonyl reductase 1 .

Glo1, glyoxalase 1; Grx, glutaredoxins; GPx, glutathione peroxidase; GR, glutathione reductase; GSNOR, GSNO reductase; GST, glutathione transferase; PDI, protein disulfide isomerase; Prx, peroxiredoxin; ROOH, hydroperoxide; Trx, thioredoxin.

glutathione-dependent proteins allow eukaryotes and many prokaryotes to metabolize a plethora of electrophilic substances, for example, to cope with chemical challenges that result from a glycolysis-driven aerobic lifestyle and the exposure to xenobiotics (60). The flexible chemistry of glutathione depends on its cysteinyl thiol group, whereas the $\gamma$-glutamyl peptide bond, as well as one positive and two negative charges, facilitates its recognition by enzymes. The repertoire of proteins and electrophiles that is considered to play a role in glutathione metabolism is summarized in Table 1 and Figure 1 and will serve as a starting point for this review. Among the multiple astonishing features of reduced glutathione (GSH) is its millimolar concentration in many organisms $(60,153,189,196,212,217)$. Which processes necessitate such a high concentration? On the contrary, how are some reactions between electrophiles and GSH prevented or, in other words, slowed down and kinetically uncoupled under these conditions? Furthermore, which of the enzymatic or nonenzymatic processes in glutathione metabolism are really relevant in vivo? These questions are difficult to address taking into account that (i) most of the genes encoding the proteins in Table 1 can be successfully knocked out in yeast and many other organisms and that (ii) noticeable phenotypes often require combined gene deletions or extreme chemical challenges $(29,60,73,105,106,119,132,163,168$, $184,195,240)$. A plausible explanation for the robustness of glutathione metabolism is that cells use redundant metabolic (backup) systems, for example, duplicated genes (297) or cytosolic and mitochondrial thioredoxin (Trx)/Trx reductase (TrxR) systems that can complement the loss of glutathione 

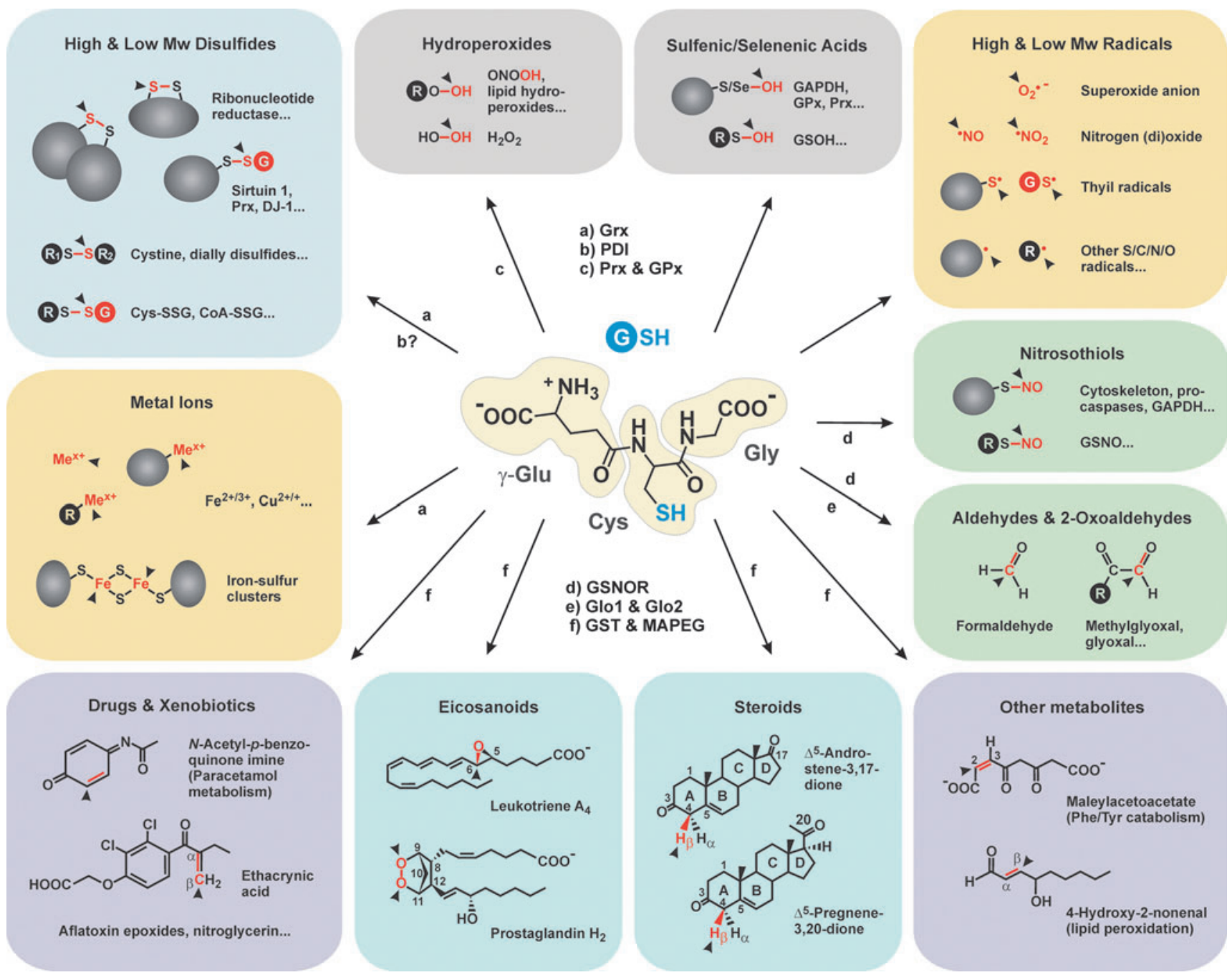

FIG. 1. Electrophilic metabolites and substrates that are considered to play a role in glutathione metabolism. Interaction sites between the electrophile and the thiolate group of glutathione (or the glutathione-dependent enzyme) are indicated by arrowheads. Enzymes are listed in Table 1. See Ref. (60) for details on the enzymatic mechanisms.

reductase in the same compartment $(11,105,109,272)$. Gene deletions can also trigger compensatory mechanisms that alter the proteome, which might affect, for example, the transport of metabolites or xenobiotics. Alternative explanations for mild or absent knockout phenotypes could be that some branches of glutathione metabolism in Figure 1 are either apparently irrelevant for survival because of the chosen experimental conditions, or are de facto irrelevant because of incorrect assumptions and concepts. How can we discriminate between these scenarios?

The redox metabolism of organelles and cells predominantly depends on kinetic instead of thermodynamic constraints as emphasized previously $(34,60,65,87,91)$. In contrast to the frequently used concept of nonenzymatic redox buffering, which is based on the Gibbs free energy of redox reactions at equilibrium, cellular systems use enzymes and work under steady-state conditions. Thus, reactions with favorable thermodynamics might be physiologically irrelevant because of a lack of catalyst, whereas less favorable reactions might occur because of a constant metabolic flux and energetic coupling. It is therefore problematic to rely on equilibrium-based redox potentials and to use the term "redox buffer" to rank redox reactions in vivo. A better quantitative approach to judge the physiological relevance of a glutathione-dependent reaction is to determine its rate and to compare it with potentially competing reactions. The ratio between the reaction rates of one and the same compound with different partners then tells us whether a kinetic competition is likely to occur. A very slow or absent reaction also tells us whether a process is kinetically uncoupled from glutathione metabolism, which is a prerequisite for the accumulation or stability of an electrophile at high GSH concentrations (e.g., of an iron-sulfur cluster or a protein disulfide bond). Reaction rates are described by rate equations $(13,28,250)$. For example, if electrophile " $S$ " either reacts in an irreversible bimolecular elementary reaction with GSH (reaction 1) or as a substrate with an enzyme "E", that obeys Michaelis-Menten kinetics (reaction 2), rate equations Eqs. 1 and 2 describe the concentration changes of " $\mathrm{S}$ " and products " $\mathrm{P}$ " and " $\mathrm{Q}$ " over time:

$$
[\mathrm{S}]+[\mathrm{GSH}] \stackrel{k_{2}}{\longrightarrow}[\mathrm{P}]
$$




$$
\begin{gathered}
{[\mathrm{S}]+[\mathrm{E}] \stackrel{k_{\mathrm{cat}}}{\longrightarrow}[\mathrm{E}]+[\mathrm{Q}]} \\
v_{1}=\frac{-d[\mathrm{~S}]}{d \mathrm{t}}=\frac{d[\mathrm{P}]}{d \mathrm{t}}=k_{2}[\mathrm{~S}][\mathrm{GSH}] \\
v_{2}=\frac{-d[\mathrm{~S}]}{d \mathrm{t}}=\frac{d[\mathrm{Q}]}{d \mathrm{t}}=\frac{k_{\mathrm{cat}}[\mathrm{E}][\mathrm{S}]}{K_{\mathrm{m}}+[\mathrm{S}]}
\end{gathered}
$$

The more competing compounds and enzymes are involved, the more reaction rates have to be considered. Rate equations have to be determined empirically. They depend on the type of mechanism and the rate-limiting elementary reaction (13). Eqs. 1 and 2 are suited for the description of many biochemical reactions. Hence, potential kinetic competitions in biochemical systems depend on rate constants and the concentrations of the reaction partners (e.g., on the secondorder rate constant $k_{2}$ and the concentration of GSH). To address potential kinetic competitions in glutathione metabolism, we need to gather information on the following factors, which I will discuss in the subsequent sections. (i) The compartment-specific metabolite and substrate repertoire, (ii) the metabolite and substrate concentrations, (iii) kinetic parameters such as rate constants and $K_{\mathrm{m}}$ values, (iv) the compartment-specific enzyme repertoire, (v) the enzyme concentrations, and (vi) the enzyme mechanisms. The effects of some of these factors - for example, the presence or absence of a specific enzyme - are obvious, whereas other factors, such as the enzyme mechanism, have more subtle consequences and are easy to miss. The aim of this review is to point out the relevance of the aforementioned factors on potential kinetic competitions and to highlight the missing puzzle pieces for a complete understanding of glutathione metabolism. Furthermore, I will apply these factors to discuss how processes such as redox sensing, protein disulfide formation, and iron-sulfur cluster binding could be kinetically uncoupled from glutathionedependent catalysis at physiological GSH concentrations.

\section{Compartment-Specific Metabolite and Substrate Repertoires}

The electrophiles that are considered to play a role in glutathione metabolism are extremely diverse and include sulfur-, oxygen-, nitrogen-, carbon-, or iron-containing metabolites or substrates (Fig. 1) (60). These compounds can be subdivided into the following categories: (i) unknown, (ii) candidate, and (iii) established electrophiles of glutathione metabolism. Before we start with these categories, we will first consider what is known about the compartmentalization of glutathione itself.

\section{Subcellular distribution and transport of glutathione}

At the current stage, we cannot reject the null hypothesis that there are subcellular compartments that do not utilize glutathione, or, in other words, we cannot fully exclude that some subcellular compartments lack GSH, glutathione disulfide (GSSG), or glutathione conjugates. GSH biosynthesis takes place in the cytosol (167) and in chloroplasts (284). Glutathione reductase (GR) uses NADPH to convert GSSG to two molecules of GSH in the cytosol, the mitochondrial matrix, and in chloroplasts (Table 1) (60). Thus, it is assumed and partially shown that GSH, GSSG, and/or glutathione conjugates are transferred from these to other compartments by permeable pores, specific transporters, or vesicles (Fig. 2).

Pores between the cytosol and the corresponding organelle include the nuclear pore complex (148), porin in the outer mitochondrial membrane (150) and the transient translocation pore in peroxisomes (182). Can glutathione freely diffuse across these pores? The glutathione pool in the mitochondrial intermembrane space was shown to equilibrate very rapidly with the cytosol (150). This was also shown for the cytosol and nucleus in yeast (58), whereas nuclear GSH was suggested to accumulate in proliferating mammalian cells (98), contradicting a free diffusion across the nuclear pore. Whether glutathione enters peroxisomes across the translocation pore has not been shown so far but has been hypothesized based on the presence of the glutathione transferase (GST) kappa (7), which is found in mitochondria and peroxisomes in a variety of eukaryotes (60).

The inner mitochondrial membrane does not contain pores and has a tightly controlled permeability. The GSH content in the matrix of mammalian mitochondria was shown to partially depend on a dicarboxylate carrier (catalyzing an antiport with inorganic phosphate) and a 2-oxoglutarate carrier (catalyzing an antiport with 2-oxoglutarate) (Fig. 2) (15). ABC transporters with a reported preference for GSSG or glutathione conjugates include (i) diverse multidrug resistance-associated proteins (MRP) in the plasma membrane of mammals (15), (ii) Atm1 and its homologues in the plasma membrane of bacteria and the inner mitochondrial membrane $(158,245,259)$, and (iii) yeast cadmium factor 1 (Ycf1) in the vacuole $(162,192)$. All these transporters are ATPases and actively pump GSSG or glutathione conjugates across the membrane. Furthermore, yeast can import GSH (and also GSSG) with the help of the proton-coupled oligopeptide transporter Opt1 (Hgt1) $(32,210)$. Its homologue Opt2 is found in peroxisomes and might export GSSG (76) (yeast does not have a GST kappa isoform that could form glutathione conjugates). Vesicular transport of GSH is assumed to affect the organelles that pinch off from the secretory pathway and their glutathione content could therefore depend on the concentrations in the endoplasmic reticulum. However, experimental evidence for the in vivo transport of glutathione into subcellular compartments is in most cases surprisingly scarce or absent (Fig. 2) $(15,272)$ (see also the Glutathione Concentrations section).

\section{Orphan proteins and unknown metabolites and substrates}

Considering the diversity of metabolites and proteins in glutathione metabolism, it is not surprising that the compartment-specific presence or identity of several of the electrophiles in Figure 1 is unknown. For example, the identification of true disulfide substrates of enzymatically active dithiol glutaredoxins (Grx) is still ongoing. We are only beginning to understand how important they are, for example, how relevant the recently identified Grx substrates sirtuin 1, CRMP2, or DJ-1 are for vascular and neuronal development or degeneration $(33,99,141)$. Likewise, physiological substrates of several GST and MAPEG (membrane$\underline{a}$ ssociated proteins with divergent functions in $\underline{e}$ icosanoid 


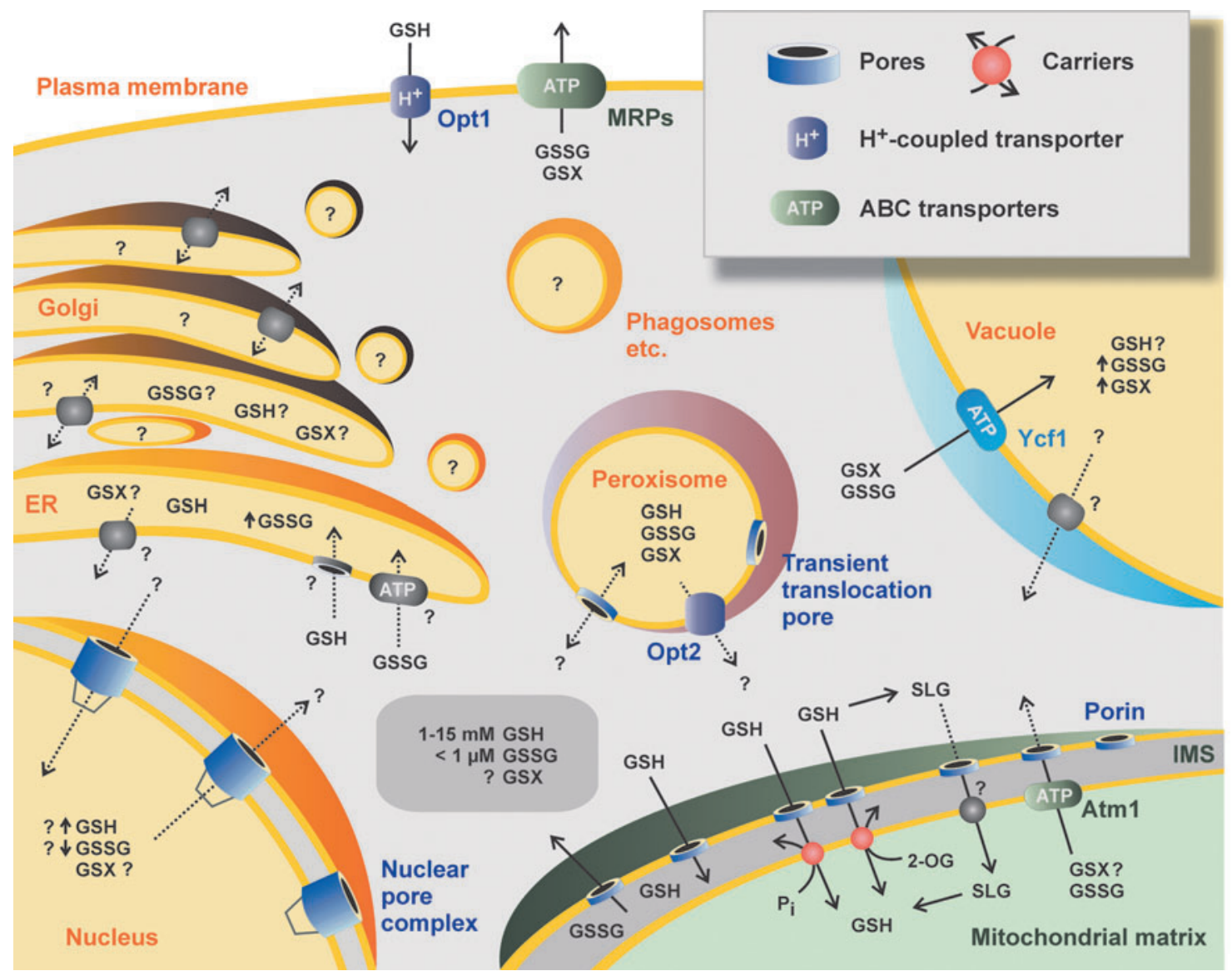

FIG. 2. Subcellular distribution and transport of glutathione. Pores, transporters, and established as well as hypothetical glutathione contents are highlighted. Enzymes and metabolic pathways are omitted for clarity. Unknown transporters are shaded in gray and suggested transport processes are highlighted by dotted arrows. Please note that the transporters might differ among eukaryotes and that the pathways are partially based on in vitro data. For example, the carrier proteins for the import of GSH into the mitochondrial matrix have been characterized in mammals but not in yeast and the import of $S$-Dlactoylglutathione has been demonstrated for isolated rat mitochondria. GSX, sum of glutathione conjugates, GSOH, GSNO, hemithioacetals, and so on; IMS, mitochondrial intermembrane space; 2-OG, 2-oxoglutarate; $\mathrm{P}_{\mathrm{i}}$, inorganic phosphate; $\mathrm{SLG}$, $S$ D-lactoylglutathione. For transporters and details, see the Subcellular Distribution and Transport of Glutathione section.

and glutathione metabolism) still remain to be identified, even though there are a variety of established functions of these enzymes in vertebrates, plants, and bacteria (Table 1 and Fig. 1) $(5,30,60,117)$. One probable reason for orphan GST- and MAPEG isoforms without established physiological substrates is that bacteria or eukaryotic model organisms are usually grown in the absence of xenobiotics, which are produced by competing microbes in real ecosystems. The absence of a growth defect for a knockout strain under optimized or even axenic laboratory conditions can therefore result in an underestimation of the true relevance of a potentially essential GST- or MAPEG-dependent detoxification process. As reviewed previously $(60,61,279)$, very little is also known about the physiological substrates of insular glyoxalases 2 (Glo2), which are sometimes found in mitochondria, plastids, or the cytosol $(29,55,281,290)$ and have a hydrolase activity for glutathione- and other thioesters in vitro $(2,280,290)$. The presence of such orphan proteins might point to novel metabolic pathways. A recent study on isolated mammalian mitochondria revealed, for example, that glutathione can be taken up as $S$-D-lactoylglutathione, which is subsequently hydro- lyzed by Glo2 yielding GSH and D-lactate in the mitochondrial matrix (Fig. 2) (9).

Other examples of orphan proteins without a defined partner are found in the monothiol Grx repertoire of Saccharomyces cerevisiae: yeast has three monothiol Grx isoforms (ScGrx3-5) that are pivotal for iron homeostasis in the mitochondrial matrix, the cytosol, and the nucleus $(214,241)$. Two additional membrane-anchored monothiol Grx isoforms, termed ScGrx6 and ScGrx7, were identified in the secretory pathway $(132,184)$. Both proteins are highly similar and catalyze GSH-dependent thiol/disulfide exchange reactions $(23,169,183)$, but have no established substrates in vivo. In contrast to ScGrx7, ScGrx6 also binds iron-sulfur clusters in vitro (183) in analogy to ScGrx3-5 (161, 228, 302). Furthermore, radioactive iron ions were bound to the catalytic cysteine of ScGrx6 after immunoprecipitation from cell lysates (132). Taken together, these findings might point to a role of ScGrx6 in iron metabolism. However, except for calcium signaling (230) and the interdependent export of a complex between the iron-oxidoreductase Fet3 and the transporter Ftr1 $(244,262)$, nothing appears to be known 
about the relevance of the endoplasmic reticulum and the Golgi complex for metal ion homeostasis or about the existence of nonheme iron ions in the secretory pathway.

\section{Candidate proteins and substrates}

Moving on from unknown metabolites and substrates, candidate proteins await us at the next level of uncertainty. Candidates are often identified after chemical labeling, affinity chromatography, and/or mass spectrometry $(54,111,133,160$, $200,243,247,264,267,289$ ). For example, numerous proteins have cysteine residues that form intramolecular disulfide bonds or that can undergo a glutathionylation, that is, form a mixed disulfide bond with glutathione in vitro. The disulfide bonds can be reduced again by Grx and such reversible thiol/disulfide exchange reactions are used to capture and identify candidate proteins $(4,163,187,243,247,264,283)$. For many of these candidates, however, it remains to be clarified whether and how disulfide bond formation and glutathionylation occur under physiological conditions (65) (see also the Kinetic Competitions for GSSG and GSSR section). False-positive hits can, for example, result from extreme nonphysiological treatments with oxidants or from (unavoidable) protein-dependent methodological pitfalls such as incomplete thiol blocking with alkylating agents before or after cell lysis $(102,254,296)$.

The situation is somehow similar regarding the repertoire of potential protein sulfenic acids, which can be trapped and detected using either a variety of dimedone-based chemical probes $(111,200)$ or a genetically encoded probe that is based on the transcription factor Yap1, which usually interacts with the sulfenic acid of yeast glutathione peroxidase 3 (GPx3) $(267,289)$. Proteomic screens also revealed numerous sets of $S$-nitrosylated protein candidates, for example, from purified rat mitochondria (49), HEK293 cell cultures (92), mouse liver (71), or rat brain $(68,133)$. How $S$-nitrosothiols are generated de novo is an ongoing matter of debate (175). Furthermore, it is only known for a few of the $S$-nitrosylated protein candidates whether they can be transnitrosylated or reduced by GSH, Trx, or other thiol-containing proteins $(24,95,173,175)$. Because of the versatile chemistry of sulfenic acids and $S$-nitrosylated thiols, the experimental conditions-for example, the reduction of $S$-nitrosothiols with ascorbate-could be even more critical than for thiol/disulfide couples and may result in falsepositive candidates (237).

\section{Established metabolites and substrates}

Reactive oxygen and nitrogen species. Established electrophiles that are considered to play a role in glutathione metabolism can be subdivided according to their source. It is usually easier to determine the spatiotemporal distribution of electrophiles with an enzymatic source. Nonenzymatic protein, lipid, and metabolite radicals are, for example, supposed to be randomly formed, whereas extracellular or phagosomal superoxide anion $\left(\mathrm{O}_{2}{ }^{--}\right)$is generated by membrane-bound NADPH oxidases (21). Other flavoenzymes can also produce $\mathrm{O}_{2}{ }^{\bullet-}$ and hydroperoxide $\left(\mathrm{H}_{2} \mathrm{O}_{2}\right)$ in vitro $(178,179)$ and it often remains to be shown which flavoenzyme significantly contributes to the production of both electrophiles in the cytosol, nucleus, mitochondria, peroxisomes, the endoplasmic reticulum, or at the plasma membrane. For instance, the flavins in complex I of bovine heart mitochondria as well as NADH dehydrogenase II and sulfite reductase in Escherichia coli were reported to be the major sources of $\mathrm{O}_{2}{ }^{--}$or $\mathrm{H}_{2} \mathrm{O}_{2}$ for these electron transport chains $(126,154,186)$. However, the contribution of the latter two enzymes for the total generation of $\mathrm{H}_{2} \mathrm{O}_{2}$ in E. coli could be rather insignificant compared to autoxidation processes of soluble flavoenzymes (126). A recent study in yeast likewise indicates that cytosolic $\mathrm{H}_{2} \mathrm{O}_{2}$ levels do not depend on autoxidation processes of the mitochondrial respiratory chain, whereas changes in cytosolic $\mathrm{H}_{2} \mathrm{O}_{2}$ also affect the $\mathrm{H}_{2} \mathrm{O}_{2}$ levels in the mitochondrial matrix (193). Other sources for $\mathrm{H}_{2} \mathrm{O}_{2}$ than flavoenzymes are cytosolic and mitochondrial superoxide dismutases $(43,125)$. Nitrogen monoxide $\left(\mathrm{NO}^{\bullet}\right)$ is produced by NO synthases and reacts nonenzymatically with $\mathrm{O}_{2}{ }^{\bullet-}$ to form peroxynitrite $\left(\mathrm{ONOO}^{-}\right)(38,81)$.

Modified cysteine residues. Both $\mathrm{H}_{2} \mathrm{O}_{2}$ and $\mathrm{ONOOH}$ can oxidize the thiol/selenol group of reactive cysteine/selenocysteine residues to sulfenic/selenenic acid $(35,38,60,113$, $238,273)$. Proteins with such reactive residues include thioldependent hydroperoxidases of the GPx and the peroxiredoxin (Prx) family (Table 1), which form extremely short-lived sulfenic/selenenic acids that are in some isoforms preferentially reduced by GSH $(35,60,89,109,261,273)$. Glyceraldehyde-3-phosphate dehydrogenase (GAPDH) is a well-established example for a nonhydroperoxidase protein with a physiologically relevant cysteine residue that is susceptible to sulfenic acid formation, $S$-nitrosothiolation, and reduction by GSH $(120,225)$. Protein $S$-nitrosylation and denitrosylation of a reactive cysteine residue have also been studied intensely for selected caspases but appear to rather depend on the Trx and not the glutathione system as reviewed previously $(24,175)$.

Protein disulfide bonds with extremely variable half-lives are formed in the cytosol, endoplasmic reticulum, mitochondrial intermembrane space, and bacterial periplasm by ribonucleotide reductase, 3'-phosphoadenosine 5'phosphosulfate reductase, GPx and Prx, flavoenzymes such as Ero1 and Erv1, as well as ubichinon-dependent DsbB. These substrates and processes have been extensively reviewed before $(34,36,64,65,78,95,115,149,163,187,204$, $238,239,273)$. Nonetheless, it is not always clear whether the disulfide bond formation or reduction depends on glutathione and several surprises might be ahead of us. One lesson learnt from ribonucleotide reductase in mammals and $E$. coli is that the overlap of the Trx and glutathione system can differ among organisms (301). Another lesson learnt from oxidative protein folding in mitochondria is that glutathione may also interfere with processes that were not necessarily considered to be a part of the glutathione puzzle: The formation of disulfide bonds in the intermembrane space of mitochondria was demonstrated to be catalyzed by the concerted action of Mia40 and Erv1 (185), which suffice to reconstitute a functional oxidoreductase system in vitro (269). It was only later that GSH, in combination with Grx, was shown to affect and potentially regulate the redox state of Mia40 and oxidative protein folding in vitro and in vivo $(26,150,151)$. Then again, processes that were thought to be glutathione dependent often lack experimental evidence. For example, for most thiol/ disulfide substrates in the endoplasmic reticulum, it remains to be shown which substrate is processed by which protein disulfide isomerase (PDI) and whether this process really depends on GSH and/or GSSG in vivo $(8,170,209)$. 
Another modification of cysteine residues is iron-sulfur cluster binding. Protein-bound iron-sulfur clusters are assembled in the mitochondrial matrix, the chloroplast, or the cytosol. They are also found in the nucleus where they contribute to iron sensing as well as DNA replication and repair $(17,56,94,153,194,214,241)$. Some of these iron-sulfur clusters form a complex with the cysteine residues of glutathione and Grx. Such clusters can be transferred to other proteins or result in altered protein-protein interactions (17, $56,164,194,214)$. At this point, it is interesting to note that the oxidative damage of selected iron-containing proteins appears to be the detrimental key event when $E$. coli is treated with oxidants, because crucial enzymes are inactivated and reactive iron ions, $\mathrm{O}_{2}{ }^{--}$or $\mathrm{H}_{2} \mathrm{O}_{2}$, are liberated $(126,145)$. Even though iron metabolism of eukaryotes, particularly of animals, is much more complex $(75,118)$, the integration of the cellular iron and redox status also depends on a labile iron-sulfur cluster, namely cytosolic aconitase/iron regulatory protein 1 . Thus, similar biochemical principles likely apply to oxidative challenges in $E$. coli and eukaryotes. This hypothesis is also supported by kinetic data on the reactivity of iron-sulfur clusters in vitro $(40,86,116)$ and genetic studies on iron metabolism in yeast $(153,194,241,285)$. Please note that the initial damage of a rather small number of susceptible (iron-containing) proteins is in contrast to common theories on oxidative stress, which predict a general accumulation of damaged proteins as well as protein sulfenic acids and disulfides (see also the Glutathione concentrations and Applications and Examples sections).

Anabolites and toxic xenobiotics and catabolites. Little is known about the intracellular spatiotemporal distribution of 2-oxoaldehydes, which can damage proteins and nucleic acids and are linked to numerous pathophysiological conditions $(85,213,232,271)$. These electrophiles are detoxified by Glo1 and Glo2 using GSH as a coenzyme (Table 1) (60, $129,270)$. Because of the relevance of glucose-derived methylglyoxal, it is usually assumed that 2-oxoaldehydes are formed in the cytosol from where they can also diffuse into the nucleus. However, the exact repertoire and distribution of 2-oxoaldehydes in different organelles have not been mapped so far. Regarding the formation of the electrophilic lipid peroxidation product 4-hydroxy-2-nonenal, several studies have addressed the plasma membrane, the endoplasmic reticulum, or the inner mitochondrial membrane $(45,257)$, whereas no data seem to exist on other membranes and compartments [e.g., peroxisomes, although the activation of peroxisome proliferator-activated receptors by 4-hydroxy-2nonenal is well established (51)]. Advances in mass spectrometry might be suited to shed some light on this topic (257).

The turnover of the remaining electrophiles in Figure 1 depends on the cell type and localization of the corresponding GST or MAPEG isoform. For example, the detoxification of xenobiotics in the liver or in plant roots depends on a whole set of compartment-specific GST isoforms (30, 60, 117). Furthermore, you will look in vain for prostaglandin $\mathrm{H}$ metabolism in yeast as opposed to GST S1-1-containing mast cells (278) or prostaglandin E synthase-containing seminal glands (205). Likewise, the GST A3-3-dependent isomerization of $\Delta^{5}$-androstene-3,17-dione will not take place in erythrocytes in contrast to gonads and adrenal glands (138).
Thus, caution is advised when general statements about the (ir)relevance of glutathione metabolism are made.

\section{Summary I: metabolite and substrate repertoires}

The current picture of the compartment-specific glutathione metabolism is all but complete. In addition to wellcharacterized enzyme/electrophile couples, there are many orphan proteins that point to unknown metabolites and substrates, for example, in mitochondria, plastids, or the secretory pathway. Advances in mass spectrometry and the development of chemical and genetically encoded probes have recently led to the identification of numerous candidate proteins with glutathione or non-glutathione disulfide bonds, sulfenic acids, or $S$-nitrosothiols. Many of these candidate proteins have to be studied in more detail to exclude false-positive hits and to investigate if and how they are connected to glutathione metabolism. Even for established electrophiles and glutathione itself, the subcellular distribution and transport across membranes are often nebulous and remain to be unraveled.

\section{Metabolite and Substrate Concentrations}

\section{Glutathione concentrations}

The concentration of GSH depends highly on the organism, cell type, and extra- or intrasubcellular compartment as reviewed previously (60). Estimated cytosolic GSH concentrations in yeast are $13 \mathrm{~m} M$ as opposed to "total" glutathione concentrations (i.e., GSH and GSSG) around 8 or $7 \mathrm{~m} M$ in mouse hybridoma or HeLa cells (Fig. 2) (124, 189, 212). The GSH concentration in some bacteria such as $E$. coli could be as high as $20 \mathrm{mM}(180,217)$. Please note that there seems to be no reliable data on the overall concentration of all other glutathione-containing substances in Figure 1 (see also the Electrophile Concentrations section). The real total glutathione concentration-including not only GSH and GSSG but also glutathionylated high- and low-molecular-weight thiols, hemithioacetals, thioesters, complexed iron-sulfur clusters, conjugated xenobiotics, GSOH, and GSNO etc.-is apparently unknown.

The endoplasmic reticulum of HeLa cells was reported to have an oxidizing half-cell reduction potential for GSH around $-0.21 \mathrm{~V}$ and to contain a calculated concentration of more than $15 \mathrm{~m} M$ "total" glutathione $(27,189)$ [see Refs. $(60,87)$ for a discussion of the half-cell reduction potential $E_{\text {GSH }}^{\prime}$. Based on previous GSH and GSSG import experiments with microsomal fractions (18), the authors therefore suggested that GSH is imported into the endoplasmic reticulum where it is trapped as GSSG (Fig. 2) (189). The elegance of this model is that two processes, namely GSH oxidation and GSSG reduction, become uncoupled because of a spatial separation and deviating enzyme repertoires. This model is in clear contrast to a previous study suggesting the import of GSSG into the endoplasmic reticulum (124). How and to which degree GSH and GSSG are transported across the endoplasmic reticulum is of fundamental relevance for our understanding of oxidative protein folding (36) and is, therefore, also a hot topic in yeast cell biology (272).

Regarding basal GSSG concentrations outside the endoplasmic reticulum, noninvasive redox measurements with genetically encoded fluorescent probes revealed in a variety of organisms that the cytosol, the nucleus, peroxisomes, and 
mitochondria are extremely reducing environments with $E_{\text {GSH }}^{\prime}$ values between -0.30 and $-0.32 \mathrm{~V}$, which translate into nanomolar GSSG concentrations (248). For example, a calculated concentration around $0.2 \mu M$ GSSG was estimated for the cytosol in yeast (192). If GR is so efficient to maintain $99.99 \%$ of "total" glutathione in a reduced state, why do so many cells and subcellular compartments contain so much glutathione? A commonly used argument is that GSH and thiol-containing proteins nonenzymatically buffer $\mathrm{H}_{2} \mathrm{O}_{2}$ and other hydroperoxides. However, as emphasized previously $(87,90,273)$, such an explanation is based on an extremely unfavorable kinetic competition with hydroperoxidases. We will evaluate this competition as an example at the end of the review once we have gathered the missing parameters.

Deletion of GR in yeast resulted in an increase of the cytosolic GSSG concentration of only about one order of magnitude to $\sim 2-3 \mu M$. Excess GSSG (>99\%) was transported into the vacuole so that the cytosol remained a highly reducing compartment (Fig. 2). A rapid ABC transportermediated export into the vacuole was also observed for wildtype yeast cells that were challenged with oxidants (192). Whether the export of GSSG on oxidative challenge is a common principle in biology still needs to be tested. Further documented examples include perfused rat liver and the bile duct (1) as well as astrocyte cell cultures (122). An export of GSSG from malaria parasites was also suggested (12) but was detected without thiol blocking agents in contrast to a subsequent study that revealed the export of GSH (19).

A rapid recovery of cytosolic $E_{\mathrm{GSH}}^{\prime}$ values after oxidative challenge has been observed within seconds or a few minutes in a variety of cell types (248), only some of which contain a vacuole. The short-term disturbance of the redox state indicates a temporary change of metabolic flux and not a static accumulation of GSSG in contrast to false equilibrium-based assumptions as emphasized previously (87). Because the de novo synthesis of GSH cannot rapidly compensate altered $E_{\text {GSH }}^{\prime}$ values, the fast recovery has to be attributed to altered GSSG concentrations. There are four hypothetical competing scenarios for the rapid removal of GSSG after oxidative challenge: (i) ATP-driven export of GSSG as observed in yeast, (ii) rapid reduction of GSSG by GR as supported by in vitro kinetics and genetic experiments, (iii) enzymatic glutathionylation of proteins yielding RSSG and GSH, and (iv) nonenzymatic glutathionylation of proteins. We will try to evaluate this potential kinetic competition as an example at the end of the review (the Kinetic Competitions for GSSG and GSSR section). The question on the intra- or extracellular fate of GSSG cannot be overemphasized because it is fundamental for the ongoing discussion on the origin of protein disulfide bonds and whether physiological challenges with oxidants results in a general protein oxidation and glutathionylation $(65,87,97,252)$.

\section{Electrophile concentrations}

Even for the established metabolites and substrates in Figure 1, there is rather limited or no information on their spatiotemporal distribution and compartment-specific concentration because of a lack of quantitative noninvasive detection methods (e.g., for xenobiotics in the cytosol, nucleus, mitochondria, peroxisomes, or endoplasmic reticulum). Some metabolites such as $\mathrm{O}_{2}{ }^{\bullet-}$ or $\mathrm{H}_{2} \mathrm{O}_{2}$ can be measured in situ by chemical trapping (43) and/or by fluorescent dyes, but these probes lack specificity and are in most cases not ratiometric so that signals highly depend on the concentration of the probe (293). In contrast, genetically encoded $\mathrm{H}_{2} \mathrm{O}_{2}$ sensors that are based on redox-sensitive fluorescent proteins are ratiometric but also measure only changes instead of absolute concentrations (248). One noninvasive method for the quantitative detection of $\mathrm{H}_{2} \mathrm{O}_{2}$ was reported decades ago by Sies and colleagues and is based on the spectral properties of the catalase reaction intermediate "compound I" (see the Differences Between Ping-Pong and Sequential Kinetic Patterns section) (43, 211, 252, 253). (Whether genetically encoded catalase in combination with different targeting sequences would allow the measurement of absolute $\mathrm{H}_{2} \mathrm{O}_{2}$ concentrations in a variety of organelles might be interesting to follow up.) Physiological steady-state concentrations of $\mathrm{H}_{2} \mathrm{O}_{2}$ in mammalian cells, yeast, and E. coli were also calculated using formation and degradation kinetics. Estimated and calculated values appear to be rather low and range from $1 \mathrm{n} M \mathrm{H}_{2} \mathrm{O}_{2}$ at basal steady-state conditions to $0.5-0.7 \mu M$ during nonlethal oxidative challenge (43, 193, 211, 249, 263). A basal steady-state concentration around $1 \mathrm{n} M$ was also calculated for $\mathrm{ONOO}^{-}(38,81)$. The concentration of $\mathrm{O}_{2}{ }^{--}$in E. coli could be as low as $0.2 \mathrm{n} M$, which translates into only 0.1 molecules per cell but does not reflect the extreme metabolic flux, that is, the continuous rapid formation and removal of $\mathrm{O}_{2}^{\bullet-}(104,126,127)$. Models on human erythrocytes suggested even lower steady-state concentrations of $\mathrm{H}_{2} \mathrm{O}_{2}$ and $\mathrm{O}_{2}{ }^{\bullet-}$ around $50 \mathrm{pM}$ and $0.5 \mathrm{pM}$, respectively (140).

Other metabolites, such as 2-oxoaldehydes, glutathione esters, and eicosanoids, are often detected with or without derivatization after cell lysis $(217,233,288)$. These invasive methods cannot discriminate between subcellular compartments because of extensive sample homogenization before the quantitative analysis, for example, by high-performance liquid chromatography or mass spectrometry (288). Nevertheless, calculated 2-oxoaldehyde concentrations in mammalian cells were reported to vary between 0.1 and $1 \mu M$ for glyoxal and between 0.5 and $5 \mu M$ for methyglyoxal (232, 233). A similar steady-state concentration of $4 \mu M$ was modeled for methylglyoxal in yeast (177). Methylglyoxal is converted to $S$-D-lactoylglutathione $(60,256,270)$. The calculated physiological steady-state concentration of this hemithioacetal in $E$. coli was lower than $50 \mu M$ and shown to only increase above this value when cells were treated with exogenous methylglyoxal (217). Human leukemia cells were reported to contain 59 pmol $S$-D-lactoylglutathione per $10^{6}$ cells (181), which roughly translates into a concentration around $0.1 \mathrm{mM}$ based on an estimated cytosol volume of $0.5 \mathrm{pl}$.

Optimized protocols to overcome disadvantages of invasive methods have been developed for the ratiometric detection of protein disulfides. For example, the physiological redox state can be "frozen" and labeled with alkylating agents before quantification by Western blotting, autoradiography, or mass spectrometry $(84,160,254,296)$. The concentration of a protein in its thiol and disulfide form might be subsequently estimated from the signal ratio, provided there is sufficient information on protein localization, molecule number per cell, and the corresponding compartment volume (Table 2). A similar arithmetical approach can be used to estimate the concentration of specific iron-sulfur clustercontaining proteins if there are data from activity assays or 
Table 2. Estimated Concentrations of RedoX- and Glutathione-Dependent Enzymes in Yeast

\begin{tabular}{|c|c|c|c|c|c|}
\hline \multirow[b]{2}{*}{ Protein/gene } & \multirow[b]{2}{*}{ Essential? } & \multirow[b]{2}{*}{ Localization } & \multicolumn{3}{|c|}{ Estimated concentration $^{\mathrm{a}}$} \\
\hline & & & $(100)$ & $(152)$ & $(48)$ \\
\hline GR/GLR1 & $\mathrm{No}^{\mathrm{b}}(106,153,192,195,216)$ & Cyt, Nu?, MM (215) & $0.44 \mu M$ & $1.5 \mu M$ & $18 \mathrm{n} M$ \\
\hline $\begin{array}{l}\text { Grx } 1 / G R X 1 \\
\text { Grx2/GRX2 } \\
\text { Grx3/GRX3 } \\
\text { Grx4/GRX4 } \\
\text { Grx5/GRX5 } \\
\text { Grx6/GRX6 } \\
\text { Grx7/GRX7 } \\
\text { Grx8/GRX8 }\end{array}$ & $\begin{array}{l}\text { No }^{b}(72,73,151,168,192) \\
N^{b}(72,73,168,192,240) \\
\text { No }{ }^{b}(194,231,240) \\
\text { No }(194,231,240) \\
\text { No }{ }^{b}(240,241) \\
\text { No }(132,184) \\
\text { No }(132,184) \\
\text { No }(73)\end{array}$ & $\begin{array}{l}\text { Cyt, Nu? } \\
\text { Cyt, MM, IMS (151, 223) } \\
\text { Cyt, Nu (188) } \\
\text { Cyt, Nu (166) } \\
\text { MM (241) } \\
\text { ER and cis-Golgi }(132,184) \\
\text { cis-Golgi (132, 184) } \\
\text { Cyt (123) }\end{array}$ & $\begin{array}{l}0.18 \mu M \\
2.1 \mu M \\
0.65 \mu M \\
0.46 \mu M \\
10 \mu M \\
3.9 \mu M \\
\overline{40 \mathrm{n} M}\end{array}$ & $\begin{array}{l}6.5 \mu M \\
2.3 \mu M \\
0.30 \mu M \\
0.14 \mu M \\
17 \mu M \\
4.1 \mu M \\
35 \mu M \\
0.16 \mu M\end{array}$ & $\begin{array}{c}27 \mathrm{n} M \\
3.4 \mathrm{n} M \\
6.8 \mathrm{n} M \\
- \\
0.5 \mu M \\
0.19 \mu M \\
0.38 \mu M \\
-\end{array}$ \\
\hline $\begin{array}{l}\text { Gto1/GTO1 } \\
\text { Gto2/GTO2 } \\
\text { Gto3/GTO3 } \\
\text { Gtt1/GTT1 } \\
\text { Gtt2/GTT2 } \\
\text { Ure2/URE2 }\end{array}$ & $\begin{array}{l}\text { No }(20) \\
\mathrm{No}^{\mathrm{b}}(20) \\
\mathrm{No}^{\mathrm{b}}(20) \\
\mathrm{No}^{\mathrm{b}}(20,47,52) \\
\mathrm{No}^{\mathrm{b}}(20,47,52) \\
\mathrm{No}^{\mathrm{b}}(292)\end{array}$ & $\begin{array}{l}\text { Per }(20) \\
\text { Cyt }(20) \\
\text { Cyt }(20) \\
\text { ER-associated (47) } \\
? \\
\text { Cyt }(74)\end{array}$ & $\begin{array}{c}0 . \overline{12 \mu M} \\
\overline{-} \\
0 . \overline{-} \mu M\end{array}$ & $\begin{array}{c}\overline{37 \mathrm{n} M} \\
\overline{-} \overline{74 \mu} M \\
\overline{71 \mathrm{n} M}\end{array}$ & $\begin{array}{l}- \\
- \\
- \\
\overline{14 \mathrm{n} M}\end{array}$ \\
\hline $\begin{array}{l}\text { TR1/TRR1 } \\
\text { TR2/TRR2 }\end{array}$ & $\begin{array}{l}\mathrm{No}^{\mathrm{b}}(274) \\
\mathrm{No}^{\mathrm{b}}(221)\end{array}$ & $\begin{array}{l}\text { Cyt } \\
\text { MM (221) }\end{array}$ & $\begin{array}{c}20 \mu M \\
0.69 \mu M\end{array}$ & $\begin{array}{c}4.2 \mu M \\
0.94 \mu M\end{array}$ & $\begin{array}{c}0.12 \mu M \\
-\end{array}$ \\
\hline $\begin{array}{l}\text { Trx } 1 / T R X 1 \\
\operatorname{Tr} x 2 / T R X 2 \\
\operatorname{Tr} \times 3 / T R X 3\end{array}$ & $\begin{array}{l}\mathrm{No}^{\mathrm{b}}(72,274) \\
\mathrm{No}^{\mathrm{b}}(72,274) \\
\text { No }(221)\end{array}$ & $\begin{array}{l}\text { Cyt } \\
\text { MM } \\
\text { MM (221) }\end{array}$ & $\begin{array}{c}0.59 \mu M \\
1.2 \mu M \\
1.7 \mu M\end{array}$ & $\begin{array}{l}17 \mu M \\
7.0 \mu M \\
25 \mu M\end{array}$ & $\begin{array}{c}69 \mathrm{n} M \\
0.16 \mu M \\
-\end{array}$ \\
\hline $\begin{array}{l}\text { GPx } 1 / G P X 1 \\
\text { GPx2/GPX2 } \\
\text { GPx3/GPX3 }\end{array}$ & $\begin{array}{l}\text { No }(14,208) \\
\text { No }(14,130) \\
N^{b}(14,59,130)\end{array}$ & $\begin{array}{l}\text { Per (208) } \\
\text { Cyt, Nu? (123) } \\
\text { Cyt (123) }\end{array}$ & $\begin{array}{l}0 . \overline{12 \mu} \mu M \\
0.56 \mu M\end{array}$ & $\begin{array}{l}1.3 \mu M \\
1.2 \mu M \\
2.3 \mu M\end{array}$ & $\begin{array}{c}-\overline{\mathrm{n} M} \\
9 \mathrm{n} M\end{array}$ \\
\hline $\begin{array}{l}\text { Tsa1/TSA1 } \\
\text { Tsa2/TSA2 } \\
\text { Ahp1/AHP1 } \\
\text { nTPx/DOT5 } \\
\text { mTPx/PRX1 }\end{array}$ & $\begin{array}{l}\text { No }{ }^{b}(42,219,298) \\
\text { No }(219,298) \\
\text { No } o^{b}(157,219,298) \\
\text { No }(41,219,298) \\
\text { No }(109,219,222,298)\end{array}$ & $\begin{array}{l}\text { Cyt (219) } \\
\text { Cyt }(219) \\
\text { Cyt }(219) \\
\text { Nu (219) } \\
\text { MM (219) }\end{array}$ & $\begin{array}{l}26 \mu M \\
0.33 \mu M \\
1.1 \mu M \\
0.76 \mu M \\
7.5 \mu M\end{array}$ & $\begin{array}{c}12 \mu M \\
0.18 \mu M \\
31 \mu M \\
1.7 \mu M \\
30 \mu M\end{array}$ & $\begin{array}{l}0.51 \mu M \\
-\overline{3 \mu M} \\
1.3 \mu M \\
17 \mathrm{n} M \\
0.18 \mu M\end{array}$ \\
\hline $\begin{array}{l}\text { Cta } 1 / C T A 1 \\
\text { Ctt } 1 / C T T 1 \\
\text { Sod1/SOD1 }\end{array}$ & $\begin{array}{l}\mathrm{No}^{\mathrm{b}}(50,107,227) \\
\mathrm{No}^{\mathrm{b}}(50,107,227) \\
\mathrm{No}^{\mathrm{b}}(25,285)\end{array}$ & $\begin{array}{l}\text { Per, MM (227) } \\
\text { Cyt (123) } \\
\text { Cyt, Nu, IMS (265) }\end{array}$ & $\begin{array}{c}0.69 \mu M \\
22 \mathrm{n} M \\
31 \mu M\end{array}$ & $\begin{array}{c}-\overline{13 \mu M} \\
71 \mu M\end{array}$ & $\overline{-} \overline{23 \mu M}$ \\
\hline $\begin{array}{l}\text { Glo1/GLO1 } \\
\text { Glo2/GLO2 } \\
\text { Glo4/GLO4 }\end{array}$ & $\begin{array}{l}\text { No }(128) \\
\text { No }(29) \\
\text { No }(29)\end{array}$ & $\begin{array}{l}\text { Cyt } \\
\text { Cyt (29) } \\
\text { MM (29) }\end{array}$ & $\begin{array}{c}0.18 \mu M \\
0.95 \mu M \\
-\end{array}$ & $\begin{array}{l}0.56 \mu M \\
0.53 \mu M \\
0.18 \mu M\end{array}$ & $26 \mathrm{n} M$ \\
\hline ADH5/ADH5 & No & Cyt (123) & $0.58 \mu M$ & $0.71 \mu M$ & $23 \mathrm{n} M$ \\
\hline
\end{tabular}

${ }^{\text {a }}$ The concentration was calculated based on protein abundances from Refs. $(48,100,152)$ as summarized in the Saccharomyces Genome Database (www.yeastgenome.org). Molecules per cell were divided by the Avogadro constant and the estimated compartment volume. Averaged cell and organelle volumes are based on Ref. (277): whole cell, $50 \mathrm{fl}\left(\mu \mathrm{m}^{3}\right)$; cytosol, $25 \mathrm{fl}$; nucleus, $4 \mathrm{fl}$; vacuole, $4 \mathrm{fl}$; mitochondria, $1 \mathrm{fl}$; endoplasmic reticulum, $0.5 \mathrm{fl}$; peroxisomes, $0.5 \mathrm{fl}$; cis-Golgi, $0.2 \mathrm{fl}$. Compartment volumes were combined for dual localized proteins.

${ }^{\mathrm{b}}$ Combined gene deletions resulted in synthetic lethality.

Cyt, cytosol; ER, endoplasmic reticulum; IMS, mitochondrial intermembrane space; Nu, nucleus; MM, mitochondrial matrix; Per, peroxisomes.

radioactive iron-labeling and immunoprecipitation experiments (194, 241). For example, activity measurements in E. coli revealed for aconitase-bound iron-sulfur clusters a calculated concentration around $10 \mu M(145)$.

\section{Summary II: metabolite and substrate concentrations}

Basal cytosolic concentrations of $\mathrm{H}_{2} \mathrm{O}_{2}$ and GSSG are probably in the nanomolar concentration range in contrast to low micromolar methylglyoxal concentrations and millimolar GSH concentrations. The compartment-specific concentrations of most of the potential and established electrophiles in Figure 1 as well as the concentrations of glutathione conjugates often remain to be determined. This is also the case for
NADPH and the extracytosolic concentrations of GSH and GSSG. The development of novel, preferentially noninvasive metabolomic methods is therefore crucial for our understanding of glutathione metabolism. However, how do substrate concentrations affect the glutathione metabolism? To answer this question, we will have to consider some aspects in enzymology.

\section{The Relevance of Kinetic Constants}

\section{Difference between true and apparent}

$\mathrm{k}_{\text {cat }}$ and $\mathrm{K}_{m}$ values

Enzymes are characterized by their kinetic constants, the $k_{\text {cat }}$ and $K_{\mathrm{m}}$ values, as exemplified in Eq. $2(28,250)$. The true 
$k_{\text {cat }}$ value or turnover number of an enzyme indicates how many molecules of substrate are metabolized by a single enzyme molecule per second at saturating substrate concentrations $\left(\mathrm{mol}_{\text {substrate }} \times \mathrm{mol}_{\text {enzyme }}{ }^{-1} \times \mathrm{s}^{-1}\right)$. Thus, the SI unit of the $k_{\text {cat }}$ value is " $\mathrm{s}^{-1}$ ", If an enzyme uses more than one substrate, which is the case for most of the enzymes in Table 1 that catalyze a glutathione-dependent conversion of an electrophile, the reaction rate can also depend on more than one substrate concentration. Using the Cleland notation, reaction 3 describes a general ping-pong mechanism with two substrates and two products, a covalently modified enzyme species " $F$ " as a reaction intermediate, and the two enzymesubstrate complexes " $\mathrm{ES}_{\mathrm{A}}$ " and " $\mathrm{FS}_{\mathrm{B}}$ ". Several of the reactions in Table 1 can be described by this or very similar schemes. (However, there are also glutathione-dependent enzymes that catalyze sequential instead of ping-pong reactions, e.g., many GST and MAPEG isoforms.)

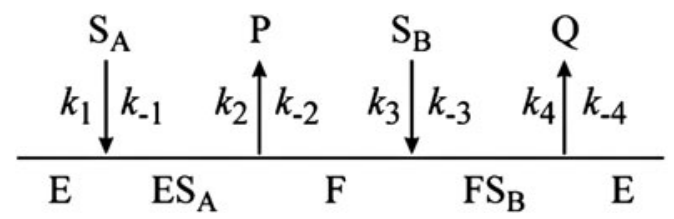

Enzyme species " $E$ " can only react with the first substrate and species " $F$ " can only react with the second substrate. Thus, the substrates never encounter each other and the reaction can be subdivided into two half-reactions, which is a perfect mechanism to kinetically uncouple two processes (as outlined in the Molecular Lego: Uncoupling Mechanisms Using Modular Enzymes section). If the initial reaction velocity $v_{0}$ is determined and no backward reaction takes place, the half-reactions can be described by sequence $4 \mathrm{a}$ and $4 \mathrm{~b}$.

$$
\begin{array}{r}
{[\mathrm{E}]+\left[\mathrm{S}_{\mathrm{A}}\right] \underset{k_{-1}}{\stackrel{k_{1}}{\rightleftharpoons}}[\mathrm{ES}] \stackrel{k_{2}}{\longrightarrow}[\mathrm{F}]+[\mathrm{P}]} \\
{[\mathrm{F}]+\left[\mathrm{S}_{\mathrm{B}}\right] \underset{k_{-3}}{\stackrel{k_{3}}{\rightleftharpoons}}[\mathrm{FS}] \stackrel{k_{4}}{\longrightarrow}[\mathrm{E}]+[\mathrm{Q}]} \\
\frac{1}{v_{0}}=\frac{K_{\mathrm{mA}}}{V_{\mathrm{max}}} \frac{1}{\left[\mathrm{~S}_{\mathrm{A}}\right]}+\frac{K_{\mathrm{mB}}}{V_{\mathrm{max}}} \frac{1}{\left[\mathrm{~S}_{\mathrm{B}}\right]}+\frac{1}{V_{\mathrm{max}}} \\
K_{\mathrm{mA}}=\frac{k_{-1}+k_{2}}{k_{1}} K_{\mathrm{mB}}=\frac{k_{-3}+k_{4}}{k_{3}}
\end{array}
$$

The rate equation for reaction 4 is best to grasp in its double reciprocal form (Eq. 3). The term $1 /\left[\mathrm{S}_{\mathrm{B}}\right]$ can be neglected at a very high concentration of the second substrate so that the kinetic relevance of reaction $4 \mathrm{a}$ is analyzed (because the enzyme is predominantly present as species " $E$ "). The same is true at a very high concentration of the first substrate and the analysis of the kinetic relevance of species " $F$ " and reaction 4 b. Under these conditions, Eq. 3 is mathematically identical to the double reciprocal form of Eq. 2 and the $k_{\text {cat }}$ value can be theoretically calculated from the maximum reaction velocity $\left(k_{\mathrm{cat}}=V_{\max } /[\mathrm{E}]\right)$. However, enzyme kinetics often cannot be measured at such high substrate concentrations. The obtained constant is therefore an apparent $k_{\text {cat }}$ value $\left(k_{\mathrm{cat}}^{\mathrm{app}}\right)$ at a defined nonsaturating substrate concentration as exemplified for the ping-pong kinetics in Figure $3 \mathrm{~A}$. The true $k_{\text {cat }}$ value is usually extrapolated from a number of $k_{\mathrm{cat}}{ }^{\text {app }}$ values using a so-called secondary plot (28, 250 ), as shown in Figure 3B. Please note that the true $k_{\text {cat }}$ value can be a combination of the rate constants $k_{2}$ and $k_{4}$ of reaction 4 , provided they are rate limiting. This is, however, not necessarily the case as outlined below.

The $K_{\mathrm{m}}$ value is the substrate concentration at which the halfmaximum reaction rate is reached. The unit of the $K_{\mathrm{m}}$ value is " $M$ '. Changes of substrate concentrations below the $K_{\mathrm{m}}$ value have a more drastic impact on the reaction rate than altered substrate concentrations far above the $K_{\mathrm{m}}$ value (e.g., the change of the reaction rate between 0 and $0.5 \mathrm{~m} M$ substrate in Figure $3 \mathrm{~A}$ is much larger than the change between 1.5 and $2 \mathrm{~m} M$ substrate). Hence, it is important to know the physiological substrate concentration to estimate its effect on the reaction rate of a specific enzyme-substrate couple. Apparent $K_{\mathrm{m}}$ values $\left(K_{\mathrm{m}}{ }^{\mathrm{app}}\right)$ are obtained if another substrate is present at a nonsaturating concentration (or if the $\mathrm{pH}$ value or a salt concentration is not optimal). $K_{\mathrm{m}}$ and $K_{\mathrm{m}}$ app values can reflect the affinity of an enzyme for its substrate. This is the case when the conversion of the enzyme-substrate complex to product is much slower than the unproductive dissociation of the complex. In other words, a lower $K_{\mathrm{mA}}$ value indicates a higher affinity for the first substrate of reaction 4, provided that $k_{2}$ is much smaller than $k_{-1}\left(K_{\mathrm{m}} \sim k_{-1} / k_{1}\right)$. The same is true for the second substrate, provided that $k_{4}$ is much smaller than $k_{-3}(28,250)$.

\section{Infinite $\mathrm{k}_{\text {cat }}$ and $\mathrm{K}_{m}$ values}

The two enzyme-substrate complexes " $\mathrm{ES}_{\mathrm{A}}$ " and " $\mathrm{FS}_{\mathrm{B}}$ ", are supposed to accumulate in scheme 3 and to reach a steadystate concentration according to the classical MichaelisMenten theory. However, many glutathione-dependent enzymes, including several hydroperoxidases and Grx, have infinite true $k_{\text {cat }}$ and $K_{\mathrm{m}}$ values and cannot be saturated even at very high substrate concentrations (Fig. 3B) (23, 69, 89, 96, $97,108,224,273,300)$. In mathematical terms, these enzymes can be defined by unusual steady-state concentrations of " $E S_{\mathrm{A}}$ " and " $\mathrm{FS}_{\mathrm{B}}$ " that tend to be zero. Dalziel established for such kinetics an elegant version of Eq. 3 (Eq. 4) (57), which can be used to describe the kinetics of many GPx and Prx as well as some Grx $(22,89,90,273)$. In this version, $k_{\mathrm{A}}$ and $k_{\mathrm{B}}$ are the rate constants of both half-reactions. (Using $V_{\text {max }}=k_{\text {cat }}[\mathrm{E}]$, Eq. 4 can be derived from Eq. 3 by multiplication with [E] so that the terms $K_{\mathrm{m}}[\mathrm{E}] / k_{\text {cat }}[\mathrm{E}]$ are reduced to the kinetic constants $k_{\mathrm{A}}{ }^{-1}$ and ${k_{\mathrm{B}}}^{-1}$. The term $1 / V_{\max }$ in Eq. 3 is zero in this special case because of the infinite $k_{\text {cat }}$ value.)

$$
\frac{[\mathrm{E}]}{v_{0}}=\frac{1}{k_{\mathrm{A}}\left[\mathrm{S}_{\mathrm{A}}\right]}+\frac{1}{k_{\mathrm{B}}\left[\mathrm{S}_{\mathrm{B}}\right]}
$$

Two mechanistic scenarios for infinite $k_{\text {cat }}$ and $K_{\mathrm{m}}$ values have been previously discussed for the oxidative and reductive half-reactions of GPx, Prx, and Grx $(90,97,273)$. (i) Rate constants $k_{2}$ and $k_{4}$ in reaction 4 are not rate limiting. This is the case when the enzyme and substrate form a very shortlived complex with such an optimized interaction that the product is immediately formed once the substrate is bound. If the half-reactions are irreversible, $k_{\mathrm{A}}$ and $k_{\mathrm{B}}$ in Eq. 4 are identical to the second-order rate constants $k_{1}$ and $k_{3}$ of reaction $4 \mathrm{a}$ and $4 \mathrm{~b}$, respectively (see also the Second-Order Rate Constants section). (ii) There is no enzyme-substrate complex that can accumulate in accordance with the classical Michaelis-Menten theory, because there is no enzyme- 

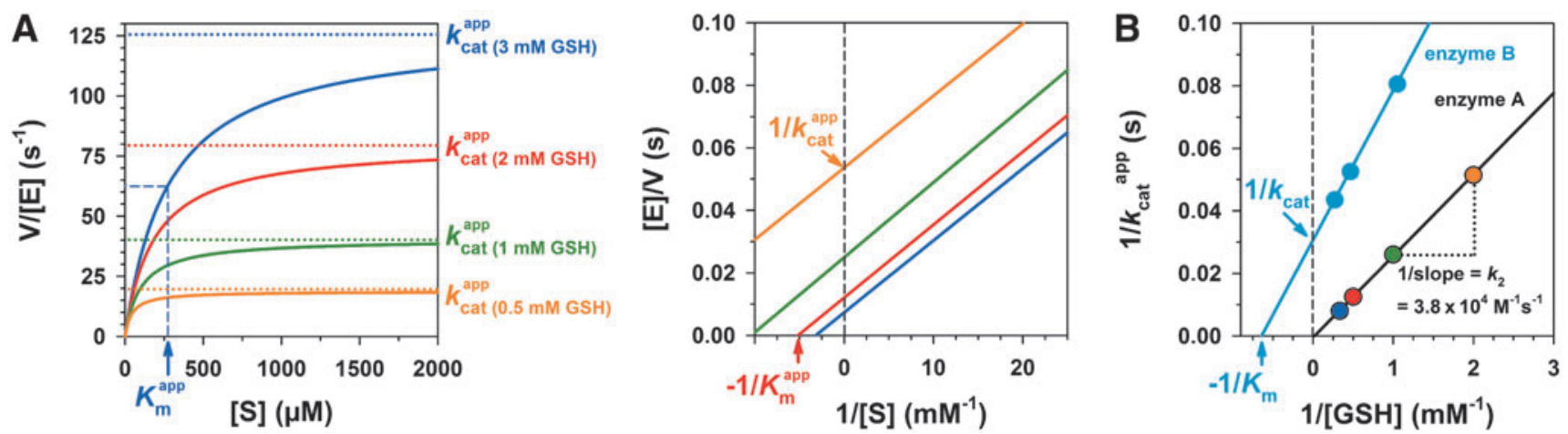

FIG. 3. Effect of variable substrate concentrations on GSH-dependent enzyme kinetics. In this example, the enzyme "E" uses a ping-pong mechanism to convert the electrophilic substrate "S." The shown patterns are typical for Grxcatalyzed reductions of glutathionylated disulfide substrates, yielding a thiol and GSSG (GSH + RSSG $\rightarrow$ RSH + GSSG). Similar patterns are found for selected GPx or Prx that catalyze the GSH-dependent reduction of hydroperoxides. (A) The normalized reaction rates for variable concentrations of " $\mathrm{S}$ " at four different constant concentrations of GSH are plotted directly according to the Michaelis-Menten theory (left panel) and in double reciprocal form according to the LineweaverBurk theory (right panel). The data can be usually fitted using the Michaelis-Menten equation (with $k_{\mathrm{cat}}{ }^{\text {app }}$ and $K_{\mathrm{m}}{ }^{\text {app }}$ values replacing $k_{\text {cat }}$ and $K_{\mathrm{m}}$ as shown in Eq. 2), yielding hyperbolic and linear curves in the direct and double reciprocal plot, respectively. The parallel lines in the Lineweaver-Burk plot are indicative for the ping-pong mechanism with the constant slope $K_{\mathrm{m}}{ }^{\mathrm{app}} / k_{\mathrm{cat}}$ app. (B) The apparent kinetic parameters at different GSH concentrations from panel A are analyzed in a (double reciprocal) secondary plot. Linear fits for enzymes with infinite $k_{\text {cat }}$ and $K_{\mathrm{m}}$ value pass through the origin (enzyme A). The true $K_{\mathrm{m}}$ and $k_{\text {cat }}$ value of other enzymes can be calculated from the x- and y-axis intercepts, respectively (enzyme B). The reciprocal slope of the linear fit corresponds to a second-order rate constant $k_{2}$, in this case for the reaction between the glutathionylated enzyme " $F$ " and GSH.

substrate interaction except for the catalytic event as shown in scheme $5(57,97,273)$.

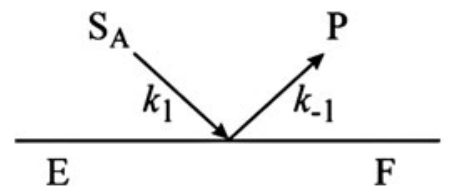

Scenarios (i) and (ii) with and without an enzymesubstrate complex can be discriminated using substrate analogs and products that could act as inhibitors. Absence of an inhibition points to the absence of an enzyme-substrate complex as previously emphasized for Grx catalysis (97). The oxidative half-reaction of GPx and Prx-that is, the irreversible reduction of hydroperoxides-probably occurs without a real enzyme-substrate complex, which makes sense considering the size of $\mathrm{H}_{2} \mathrm{O}_{2}$ and the rapid turnover of structurally diverse hydroperoxide substrates $(35,89,273)$. The reversible reduction of glutathionylated substrates by Grx was also suggested to occur without an enzyme-substrate complex (97) because many Grx are poorly inhibited by $S$ methylglutathione or $\mathrm{L}-\gamma$-glutamyl-L- $\alpha$-aminobutyrylglycine (ophthalmic acid) $(22,96,97,258,268)$. Nevertheless, Grx require two distinct glutathione interaction sites for catalysis $(22)$, and several partially conserved residues $(22,60)$ presumably confer specificity for the $\gamma$-glutamyl moieties of the glutathione disulfide substrate (GSSR) and GSH substrate $(77,224,234,258)$. The situation is similar to the reductive half-reaction of glutathione-dependent GPx, which have partially conserved glutathione-binding sites but are poorly inhibited by GSSG $(60,88,273)$. For oxidized GPx, an enzyme-substrate complex is supposed to be formed (273). A hit-and-run mechanism involving specific glutathione-interacting residues was also suggested for Glo2, which works with a sequential Theorell-Chance and not a ping-pong mechanism $(60,280)$.
Regardless of the true mechanism of these glutathionedependent enzymes, it is important to note that even enzymes with infinite true $k_{\text {cat }}$ and $K_{\mathrm{m}}$ values can have an apparent saturation behavior (Fig. 3A). This becomes understandable considering that enzymes with a ping-pong mechanism alternate between species " $E$ " and " $F$ " as shown in scheme 3 . If one substrate is present at a limiting concentration, only a fraction of the enzyme becomes available for the other substrate resulting in an apparent saturation. What are the implications regarding the interpretation of apparent $K_{\mathrm{m}}$ and $k_{\text {cat }}$ values? The interpretation of $K_{\mathrm{m}}{ }^{\text {app }}$ and $k_{\text {cat }}$ app of enzymes with infinite kinetic parameters depends on the investigated protein and requires thorough kinetic analyses at different substrate and inhibitor concentrations. As recently shown in a comparative study on wild-type and mutant Grx from yeast and Plasmodium falciparum (22), lowering the concentration of the first substrate lowered the $K_{\mathrm{m}}{ }^{\text {app }}$ value for the second substrate because of a decreased steady-state concentration of species " $F$ "' (and not because of a higher substrate affinity). Likewise, the $k_{\text {cat }}$ app value was lowered reflecting that fewer molecules of species " $F$ " were available for the turnover of the second substrate. Please note that the ratio $k_{\text {cat }}{ }^{\text {app }} / K_{\mathrm{m}}{ }^{\text {app }}$ is correlated with the second-order rate constant of the reaction and should therefore remain constant (as outlined in the Second-Order Rate Constants section and illustrated by the parallel lines in the Lineweaver-Burk plot in Fig. 3A).

\section{Second-order rate constants}

Infinite true $k_{\text {cat }}$ and $K_{\mathrm{m}}$ values provide rather limited information on the reactivity of a catalyst. They are sometimes detected for extremely efficient catalysts as well as for lousy enzyme-substrate couples (e.g., when the wrong substrate is analyzed in vitro). Enzymes with infinite true $k_{\text {cat }}$ and $K_{\mathrm{m}}$ values, such as many GPx, Prx, or Grx, are therefore often characterized by their second-order rate constant or by their 
$k_{\text {cat }}{ }^{\text {app }}$ and $K_{\mathrm{m}}{ }^{\text {app }}$ values. For the second-order rate constant, enzyme and substrate are treated as regular chemicals that react in a bimolecular elementary reaction according to Eq. 1 . The value for $k_{2}$ in Eq. 1 (or $k_{\mathrm{A}}$ according to Eq. 4) can be determined from the reciprocal slope of secondary plots (Fig. 3B). Similar values are often obtained for the catalytic efficiency $\left(k_{\mathrm{cat}}{ }^{\mathrm{app}} / K_{\mathrm{m}}{ }^{\mathrm{app}}\right)$. Please note that the MichaelisMenten Eq. 2 can be simplified for $[\mathrm{S}] \ll<K_{\mathrm{m}}$, yielding a rate equation that is, from a mathematical point of view, identical to Eq. $1\left(k_{\text {cat }}{ }^{\text {app }} / K_{\mathrm{m}}{ }^{\text {app }}=k_{2}\right)$.

The second-order rate constant $k_{2}$ and the catalytic efficiency have the unit " $M^{-1} \mathrm{~s}^{-1}$ ", and are highly suited to directly compare the reactivity of potentially competing molecules. Some of the values used in the Applications and Examples section are listed in Table 3. For example, the second-order rate constant for the reaction between superoxide dismutase and $\mathrm{O}_{2}^{\bullet-}$ is $\sim 2 \times 10^{9} \mathrm{M}^{-1} \mathrm{~s}^{-1}$, which is about 10 million times faster than the second-order rate constant for the nonenzymatic reaction between $\mathrm{GSH}$ and $\mathrm{O}_{2}{ }^{\bullet-}$ around $200 M^{-1} \mathrm{~s}^{-1}(82,142)$. Likewise, second-order rate constants for the reaction between hydroperoxidases and $\mathrm{H}_{2} \mathrm{O}_{2}$ are often between $10^{5}$ and $10^{7} M^{-1} \mathrm{~s}^{-1}$, which is again up to 10 million times faster than the second-order rate constant for the nonenzymatic reaction between $\mathrm{GSH}$ and $\mathrm{H}_{2} \mathrm{O}_{2}$ around 1
$M^{-1} \mathrm{~s}^{-1}(35,273,275,295)$. It is important to note that the rate constant of GSH is similar to other low-molecular-weight thiols (295). Even the active site cysteines of Trx and other enyzmes have similar second-order rate constants $(235,263)$. One exception to the slow sulfenic acid formation in nonhydroperoxidases is the redox-sensitive cysteine residue of GAPDH with an intermediate rate constant of $100 \mathrm{M}^{-1} \mathrm{~s}^{-1}$ at $\mathrm{pH} 7$ and $0^{\circ} \mathrm{C}$ (165). The higher reactivity of GAPDH depends on the protonation of the generated hydroxyl ion, which is a very poor leaving group (225). The latter property explains the relative stability of $\mathrm{H}_{2} \mathrm{O}_{2}$ and its low reactivity with other enzymes that contain a cysteine thiolate residue [see Refs. (34, 91, 111, 263) for further rate constants of protein thiols]. Thus, taking only the rate constants into account, superoxide dismutases and hydroperoxidases clearly outcompete the cysteine residues of GSH or regular proteins for the reduction of $\mathrm{O}_{2}{ }^{\bullet-}$ or $\mathrm{H}_{2} \mathrm{O}_{2}(34,91,142,263,294)$. The kinetics of these established electrophiles provides good examples for the relevance of rate constants. At this point it is important to note that rate constants, for example, of disulfides and sulfenic acids, can be extremely variable and depend on multiple factors such as the protein environment $(60,65,111$, $198,201)$. Furthermore, even when the rate constants of potentially competing reactions have been determined, they are

Table 3. Selected Rate Constants and Catalytic Efficiencies

\begin{tabular}{|c|c|c|c|}
\hline Reaction & Catalyst? & $\begin{array}{l}\text { Rate constant } \\
\text { or } \mathrm{k}_{\mathrm{cat}}^{\text {app }} / \mathrm{K}_{\mathrm{m}}^{\text {app }} \text { value }\end{array}$ & Reference \\
\hline $\begin{array}{l}\mathrm{GSH}+\mathrm{O}_{2}^{\bullet-}+\mathrm{H}^{+} \rightarrow \mathrm{GS}^{\bullet}+\mathrm{H}_{2} \mathrm{O}_{2} \\
2 \mathrm{O}_{2}^{\bullet-}+2 \mathrm{H}^{+} \rightarrow \mathrm{O}_{2}+\mathrm{H}_{2} \mathrm{O}_{2} \\
2 \mathrm{O}_{2}^{\bullet-}+2 \mathrm{H}^{+} \rightarrow \mathrm{O}_{2}+\mathrm{H}_{2} \mathrm{O}_{2} \\
\mathrm{GS}^{\bullet^{-}}+\mathrm{NO}^{\bullet} / \mathrm{NO}_{2} \cdot \mathrm{GS}^{-} \rightarrow \mathrm{GSNO}^{-} / \mathrm{NO}_{2} / \mathrm{SG}^{\bullet-}\end{array}$ & $\begin{array}{l}\text { Nonenzymatic } \\
\text { Nonenzymatic } \\
\text { Superoxide dismutase } \\
\text { Nonenzymatic }\end{array}$ & $\begin{array}{l}\sim 200 M^{-1} \mathrm{~s}^{-1} \\
2 \times 10^{5} M^{-1} \mathrm{~s}^{-1} \\
2 \times 10^{9} M^{-1} \mathrm{~s}^{-1} \\
\sim 10^{9} M^{-1} \mathrm{~s}^{-1}\end{array}$ & $\begin{array}{c}(142) \\
(93) \\
(82) \\
(38,147)\end{array}$ \\
\hline $\begin{array}{l}\mathrm{GSH}+\mathrm{H}_{2} \mathrm{O}_{2} \rightarrow \mathrm{GSOH}+\mathrm{H}_{2} \mathrm{O} \\
\mathrm{GSH}+\mathrm{H}_{2} \mathrm{O}_{2} \rightarrow \mathrm{GSOH}+\mathrm{H}_{2} \mathrm{O} \\
\mathrm{GAPDH}_{\mathrm{red}}+\mathrm{H}_{2} \mathrm{O}_{2} \rightarrow \mathrm{GAPDH} \\
\mathrm{Grx}_{\text {red }}+\mathrm{H}_{2} \mathrm{O}_{2} \rightarrow \mathrm{Grx}_{\mathrm{ox}}+\mathrm{H}_{2} \mathrm{O} \\
\mathrm{Grx}_{\text {red }}+\mathrm{H}_{2} \mathrm{O}_{2} \rightarrow \mathrm{Grx}_{\mathrm{ox}}+\mathrm{H}_{2} \mathrm{O} \\
\mathrm{Grx}_{\text {red }}+\mathrm{H}_{2} \mathrm{O}_{2} \rightarrow \mathrm{Grx}_{\mathrm{ox}}+\mathrm{H}_{2} \mathrm{O} \\
\mathrm{Grx}_{\text {red }}+\mathrm{H}_{2} \mathrm{O}_{2} \rightarrow \mathrm{Grx}_{\mathrm{ox}}+\mathrm{H}_{2} \mathrm{O} \\
\mathrm{Prx}_{\text {red }}+\mathrm{H}_{2} \mathrm{O}_{2} \rightarrow \mathrm{Prx}_{\mathrm{ox}}+\mathrm{H}_{2} \mathrm{O} \\
\mathrm{Prx}_{\text {red }}+\mathrm{H}_{2} \mathrm{O}_{2} \rightarrow \operatorname{Prx}_{\mathrm{ox}}+\mathrm{H}_{2} \mathrm{O} \\
\mathrm{GPx}_{\text {red }}+\mathrm{H}_{2} \mathrm{O}_{2} \rightarrow \mathrm{GPx}_{\mathrm{ox}}+\mathrm{H}_{2} \mathrm{O} \\
\text { Prx }_{\text {red }}+\mathrm{H}_{2} \mathrm{O}_{2} \rightarrow \operatorname{Prx}_{\mathrm{ox}}+\mathrm{H}_{2} \mathrm{O}\end{array}$ & $\begin{array}{l}\text { Nonenzymatic } \\
\text { Ure2 } \\
\text { GAPDH } \\
\text { mGrx2 } \\
\text { hGrx2 } \\
\text { ScGrx1 } \\
\text { ScGrx2 } \\
\text { Tsa1 } \\
\text { Tsa2 } \\
\text { Mammalian GPx1/3 } \\
\text { Prx2 }\end{array}$ & $\begin{aligned} & 0.87 M^{-1} \mathrm{~s}^{-1} \\
& 84 M^{-1} \mathrm{~s}^{-1} \\
& \sim(2-11) \times 10^{2} M^{-1} \mathrm{~s}^{-1} \\
& 7.7 \times 10^{3} M^{-1} \mathrm{~s}^{-1} \\
& 2.5 \times 10^{4} M^{-1} \mathrm{~s}^{-1} \\
& 5.3 \times 10^{4} M^{-1} \mathrm{~s}^{-1} \\
& 2.6 \times 10^{4} M^{-1} \mathrm{~s}^{-1} \\
& 2.2 \times 10^{7} M^{-1} \mathrm{~s}^{-1} \\
& 1.3 \times 10^{7} M^{-1} \mathrm{~s}^{-1} \\
&(4-5) \times 10^{7} M^{-1} \mathrm{~s}^{-1} \\
& 10^{8} M^{-1} \mathrm{~s}^{-1}\end{aligned}$ & $\begin{array}{l}(295) \\
(16) \\
(165) \\
(80) \\
(80) \\
(52) \\
(52) \\
(207) \\
(207) \\
(89,273) \\
(174)\end{array}$ \\
\hline $\begin{array}{l}\mathrm{GSH}+\mathrm{HSA}(\mathrm{SOH}) \rightarrow \mathrm{HSA}(\mathrm{SSG})+\mathrm{H}_{2} \mathrm{O} \\
\mathrm{Cys}(\mathrm{SH})+\mathrm{Cys}(\mathrm{SOH}) \rightarrow \mathrm{CySSSCys}+\mathrm{H}_{2} \mathrm{O} \\
2 \mathrm{GSH}+\mathrm{GPx}(\mathrm{SeOH}) \rightarrow \mathrm{GPx}(\mathrm{SeH})+\mathrm{GSSG} \\
\mathrm{Trx}_{\mathrm{red}}+\mathrm{GPx} / \operatorname{Prx}(\mathrm{SOH}) \rightarrow \mathrm{GPx} / \operatorname{Prx}(\mathrm{SH})+\operatorname{Trx}_{\mathrm{ox}}\end{array}$ & $\begin{array}{l}\text { Nonenzymatic } \\
\text { Nonenzymatic } \\
\text { Mammalian GPx } 1 / 3 / 4 \\
\text { Other GPx }\end{array}$ & $\begin{array}{c}2.9 M^{-1} \mathrm{~s}^{-1} \\
>10^{5} M^{-1} \mathrm{~s}^{-1} \\
(0.6-4) \times 10^{5} M^{-1} \mathrm{~s}^{-1} \\
\sim 10^{4}-10^{6} M^{-1} \mathrm{~s}^{-1}\end{array}$ & $\begin{array}{l}(276) \\
(199) \\
(273) \\
(273)\end{array}$ \\
\hline $\begin{array}{l}\mathrm{LMW}(\mathrm{SH})+\mathrm{RSSG} \rightarrow \mathrm{LMW}(\mathrm{SSG})+\mathrm{RSH} \\
\mathrm{Grx}(\mathrm{SH})+\mathrm{Cys}(\mathrm{SSG}) \rightarrow \mathrm{Grx}(\mathrm{SSG})+\mathrm{Cys} \\
\mathrm{GSH}+\mathrm{Grx}(\mathrm{SSG}) \rightarrow \mathrm{Grx}(\mathrm{SH})+\mathrm{GSSG} \\
\mathrm{Grx}(\mathrm{SH})+\mathrm{Cys}(\mathrm{SSG}) \rightarrow \mathrm{Grx}(\mathrm{SSG})+\mathrm{Cys} \\
\mathrm{GSH}+\mathrm{Grx}(\mathrm{SSG}) \rightarrow \mathrm{Grx}(\mathrm{SH})+\mathrm{GSSG} \\
\mathrm{Grx}(\mathrm{SH})+\mathrm{BSA}(\mathrm{SSG}) \rightarrow \mathrm{Grx}(\mathrm{SSG})+\mathrm{BSA} \\
\mathrm{GSH}+\mathrm{Grx}(\mathrm{SSG}) \rightarrow \mathrm{Grx}(\mathrm{SH})+\mathrm{GSSG} \\
\mathrm{Grx}(\mathrm{SH})+\mathrm{GSSG} \rightarrow \mathrm{Grx}(\mathrm{SSG})+\mathrm{GSH} \\
\mathrm{Grx}(\mathrm{SH})+\mathrm{Cys}(\mathrm{SSG}) \rightarrow \mathrm{Grx}(\mathrm{SSG})+\mathrm{Cys} \\
\mathrm{GSH}+\mathrm{Grx}(\mathrm{SSG}) \rightarrow \mathrm{Grx}(\mathrm{SH})+\mathrm{GSSG} \\
\mathrm{Grx}(\mathrm{SH})+\mathrm{Cys}(\mathrm{SSG}) \rightarrow \mathrm{Grx}(\mathrm{SSG})+\mathrm{Cys} \\
\mathrm{GSH}+\mathrm{Grx}(\mathrm{SSG}) \rightarrow \mathrm{Grx}(\mathrm{SH})+\mathrm{GSSG}\end{array}$ & $\begin{array}{l}\text { Nonenzymatic } \\
\text { hGrx1 } \\
\text { hGrx1 } \\
\text { hGrx2 } \\
\text { hGrx2 } \\
\text { PtGrxS12 } \\
\text { PtGrxS12 } \\
\text { SsGrx1 } \\
\text { ScGrx7 } \\
\text { ScGrx7 } \\
\text { PfGrx } 32 \text { S/C88S } \\
\text { PfGrx }\end{array}$ & $\begin{array}{l}0.01-200 M^{-1} \mathrm{~s}^{-1} \\
7.0 \times 10^{5} M^{-1} \mathrm{~s}^{-1} \\
9.9 \times 10^{4} M^{-1} \mathrm{~s}^{-1} \\
1.0 \times 10^{5} M^{-1} \mathrm{~s}^{-1} \\
6.3 \times 10^{3} M^{-1} \mathrm{~s}^{-1} \\
8.0 \times 10^{5} M^{-1} \mathrm{~s}^{-1} \\
2.5 \times 10^{4} M^{-1} \mathrm{~s}^{-1} \\
7.1 \times 10^{5} M^{-1} \mathrm{~s}^{-1} \\
(7.3-9.7) \times 10^{5} M^{-1} \mathrm{~s}^{-1} \\
(2.5-4.7) \times 10^{5} M^{-1} \mathrm{~s}^{-1} \\
1.4 \times 10^{6} M^{-1} \mathrm{~s}^{-1} \\
1.2 \times 10^{5} M^{-1} \mathrm{~s}^{-1}\end{array}$ & $\begin{array}{l}(23,198,266 \\
(96) \\
(96) \\
(96) \\
(96) \\
(300) \\
(300) \\
(234) \\
(22) \\
(22) \\
(22) \\
(22)\end{array}$ \\
\hline $\mathrm{Fd}+\mathrm{Grx}\left[2 \mathrm{Fe}_{2} \mathrm{~S}_{2}(\mathrm{GS})_{2}\right] \rightarrow \mathrm{Fd}\left[2 \mathrm{Fe}_{2} \mathrm{~S}_{2}\right]+\mathrm{Grx}+2 \mathrm{GSH}$ & PtGrxS14 & $3.3 \times 10^{2} M^{-1} \mathrm{~s}^{-1}$ & (17) \\
\hline
\end{tabular}


not sufficient to judge a competition as outlined in The Relevance of the Enzyme Concentration section.

\section{Summary III: the relevance of kinetic constants}

Second-order rate constants and $k_{\mathrm{cat}}{ }^{\mathrm{app}} / K_{\mathrm{m}}{ }^{\text {app }}$ values are highly suited to directly compare the reactivity of enzymes and other potentially competing molecules. $K_{\mathrm{m}}{ }^{\text {app }}$ and $k_{\mathrm{cat}}{ }^{\text {app }}$ values are useful to estimate the rate of an enzyme-catalyzed reaction under physiological conditions, for example, at nonsaturating substrate concentrations. Even enzymes with infinite true $k_{\text {cat }}$ and $K_{\mathrm{m}}$ values can have an apparent saturation behavior. To compare potentially competing reactions, we have to know both, the physiological substrate concentrations and the kinetic constants.

\section{The Relevance of the Enzyme Repertoire}

Within the past decades, the localization of numerous glutathione-dependent enzymes has been determined in a variety of organisms. Thus, it is well known in which subcellular compartment most of these proteins are (Table 2), although dual protein targeting complicates the situation and seems to be a quite common feature in glutathione metabo$\operatorname{lism}(35,55,60,70,144,171,191,215,223)$. However, there are still some blind spots and missing pieces. These include glutathione transporters (Fig. 2) as well as the tissue- and organelle-specific distribution of several of the Grx and GST isoforms in plants and animals.

Many low-molecular-weight electrophiles such as disulfides, hydroperoxides, and xenobiotics are metabolized by seemingly redundant enzymes within a single organism. Some of the redundancy can be explained by overlapping but nonidentical substrate preferences or by the compartmentalization of eukaryotic cells. However, even prokaryotes as well as selected compartments of eukaryotes harbor multiple enzymes with similar or identical substrate preferences. I will illustrate this again for the hydroperoxidases, simply because there is much more information on these enzymes than on the other proteins that are listed in Table 1. Three major families of hydroperoxidases (GPx, Prx, and catalases) are found in parallel in many prokaryotic and eukaryotic cells. These enzymes have deviating properties and can be further subdivided into a variety of isoforms (Fig. 4) (35, 60, 113, 202, 273). The cytosol of yeast, for example, contains the catalase Ctt1, the Prx isoforms Tsa1, Tsa2, and Ahp1, as well as the GPx isoforms GPx2 and GPx3 (Table 2). Among the thioldependent hydroperoxidases, selenocysteine-containing mammalian GPx are the most reactive enzymes with secondorder rate constants for $\mathrm{H}_{2} \mathrm{O}_{2}>10^{7} M^{-1} \mathrm{~s}^{-1}(35,89,273)$. In contrast, cysteine-containing GPx and Prx-only some of which use GSH as an electron donor $(60,69,83,273)$ - have rate constants that often range from $10^{4}$ to $10^{7} M^{-1} \mathrm{~s}^{-1}(35$, $273,275,294)$. Heme-containing catalases have rate constants $>10^{7} M^{-1} \mathrm{~s}^{-1}$ but are thiol independent and catalyze the disproportionation reaction $2 \mathrm{H}_{2} \mathrm{O}_{2} \rightarrow \mathrm{O}_{2}+2 \mathrm{H}_{2} \mathrm{O}(3,31,202$, 206). Please note that the reaction rates of peroxidases are usually linear at low nanomolar substrate concentrations and can be described by Eq. 1 ([S] $<<K_{\mathrm{m}}$, Second-Order Rate Constants section). Some 1-Cys Prx isoforms, however, might be even inactivated at such low $\mathrm{H}_{2} \mathrm{O}_{2}$ concentrations, which would explain why they are inactive in standard enzymatic assays in vitro $(62,66,203)$. Why do many organisms possess members of all three major hydroperoxidase families in a single compartment? Furthermore, what is the benefit or function of less efficient Prx isoforms?

\section{Alternative substrate concentrations and preferences}

A comparison of the normalized reaction rates and $K_{\mathrm{m}}{ }^{\text {app }}{ }_{(\mathrm{H} 2 \mathrm{O} 2)}$ values of GPx, Prx, and catalases suggests the following physiological implications. Catalases are excellent catalysts at all substrate concentrations. They have an advantage at peak concentrations of $\mathrm{H}_{2} \mathrm{O}_{2}$ above $50 \mu M$ because of an absent substrate saturation (Fig. 4A). However, whether this is of physiological relevance is questionable for many organisms (as outlined in the Electrophile Concentrations section). Selenocysteine-containing GPx are the most active hydroperoxidases at $\mathrm{H}_{2} \mathrm{O}_{2}$ concentrations below $50 \mu \mathrm{M}$, whereas some cysteine-containing GPx and Prx have similar activities as catalases at $\mathrm{H}_{2} \mathrm{O}_{2}$ concentrations $\leq 0.1 \mu M$ (Fig. 4B, C). Thus, a broad hydroperoxidase repertoire might reflect an adaptation to variable $\mathrm{H}_{2} \mathrm{O}_{2}$ concentrations, for
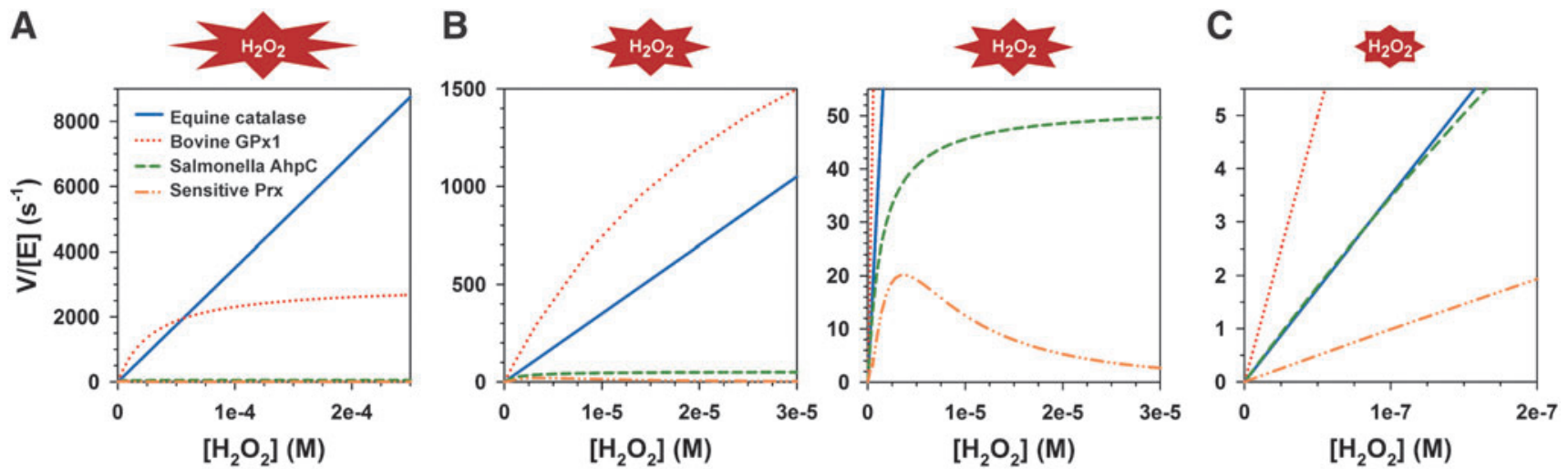

FIG. 4. Comparison of normalized hydroperoxidase activities at variable $\mathrm{H}_{2} \mathrm{O}_{2}$ concentrations. Normalized reaction rates at (A) high, (B) intermediate, and (C) low $\mathrm{H}_{2} \mathrm{O}_{2}$ concentrations are shown from left to right. Kinetic parameters for equine catalase $\left(k=3.5 \times 10^{7} M^{-1} \mathrm{~s}^{-1}\right)$, bovine GPx1 at $4 \mathrm{mM} \mathrm{GSH}\left(k_{\mathrm{cat}}{ }^{\mathrm{app}}=3 \times 10^{3} \mathrm{~s}^{-1}, K_{\mathrm{m}}{ }^{\text {app }}=3 \times 10^{-5} M\right)$, and recombinant peroxiredoxin AhpC from Salmonella typhimurium $\left(k_{\mathrm{cat}}{ }^{\text {app }}=52 \mathrm{~s}^{-1}, K_{\mathrm{m}}{ }^{\text {app }}=1.4 \times 10^{-6} M\right)$ are based on reported measurements by Ogura (206), Flohe et al. (89), and Parsonage et al. (220), respectively. The parameters for the modeled sensitive Prx isoform are $k_{\text {cat }}^{\text {app }}=100 \mathrm{~s}^{-1}$ and $K_{\mathrm{m}}{ }^{\text {app }}=1 \times 10^{-5} M$. 
example, in pathogenic organisms that have to compensate basal $\mathrm{H}_{2} \mathrm{O}_{2}$ concentrations as well as short-term peak concentrations because of plant or animal host defense mechanisms.

Even though members of all three hydroperoxidase families convert $\mathrm{H}_{2} \mathrm{O}_{2}$ as an oxidizing substrate, they utilize different reducing agents. Catalases have the advantage that they do not rely on the NADPH-dependent replenishment of thiol pools and that the demand for reducing equivalents is coupled to its supply (because $\mathrm{H}_{2} \mathrm{O}_{2}$ is the electron acceptor and donor). The combination of GPx and Prx might allow a balanced consumption of electrons from different thiol pools, for example, from the GSH and Trx pool. Please note that although many Prx and GPx are specific for their electron donor, several isoforms appear to be more promiscuous and accept electrons from Trx, Grx, and/or GSH (60, 66, 69, 83, 236, 242, 261, 273). The thiol-dependent hydroperoxidases also have deviating preferences regarding the oxidizing substrate. For example, monomeric mammalian GPx4 reduces membrane-bound lipid hydroperoxides in contrast to the soluble tetrameric GPx homologues (35).

\section{Redox sensing and moonlighting functions}

Another explanation for the variety of cellular hydroperoxidases is that some GPx and $\operatorname{Prx}$ are $\mathrm{H}_{2} \mathrm{O}_{2}$ sensors, which allow a fine-tuned redox regulation. As reviewed previously, these proteins are inactivated at higher hydroperoxide concentrations or form mixed protein-protein disulfide bonds with intermediate half-lives for signal transduction $(34,46,59,65,110,131,137,238,255,299)$. Last but not least, hydroperoxidases can also exert moonlighting functions, for example, as chaperones or for sperm maturation (39, 136, 282).

\section{Summary IV: relevance of the enzyme repertoire}

Seemingly redundant enzyme repertoires can result in kinetic competitions. The repertoires originate from many factors, including the compartmentalization of eukaryotic cells, overlapping but nonidentical substrate preferences, an adaptation to variable substrate concentrations and electron donors, as well as alternative (moonlighting) functions, for example, in redox signaling or protein folding. These factors have been intensely studied for peroxidases and are presumably also important for Grx, GST, glyoxalases, and other glutathione-dependent enzymes, even though their physiological functions often remain to be characterized (Table 1) $(60,65,279)$. Thus, to understand glutathione metabolism, it is crucial to determine the compartment-specific enzyme repertoires and to assign a function to each member of these highly diverse protein families.

\section{The Relevance of the Enzyme Concentration}

Turnover numbers and second-order rate constants of redox enzymes differ by several orders of magnitude. However, just because an enzyme is much less reactive does not mean that it is irrelevant. I will first illustrate this again for the hydroperoxidases and subsequently discuss the implications for other proteins and for common genetic approaches.

\section{Hydroperoxidase concentrations}

Based on the normalized reaction rates in Figure 4A and B, one might assume that some Prx play a rather minor role for the detoxification of $\mathrm{H}_{2} \mathrm{O}_{2}$ compared to catalase and selenocysteine-containing GPx. However, if we consider the physiological concentration of $\mathrm{H}_{2} \mathrm{O}_{2}$ in the nanomolar (or maybe picomolar) concentration range, which is usually far below the $K_{\mathrm{m}}{ }^{\text {app }}$ value, the differences between the peroxidases are less pronounced (Fig. 5A). If we now take into account that many Prx are among the most abundant proteins (top 5\%) in many eu- and prokaryotes (287), the lower activity compared to catalase is more than compensated (Fig. 5B, C). For example, deficiencies of catalase or GPx1 in mouse erythrocytes were reported to result in rather mild phenotypes in contrast to the loss of Prx2, which caused hemolytic anemia (159). The latter phenotype and the significant contribution of $\mathrm{Prx} 2$ to $\mathrm{H}_{2} \mathrm{O}_{2}$ removal $(140,159)$ become explainable considering that Prx2 has an estimated concentration of $0.24 \mathrm{~m} M$ in erythrocytes (190). (However, additional Prx2-specific functions, for example, in redox signaling or hemoglobin stabilization $(46,114,299)$, could also contribute to the phenotype.) Figure $5 \mathrm{~B}$ and $\mathrm{C}$ also reveals how an enzyme with a high second-order rate constant can become completely irrelevant if competing enzymes are much more concentrated in the same compartment. Please note that such deviating concentrations are not unusual for redox enzymes. For instance, a ratio of $\sim 1200: 1$ was reported for the yeast peroxiredoxin Tsa1 and the cytosolic catalase Ctt1 (100). Based on a cytosol volume of roughly $50 \mathrm{fl}$, the data translate into estimated concentrations of Tsa1 and Ctt1 around $25 \mu M$ and $20 \mathrm{n} M$, respectively (Table 2). This scenario is similar to the one for protein $\mathrm{A}$ and $\mathrm{C}$ in Figure 5C. Thus, the comparison of reaction rates taken alone can be misleading.

\section{Implications for other enzymes}

Effects of variable reactivities and concentrations also apply to other potentially competing glutathione-dependent enzymes such as Grx or GST isoforms. It is therefore important to determine not only the presence and kinetic constants of these enzymes but also their compartment-specific concentrations using the same approaches as outlined for the protein substrates (Electrophile Concentrations section). Activity measurements of Glo1 and Glo2 in E. coli revealed, for example, calculated concentrations around 0.6 and $3 \mu M$, respectively (217). A nice example for the compartment-specific distribution of an enzyme in eukaryotes is $\mathrm{Cu} / \mathrm{Zn}$-superoxide dismutase, which was determined for rat hepatocytes by quantitative immunocytochemistry (44): The highest amount of the enzyme was found in the cytosol and nucleus, whereas highest estimated concentrations were detected in lysosomes (42 and $22 \mu M$ vs. $240 \mu M$, respectively). Peroxisomes contained lower concentrations of superoxide dismutase around $8 \mu M$ and the secretory pathway was (almost) devoid of the enzyme (44). Complementing approaches were also developed for the quantification of catalase and GPx (291). Thus, it is, in principle, possible to obtain reasonable estimates for compartment-specific enzyme concentrations. The situation for multicellular organisms is of course further complicated because of tissue-specific differences as highlighted in the mouse "redox atlas" (103). One advantage of yeast as a model organism is the availability of quantitative data on protein abundances. A major drawback is, however, that data sets can differ by up to two orders of magnitude (Table 2) $(48,100,152)$. These 

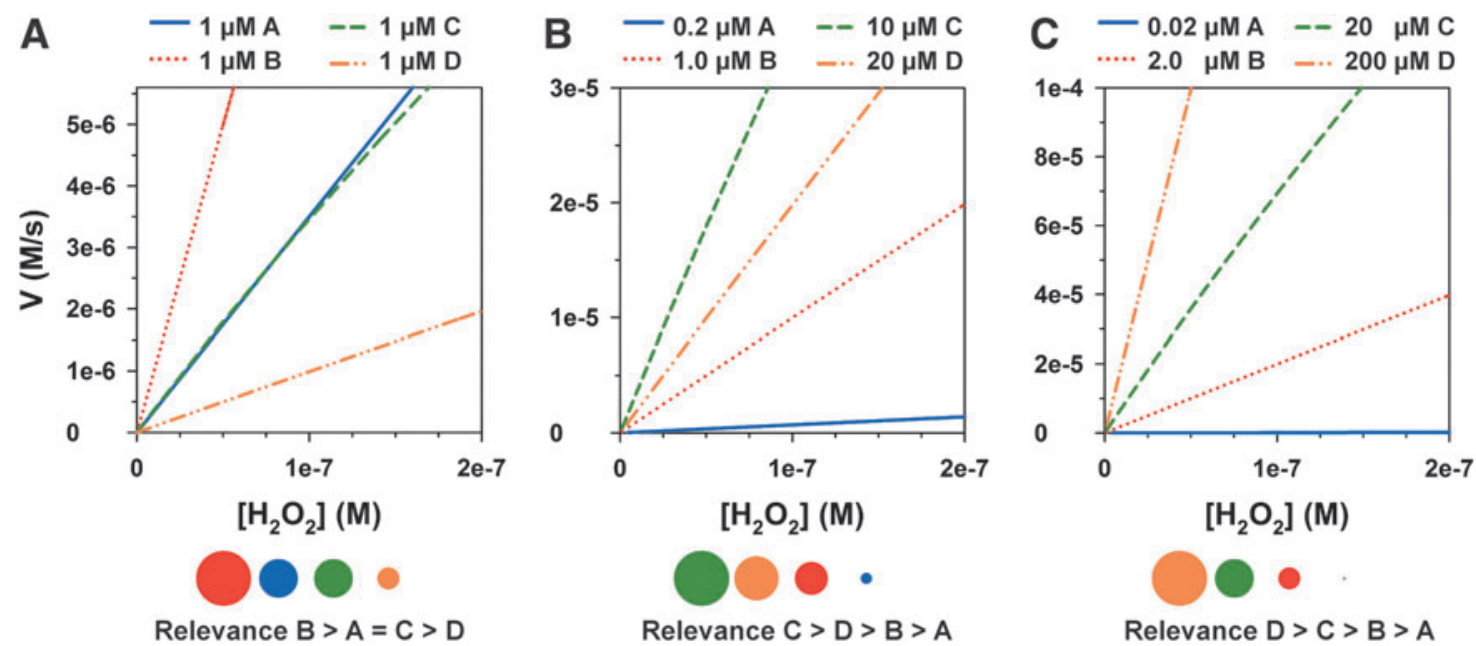

FIG. 5. Variable enzyme concentrations have drastic effects on reaction rates. Reaction rates for hypothetical hydroperoxidases A-D are shown from left to right at three different enzyme concentrations and variable $\mathrm{H}_{2} \mathrm{O}_{2}$ concentrations. The kinetic parameters of enzymes A-D are identical to the enzymes in Figure 4. The relevance of each enzyme is depicted below each plot. (A) Model with an identical concentration of $1 \mu M$ for all four proteins. (B) Model with enzyme concentrations differing by two orders of magnitude. (C) Model with enzyme concentrations differing by four orders of magnitude. Similar enzyme concentrations are found in Table 2.

differences presumably originate from alternative quantification methods using the fluorescence intensity of $\mathrm{C}$ terminally GFP-tagged proteins (48), Western blot signals of C-terminally TAP-tagged proteins (100), or mass spectrometry signals from untagged peptides (152).

\section{Implications for genetic approaches}

An often neglected aspect regarding enzyme concentrations is that the scenarios in Figure 5B and $\mathrm{C}$ do not occur only under normal growth conditions. Such scenarios are also artificially generated by reverse genetics, for example, by gene deletions or complementation studies with high copy number plasmids or strong promoters. Such tools are commonly used to aggravate a metabolic imbalancefor example, on the addition of highly concentrated electrophiles - to trigger pronounced growth defects or a rescue phenotype. This is certainly a great approach to gain first insights on the potential function of a protein in vivo. However, it may also lead to an over- or underestimated relevance of an enzyme or might even result in an incorrect functional assignment. If, for example, candidate peroxidase $\mathrm{A}$ only rescues a knockout strain of peroxidase $\mathrm{B}$ on $\mathrm{H}_{2} \mathrm{O}_{2}$ treatment when protein $\mathrm{A}$ is about a hundred times more abundant than under normal growth conditions-e.g., using a high copy number plasmid for expression-then it is not necessarily justified to conclude that protein $\mathrm{A}$ is important for the removal of $\mathrm{H}_{2} \mathrm{O}_{2}$. Likewise, some phenotypes might require the deletion of another gene. For example, the comparison of two peroxidase candidates A and B might only reveal an interesting phenotype for a strain that lacks the major peroxidase C. Such experiments might rather point to the irrelevance of candidates A or B compared to peroxidase $\mathrm{C}$ but are sometimes used to promote a novel function in vivo (see also the Kinetic Competitions for hydroperoxides I: Grx and GST section).

\section{Summary V: relevance of the enzyme concentration}

The relevance of enzyme concentrations for the reaction rates of potentially competing processes can be easily underestimated. There are rather few examples for which we know reliable compartment-specific enzyme concentrations. Much more data are required to quantify potential kinetic competitions. Furthermore, genetic approaches that are commonly used to address the relevance of glutathione-dependent processes require sufficient controls to avoid incorrect functional assignments because of altered enzyme concentrations.

\section{The Relevance of Enzymatic Mechanisms and Kinetic Patterns}

\section{Differences between ping-pong and sequential kinetic patterns}

Kinetic patterns of glutathione-dependent enzymes depend on the substrates and the catalytic mechanisms. These can differ drastically among the protein families in Table 1 (60). Enzymes with two substrates often have either ping-pong or sequential kinetic patterns $(28,250)$. Both kinetic patterns are easily distinguished in Lineweaver-Burk plots as depicted in Figure 6. The patterns are not always predictable and have to be determined experimentally for each enzyme-substrate couple. A sequential pattern usually indicates a ternary complex between the enzyme and both substrates. However, pingpong mechanisms can also result in sequential kinetic patterns, for example, when a substrate or product acts as an inhibitor $(28,250)$. In contrast to the glutathionylated substrates of Grx (Fig. 6A), this seems to be the case for the non-glutathione model substrate bis(2-hydroxyethyl)disulfide (HEDS) (Fig. 6B): Grx reduces HEDS enzymatically (23) yielding the mixed disulfide between GSH and 2-mercaptoethanol (GSSEtOH) as a product. GSSEtOH is subsequently utilized as a glutathionylated substrate in the same assay. However, newly formed 

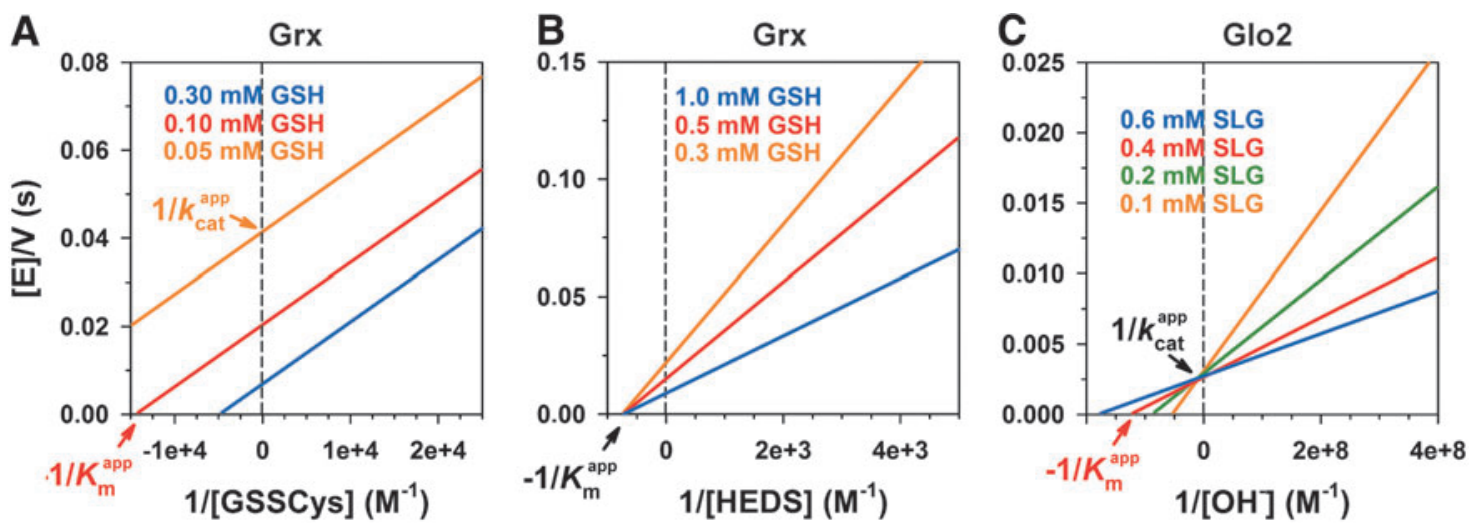

FIG. 6. Kinetic patterns depend on the enzyme and substrate. Lineweaver-Burk plots are shown for three different enzyme-substrate combinations. (A) Ping-pong patterns of ScGrx7 with the model substrate L-cysteine-glutathione disulfide (GSSCys) at three different GSH concentrations based on data from Ref. (22). The reciprocal slope (the $k_{\mathrm{cat}}$ app $/ K_{\mathrm{m}}{ }^{\text {app }}$ value) remains constant because an increase of the $k_{\mathrm{cat}}{ }^{\text {app }}$ value is coupled to an increase of the $K_{\mathrm{m}}{ }^{\text {app }}$ value. (B) Sequential kinetic patterns of ScGrx7 with the model substrate HEDS at three different GSH concentrations based on data from Ref. (22). The reciprocal slope (the $k_{\mathrm{cat}}{ }^{\text {app }} / K_{\mathrm{m}}$ app value) and the $k_{\mathrm{cat}}{ }^{\text {app }}$ values vary, whereas the $K_{\mathrm{m}}{ }^{\text {app }}$ values remain constant. (C) $\mathrm{pH}$ dependent sequential kinetic patterns of PfGlo2 at four different concentrations of SLG based on data from Ref. (280). The reciprocal slope (the $k_{\text {cat }}$ app $/ K_{\mathrm{m}}$ app value) and the $K_{\mathrm{m}}^{\text {app }}$ values vary, whereas the $k_{\text {cat }}{ }^{\text {app }}$ values remain constant. HEDS, bis(2-hydroxyethyl)disulfide; SLG, $S$-D-lactoylglutathione.

GSSEtOH probably adopts a futile orientation at the enzyme and has to be released before it is accepted as a substrate (22). Thus, GSSEtOH also seems to act as an inhibitor that causes the sequential kinetic patterns. To which degree similar Grxcatalyzed reactions occur in vivo remains to be clarified. Potential non-glutathione substrates that might cause such kinetic patterns include L-cystine, coenzyme A disulfides or diallyl disulfides, and related compounds from garlic and other Allium species (23).

In addition to standard ping-pong or sequential patterns, Lineweaver-Burk plots are sometimes curved or biphasic. This can point to a glutathione-dependent allostery or cooperativity as revealed for a monomeric Glo1 isoform and a PrxV-type enzyme from malaria parasites $(67,69,261)$. Classical heme-containing catalases use the following unusual ping-pong mechanism: reduction of the first $\mathrm{H}_{2} \mathrm{O}_{2}$ molecule yields the oxidized enzyme, an oxoferryl porphyrin cation radical termed "compound I". Oxidation of the second $\mathrm{H}_{2} \mathrm{O}_{2}$ molecule regenerates the $\mathrm{Fe}^{3+}$-containing enzyme (3). Because $\mathrm{H}_{2} \mathrm{O}_{2}$ is the substrate for both half-reactions, catalase cannot be saturated, resulting in a linear substrate concentration dependence of the reaction rate (Fig. 4A). However, the physiological situation is more complicated because the enzyme gets inactivated by $\mathrm{O}_{2}^{\bullet-}$, and alternative electron donors such as ethanol compete for the reductive half-reaction of bifunctional catalase peroxidases (43). Further mechanisms of the enzymes in Table 1 are reviewed in Ref. (60).

Why are the mechanisms and kinetic patterns important? An allostery or cooperativity points to a glutathionedependent enzyme regulation. For example, glutathione was shown to alter the oligomerization, activity, and function of selected Prx in vitro $(69,218,226)$. Furthermore, the second substrates of enzymes with ping-pong or sequential kinetic patterns have different effects on the kinetic parameters. (i) Decreasing the concentration of the second substrate of an enzyme with ping-pong patterns shifts the ratio between the enzyme species "E" and " $F$ " in scheme 3 toward species
" $F$ " and results in lower $k_{\mathrm{cat}}$ app and $K_{\mathrm{m}}$ app values for the first substrate (Fig. 6A). Different GSH concentrations in the cytosol and the endoplasmic reticulum should therefore alter the ratio between reduced and glutathionylated GPx isoforms in these compartments. (ii) In contrast, decreasing the concentration of the second substrate of an enzyme with sequential patterns results in lower $k_{\mathrm{cat}}{ }^{\text {app }}$ values and/or higher $K_{\mathrm{m}}{ }^{\text {app }}$ values (Fig. $6 \mathrm{~B}, \mathrm{C}$ ). Both effects cause a drop of the catalytic efficiency (the $k_{\mathrm{cat}}{ }^{\mathrm{app}} / K_{\mathrm{m}}{ }^{\text {app }}$ value), whereas the efficiencies of enzymes with ping-pong patterns remain unaffected by the substrate concentration. The latter aspect might be helpful to decipher the physiological role of high GSH concentrations (Mother Nature Invented GSH: But Why So Much section).

\section{Molecular Lego: uncoupling mechanisms using modular enzymes}

Why do pro- and eukaryotes contain so many catalytically inactive Grx isoforms that are involved in iron metabolism? How can some GPx and Prx isoforms exert additional functions as redox sensors? All these enzymes have in common that they utilize ping-pong mechanisms for catalysis. The selectivity of glutathione-dependent enzymes appears to depend on the geometric and electrostatic complementarity of the protein-substrate couple. In other words, the substrate and the transition state nicely fit into the active site of the protein, and the recruitment of the substrate in a suitable orientation is guided by the electrostatic surface potential $(22,60,65)$. As outlined in the Difference Between True and Apparent $k_{\text {cat }}$ and $K_{\mathrm{m}}$ Values section, substrates of enzymes with ping-pong mechanisms never encounter each other (scheme 3). Furthermore, the trigonal bipyramidal transition states during GPx, Prx, and Grx catalysis necessitate either drastic conformational changes or two distinct substrate interaction sites $(22,60,73)$. These chemical constraints result in a modular enzyme architecture, which is even more pronounced in 


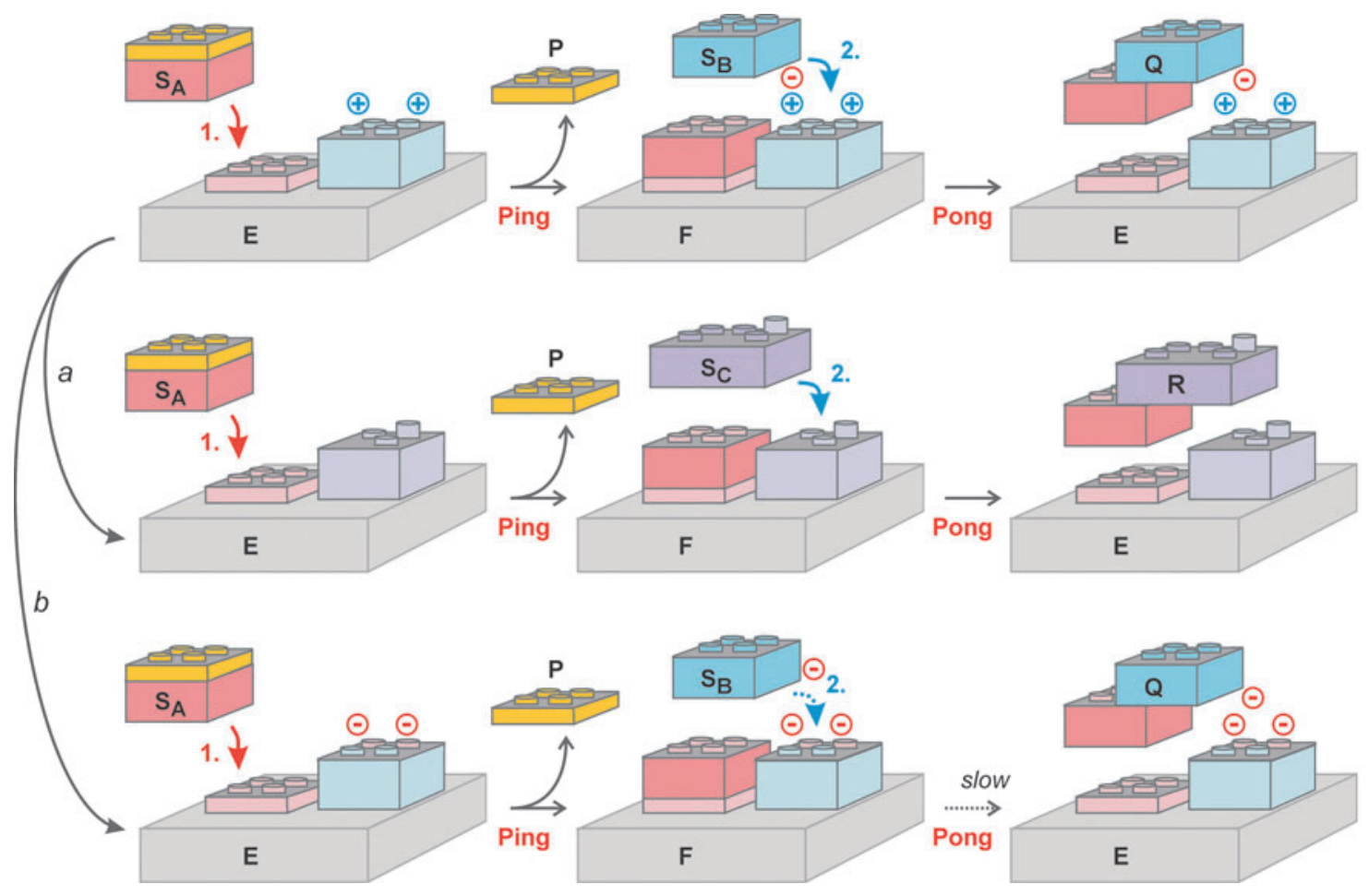

FIG. 7. The modular architecture of enzymes with ping-pong mechanisms facilitates the gain of novel functions. Two evolutionary scenarios are shown to illustrate how point mutations affect the geometric and electrostatic complementarity between the enzyme and substrate. For enzymes with ping-pong mechanisms, mutations can selectively alter the substrate preferences (scenario $a$ ) and/or kinetics (scenario $b$ ). This can result in trapped enzyme species and novel functions, for example, in redox signaling or iron-sulfur cluster biogenesis. The model may apply to all kinds of enzymes with ping-pong mechanisms such as Grx, Prx, GPx, GR, and TrxR [see Ref. (60) for details on the respective enzyme mechanisms]. Please note that the relevant enzyme-substrate interactions might be very temporary. Furthermore, they are not restricted to the reaction center and also include the protein surface that can affect the substrate recruitment.

redox-active flavoenzymes such as GR, TrxR, or Erv $(60,64)$. Thus, point mutations in enzymes with ping-pong mechanisms can have a specific effect on only one of both half-reactions and enzyme-substrate interactions. This allows the utilization of alternative substrates or the deceleration or inactivation of a half-reaction to kinetically uncouple a process and to accumulate a metastable intermediate (Fig. 7).

Mutations and the spatiotemporal separation of the hydroperoxide reduction from the reductive half-reaction allowed Prx and GPx, for example, to switch between different reducing agents and to accumulate a metastable oxidized enzyme species for redox signaling $(59,60,113,261,273$, 299). A similar scenario was suggested for Grx catalysis (60, 73), which was recently shown to require two distinct glutathione interaction sites, one for GSSR and one for GSH (Fig. 8) (22). In the course of evolution, mutations in the rather ill-defined GSH interaction site presumably abolished the enzymatic activity of most monothiol Grx isoforms. The mutations include the loss of a hydroxyl group of a conserved tyrosine residue and the introduction of a rigid proline and a bulky tryptophan residue (Fig. 8) (22, 60, 63, 183). Loss of the GSH interaction resulted in a kinetic uncoupling from GSH catalysis and probably stabilized the interaction between glutathione and an iron-sulfur cluster at the GSSR binding site. The kinetic uncoupling from redox catalysis obviously allowed an important gain of function for Grx in iron metabolism $(17,56,163,194,214,241)$, which has been suggested to be, at least in yeast, the most relevant branch of glutathione metabolism (153). It may also allow GSSG sensing by monothiol Grx (Kinetic Competitions for GSSG and GSSR section)

Are there further candidates for molecular uncoupling mechanisms? Many dithiol and monothiol Grx isoforms have an additional, catalytically irrelevant cysteine residue after a GG motif $(60,69)$. The residue was shown to form a variety of mixed disulfide bonds in vitro (69). Such modifications could interfere with the GSSR interaction site and might uncouple the oxidative instead of the reductive half-reaction of Grx. This might shut off the deglutathionylation activity of Grx. An alternative inactivation of the oxidative half-reaction includes the phosphorylation of selected threonine or serine residues, as hypothesized previously (97). Please note that both reversible uncoupling scenarios might solve the dilemma how specific glutathionylated substrates should accumulate at high GSH concentrations in the presence of Grx (Kinetic Competitions for GSSG and GSSR section).

\section{Summary VI: relevance of enzymatic mechanisms and kinetic patterns}

The knowledge on enzyme mechanisms and kinetic patterns is crucial to estimate the physiological effects of altered substrate concentrations or inhibitors. Modular ping-pong reactions facilitate a molecular evolution that results in the 

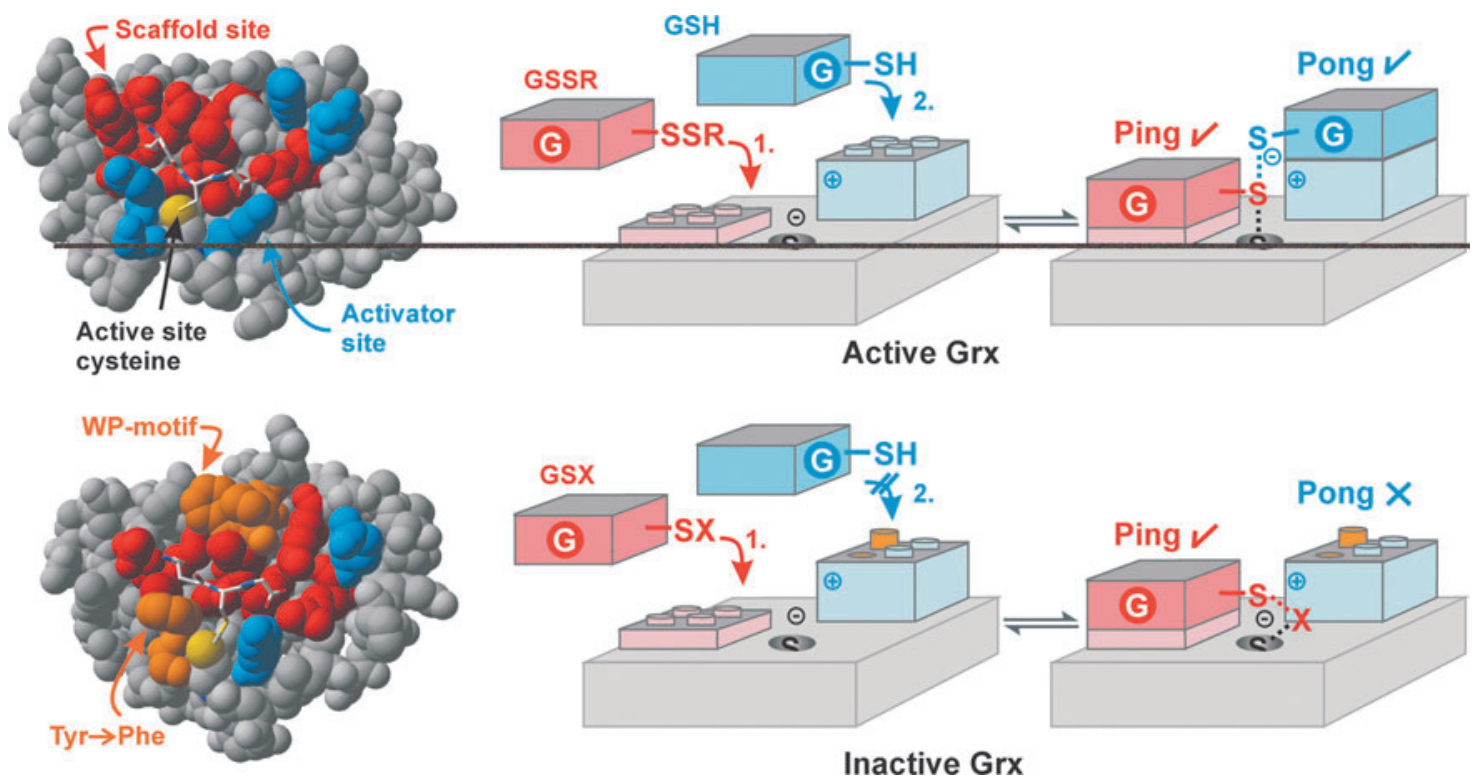

FIG. 8. The modular architecture of enzymes with ping-pong mechanisms allows a kinetic uncoupling of the halfreactions. Grx catalysis with glutathionylated substrates (GSSR) requires two distinct glutathione interaction sites because of the transition-state geometry of thiol/disulfide exchange reactions $(22,60,183)$. The upper and lower parts illustrate differences and similarities between active and inactive Grx isoforms. Both groups have partially conserved residues for the interaction with the GSSR substrate at the so-called scaffold site. This interaction results in the glutathionylation of the active site cysteine residue. The scaffold site can also interact with glutathione that is bound to other groups (X) such as glutathione conjugates or iron-sulfur clusters $(161,164,183,302)$. Inactive Grx lack the hydroxyl group of a conserved tyrosine residue in a $\mathrm{CxY}(\mathrm{C} / \mathrm{S})$-motif and have a bulky WP-motif that probably interferes with the GSH interaction at a predominantly uncharacterized activator site $(22,60,63,183)$. Thus, the reductive half-reaction of inactive Grx is either very slow or cannot take place anymore because of an incompatible geometric and electrostatic complementarity between the enzyme and GSH $(22,60,65)$.

use of alternative substrates and that allows a kinetic uncoupling of processes from redox catalysis at physiological GSH concentrations. Such processes include redox sensing, iron-sulfur cluster binding, and maybe protein glutathionylation and oxidative protein folding.

\section{Applications and Examples}

Now that we have gained an overview on the relevant parameters and gathered some quantitative data, we can apply this information to estimate the reaction rates of potentially competing enzymatic as well as nonenzymatic reactions in glutathione metabolism. I will provide three examples to address (i) whether hydroperoxide detoxification is a common function of glutathione metabolism, (ii) whether GSSGdependent glutathionylations occur during oxidative challenge, and (iii) whether GSH plays a role as a radical scavenger. The reader is encouraged to raise the question whether similar quantitative approaches might be helpful to address other aspects of glutathione metabolism, for example, using the data from Tables 1-3.

\section{Kinetic competitions for hydroperoxides I: Grx and GST}

Which glutathione-dependent processes contribute to the detoxification of hydroperoxides and/or $\mathrm{H}_{2} \mathrm{O}_{2}$-dependent redox signaling? As reviewed previously, glutathione-dependent hydroperoxidases are rather the exception, and most characterized GPx and Prx isoforms were shown to use Trx isoforms as electron donors $(60,90,172,273)$. From an evolutionary perspective, this contradicts the hypothesis that high GSH concentrations are pivotal for the detoxification of hydroperoxides. To rescue the hypothesis, one might consider other ubiquitous glutathione-dependent proteins. A hydroperoxidase activity was indeed not only detected for selected GPx and Prx $(35,60,89,109,261,273)$ but also for several GST, MAPEG, and Grx isoforms $(16,52,53,60,80,121,134,135,229)$. Are these in vitro activities high enough to become physiologically relevant, as has been suggested by independent groups based on survival and protection assays in yeast and human cell cultures $(52,53,80)$ ?

Mammalian Grx2 as well as yeast ScGrx1 and ScGrx2 were reported to have quite high hydroperoxidase activities with $k_{\text {cat }}$ app $/ K_{\mathrm{m}}$ app values for $\mathrm{H}_{2} \mathrm{O}_{2}$ ranging from $7.7 \times 10^{3}$ to $5.3 \times 10^{4} M^{-1} \mathrm{~s}^{-1}$ (Table 3 ) $(52,80)$. Only one GSH concentration was tested for these enzymes so that we can only speculate on the kinetic patterns. For the sake of simplicity, we will assume ping-pong patterns with constant $k_{\mathrm{cat}}{ }^{\mathrm{app}} / K_{\mathrm{m}}$ app values irrespective of the GSH concentration. Furthermore, we will assume that the $k_{\mathrm{cat}}{ }^{\text {app }} / K_{\mathrm{m}}{ }^{\text {app }}$ values really reflect the oxidative half-reaction and are comparable with the second-order rate constants of GPx and Prx. Estimated concentrations for cytosolic ScGrx1 and ScGrx2 range from $3.4 \mathrm{n} M$ to $6.5 \mu M$. The estimated concentration of the competing cytosolic Prx isoform Tsa1 is between 0.51 and $26 \mu M$ (Table 2). Secondorder rate constants of Tsa1/2 for $\mathrm{H}_{2} \mathrm{O}_{2}$ are about $10^{7} M^{-1} \mathrm{~s}^{-1}$ (Table 3) (207). To evaluate a competition at a theoretical $\mathrm{H}_{2} \mathrm{O}_{2}$ concentration of $10 \mathrm{n} M$, we will use the highest $k_{\text {cat }}^{\text {app/ }}$ $K_{\mathrm{m}}{ }^{\text {app }}$ value of Grx. Taking all these parameters into account, we can now estimate the reaction rates using Eq. 1 (Box 1). 
Box 1. Calculated Reaction Rates of Grx, Prx, AND GPX AT IO NM $\mathrm{H}_{2} \mathrm{O}_{2}$

\begin{tabular}{|c|c|c|}
\hline \multirow{2}{*}{\multicolumn{3}{|c|}{$\begin{array}{l}v_{\text {Grx (high) }}=5.3 \times 10^{4} \mathrm{M}^{-1} \mathrm{~s}^{-1} \times 6.5 \mu \mathrm{M} \times 10 \mathrm{nM}=\mathbf{3 . 4} \times \mathbf{1 0}^{-\mathbf{9}} \mathbf{M} / \mathbf{s} \\
v_{\text {Grx (low) }}=5.3 \times 10^{4} \mathrm{M}^{-1} \mathrm{~s}^{-1} \times 3.4 \mathrm{nM} \times 10 \mathrm{nM}=\mathbf{1 . 8} \times \mathbf{1 0}^{-\mathbf{1 2}} \mathbf{M} / \mathrm{s}\end{array}$}} \\
\hline & & \\
\hline \multirow{2}{*}{\multicolumn{2}{|c|}{$\begin{array}{l}v_{\text {Tsa(high) }}=10^{7} \mathrm{M}^{-1} \mathrm{~s}^{-1} \times 26 \mu \mathrm{M} \times 10 \mathrm{nM} \\
v_{\text {Tsa(low) }}=10^{7} \mathrm{M}^{-1} \mathrm{~s}^{-1} \times 0.5 \mu \mathrm{M} \times 10 \mathrm{nM}\end{array}$}} & $=2.6 \times 10^{-6} \mathrm{M} / \mathrm{s}$ \\
\hline & & $=5.0 \times 10^{-8} \mathrm{M} / \mathrm{s}$ \\
\hline$v_{\mathrm{GPx} 1}$ & $=4.7 \times 10^{7} \mathrm{M}^{-1} \mathrm{~s}^{-1} \times 1 \mu \mathrm{M} \times 10 \mathrm{nM}$ & $=4.7 \times 10^{-7} \mathrm{M} / \mathrm{s}$ \\
\hline$v_{\operatorname{Prx} 2}$ & $=10^{8} \mathrm{M}^{-1} \mathrm{~s}^{-1} \times 10 \mu \mathrm{M} \times 10 \mathrm{nM}$ & $=1.0 \times 10^{-5} \mathrm{M} / \mathrm{s}$ \\
\hline
\end{tabular}

The most optimistic scenario at a high Grx and low Tsa1 concentration suggests that the reaction rate of Grx accounts for $7 \%$ of the Tsal rate, which is still too slow for an efficient competition. If this scenario is correct, a fraction of Grx might, nonetheless, form a sulfenic acid and act as a redox sensor to explain the observed survival effects. However, redox sensing would require a kinetic uncoupling from the reduction by GSH, that is, a stabilization of the sulfenic acid or an efficient competition between GSH and a cysteine residue (Molecular Lego: Uncoupling Mechanisms Using Modular Enzymes section). For the most pessimistic scenario, the reaction rate of $\mathrm{H}_{2} \mathrm{O}_{2}$ with $\mathrm{Grx}$ is up to six orders of magnitude smaller than the rate with Tsa1. This scenario is quite likely considering that Tsa1 was reported to constitute $0.7 \%$ of the total soluble protein from yeast (146). Thus, the reaction of Grx with $\mathrm{H}_{2} \mathrm{O}_{2}$ is too slow to compete with the established hydroperoxidases in yeast.

Box 1 also shows calculated reaction rates for mammalian GPx1 and Prx2 using rate constants of $4.7 \times 10^{7} M^{-1} \mathrm{~s}^{-1}$ and $10^{8} M^{-1} \mathrm{~s}^{-1}(89,174,273)$ as well as hypothetical protein concentrations of 1 and $10 \mu M$, respectively. The reaction rates at $10 \mathrm{nM} \mathrm{H} \mathrm{H}_{2} \mathrm{O}_{2}$ between $5 \times 10^{-7}$ and $10^{-5} \mathrm{M} / \mathrm{s}$ are in the same range as for Tsa 1 in yeast. This would explain why glutathione-dependent mammalian GPx isoforms can play a role in hydroperoxide removal, although there are certainly kinetic competitions with Prx and catalase depending on the substrate, the subcellular localization, and the enzyme concentration (Fig. 5) $(35,89,273)$. Regarding the moderate hydroperoxidase activity of mammalian Grx2 isoforms in Table 3, it appears unlikely that these enzymes are concentrated enough to compete with the established hydroperoxidases.

Which information is available on the potential relevance of GST in yeast? The cytosolic GST isoform Ure 2 was reported to have a hydroperoxidase activity with sequential kinetic patterns (16). The $k_{\mathrm{cat}}{ }^{\text {app }} / K_{\mathrm{m}}{ }^{\text {app }}$ value at $1 \mathrm{~m} M \mathrm{GSH}$ is about a hundred times higher than the second-order rate constant for the nonenzymatic $\mathrm{H}_{2} \mathrm{O}_{2}$-dependent formation of $\mathrm{GSOH}$ (Table 3). Considering an estimated concentration of Ure2 between 14 and $490 \mathrm{n} M$ (Table 2), which is more than a thousand-fold lower than the GSH concentration, the Ure2-dependent reaction rate is not only negligible compared to Tsal but also much slower than the nonenzymatic reaction between $\mathrm{H}_{2} \mathrm{O}_{2}$ and $\mathrm{GSH}$ (which ranges from $10^{-11}$ to $10^{-12} \mathrm{M} / \mathrm{s}$ at $10 \mathrm{nM} \mathrm{H}_{2} \mathrm{O}_{2}$ ).
In summary, a physiological relevance of Grx and GST isoforms as hydroperoxidases is highly questionable, unless (i) there is a specific substrate, (ii) the compartment contains no classical hydroperoxidases, (iii) the enzyme is either very concentrated or directly targeted to the $\mathrm{H}_{2} \mathrm{O}_{2}$ source, or (iv) one of the assumptions above is completely wrong. Considering that the reported effects in yeast and human cell cultures required an overexpression of $\operatorname{Grx}(52,53,80)$, it is likely that the results are based on artificially high Grx concentrations (similar to shifting the relevance of enzyme A from Fig. 5C or 5B to 5A). This interpretation is also supported by genetic and proteomic studies suggesting that the Trx/TrxR system is the major electron donor for the reduction of hydroperoxides in yeast $(153,156)$.

\section{Kinetic competitions for hydroperoxides II: GAPDH}

What can we say about the formation of sulfenic acids in other proteins than GPx and Prx? As emphasized previously, there are only few cysteine residues with rate constants above $10^{2} M^{-1} \mathrm{~s}^{-1}$ that might compete with the activity of hydroperoxidases $(34,59,65,91,263)$. One exception is GAPDH (Table 3), which forms a sulfenic acid that is susceptible to the reduction by GSH $(111,120,225,246,251)$. The extrapolation of the rate constant of GAPDH with $\mathrm{H}_{2} \mathrm{O}_{2}$ at $25^{\circ} \mathrm{C}$ depends on the activation energy. Using the Arrhenius equation, the rate constant from Ref. (165) at $0^{\circ} \mathrm{C}$, and a hypothetical activation energy between 65 and $20 \mathrm{~kJ} / \mathrm{mol}$, reasonable estimates for the $k_{2}$ value range from 200 to 1100 $M^{-1} \mathrm{~s}^{-1}$. Furthermore, GAPDH is one of the most abundant cytosolic proteins (top 5\%) (287) and was suggested to have a concentration of up to $1 \mathrm{mM}$ (225). Combining the information, the estimated reaction rate of GAPDH at $10 \mathrm{nM} \mathrm{H}_{2} \mathrm{O}_{2}$ is between $2 \times 10^{-9} \mathrm{M} / \mathrm{s}$ and $1.1 \times 10^{-8} \mathrm{M} / \mathrm{s}$. A comparison with the reaction rates from Box 1 reveals for the most optimistic scenario-with a $k_{2}$ value of $1100 \mathrm{M}^{-1} \mathrm{~s}^{-1}$ and an unrealistic low Tsa1 concentration - that the reaction rate of GAPDH is about $20 \%$ of the Tsa1 rate (or $2 \%$ of the reaction rate of GPx 1 in mammals). If the concentration of GAPDH is lower, the $k_{2}$ value is smaller, and/or the Tsa1 concentration is higher, less than $0.02 \%$ of $\mathrm{H}_{2} \mathrm{O}_{2}$ might react with GAPDH, which is more realistic. However, in contrast to GPx, Prx, and also Grx, the cysteine residue of GAPDH is quite buried, and the reduction by GSH is probably much slower than the reduction of the other proteins (Table 3). Thus, GAPDH(SOH) can accumulate over time and reach detectable steady-state concentrations (111). The accumulation of oxidized GAPDH was suggested to either affect moonlighting functions or to shift the metabolic flux of glucose toward the pentose phosphate pathway, yielding NADPH for the reduction of Trx and GSSG $(120,225,251)$.

It remains highly controversial whether sulfenic acids of less abundant and reactive proteins accumulate in vivo. On the one hand, low nanomolar steady-state concentrations translate into only a handful of $\mathrm{H}_{2} \mathrm{O}_{2}$ molecules in subcellular compartments with a volume around $1 \mathrm{fl}$ (see Table 2 legend for estimated compartment volumes). If a highly reactive and abundant peroxidase is present, the chances of $\mathrm{H}_{2} \mathrm{O}_{2}$ to react with a common nonreactive cysteine residue are minuscule because of an unwinnable kinetic competition. Even for GAPDH, a rate constant of $1100 M^{-1} \mathrm{~s}^{-1}$ at a steady-state concentration of $\mathrm{H}_{2} \mathrm{O}_{2}$ around $10 \mathrm{n} M$ translates into a half- 
time for sulfenic acid formation of $12 \mathrm{~h}$. In other words, it would require $12 \mathrm{~h}$ (or $15 \mathrm{~min}$ at $0.5 \mu M \mathrm{H}_{2} \mathrm{O}_{2}$ ) to oxidize $50 \%$ of GAPDH, provided that the sulfenic acid is not reduced again. In the same time, only $0.04 \%$ of a regular cysteine residue with a rate constant of $1 M^{-1} \mathrm{~s}^{-1}$ would become oxidized, and it would take about 12 days at $10 \mathrm{n} M \mathrm{H}_{2} \mathrm{O}_{2}$ until $1 \%$ of the oxidized protein accumulates (always provided that the sulfenic acid is not reduced again). This also shows that even compartments without highly concentrated peroxidases will only accumulate sulfenic acids very slowly as long as the $\mathrm{H}_{2} \mathrm{O}_{2}$ concentration does not rise. The only way to accelerate the reaction is to either alter the rate constant, for example, by increasing the $\mathrm{pH}$ or by increasing the (local) $\mathrm{H}_{2} \mathrm{O}_{2}$ concentration. The latter scenario might occur in vivo when $\mathrm{H}_{2} \mathrm{O}_{2}$ is generated in the proximity of a cysteine residue, for example, by a flavoenzyme or a damaged iron-sulfur cluster. These conditions would increase the likelihood for a successful sulfenic acid formation. However, even that is not enough to result in the accumulation of sulfenic acids at steady-state conditions. For this, the reduction of the sulfenic acid has to be slow. Reported rate constants for the in vitro reduction of sulfenic acids depend on the protein environment and range from 0.012 to $>10^{5}$ $M^{-1} \mathrm{~s}^{-1}$ (Table 3) $(111,199)$.

In summary, a general accumulation of sulfenic acids cannot occur in vivo. The formation of specific sulfenic acids requires unusual conditions such as (i) high (local) hydroperoxide concentrations, (ii) the absence of competing hydroperoxidases, or (iii) a very reactive cysteine residue in combination with a high protein concentration. Except for GAPDH, the bacterial transcription factor OxyR, and maybe a few other candidates, it is questionable whether sulfenic acids of nonhydroperoxidases are formed to a significant extent in vivo $(34,65,91)$. The steady-state concentration of such species depends not only on the oxidation but also on the reduction rate, both of which are usually unknown.

\section{Kinetic competitions for GSSG and GSSR}

A reiterated model of diverse theories on oxidative stress is that protein cysteine residues are protected from "overoxidation" by unspecific glutathionylations. Such theories are sometimes supported by proteomic screens revealing hundreds of glutathionylated candidates (143). Glutathionylated residues are suggested to be formed from (i) sulfenic acids and GSH, from (ii) thiols that react with accumulated GSSG, from (iii) nitrosothiols, or (iv) from radicals [see Ref. (95) for review]. Another way to obtain a glutathionylated protein is of course the reaction between a protein disulfide bond and GSH, however, it is not really plausible why the initial disulfide bond should be less protected under oxidative challenge than the mixed disulfide bond with glutathione. The promiscuous formation of sulfenic acids under oxidative challenge is implausible and can be discarded as a general glutathionylation mechanism (Kinetic competitions for hydroperoxides II: GAPDH section). Radical reactions are discussed in the Kinetic Competitions for Radicals section. We will therefore continue with potential nonenzymatic and enzymatic competitions for GSSG.

Cytosolic Grx are, because of their ping-pong mechanism, supposed to be predominantly present in the reduced state at physiological GSH concentrations. No apparent substrate saturation is expected at nanomolar or low micromolar GSSG concentrations (in analogy to the hydroperoxidases shown in Fig. 5). The concentration of enzymatically active mammalian Grx is $\sim 1 \mu M$ in the cytosol and in the mitochondrial matrix (97). Estimated concentrations for yeast ScGrx1 and ScGrx2 range from $3.4 \mathrm{n} M$ to $6.5 \mu M$ (Table 2). Second-order rate constants of Grx with glutathionylated substrates, including GSSG, are usually between $10^{5}$ and $10^{6} \mathrm{M}^{-1} \mathrm{~s}^{-1}(22$, $96,300)$, whereas common thiols have $k_{2}$ values that are $10^{3}$ to $10^{8}$-times smaller (Table 3$)(198,266)$. A kinetic competition between a protein thiol and Grx for GSSG or GSSR is only possible if the concentrations of Grx and the protein thiol differ by the same order of magnitude. Such a scenario is unlikely for cytosolic proteins. Thus, peak concentrations of cytosolic GSSG rather yield Grx(SSG) than protein(SSG) as an intermediate product. A subsequent enzymatic transfer of the glutathione moiety from $\mathrm{Grx}(\mathrm{SSG})$ to a protein cysteine residue is, in principle, possible. However, such a reaction has to compete with millimolar GSH and rate constants between $6 \times 10^{3}$ and $5 \times 10^{5} M^{-1} \mathrm{~s}^{-1}$ (Table 3 ). Protein glutathionylation therefore requires a high protein concentration, an unusual rate constant, or kinetic uncoupling of Grx catalysis from GSH because of an altered reductive half-reaction (Fig. 7). Enzymatically inactive Grx isoforms are uncoupled, provide the properties to sense GSSG $(60,73)$ and might transfer the glutathionylation signal to specific transducer proteins in accordance with the concept on redox signaling from Ref. (34).

The competition between protein thiols and Grx also brings us back to the four possible mechanisms for the rapid recovery of intracellular $\mathrm{E}_{\mathrm{GSH}}^{\prime}$ values after oxidative challenge (Glutathione concentrations section). Peak concentrations of GSSG are very temporary, and the number of cytosolic GSSG molecules under steady-state conditions is probably small. As I just outlined, a Grx-independent buffering of cytosolic GSSG as protein(SSG) does not make sense. Whether there is a transient Grx-catalyzed glutathionylation of proteins depends on the competition between Grx and the GR- or transportercatalyzed removal of GSSG. GR from rat has a $k_{\mathrm{cat}}{ }^{\text {app }} / K_{\mathrm{m}}$ app value for GSSG of $4.9 \times 10^{6} M^{-1} \mathrm{~s}^{-1}$ (37), which is roughly 10 times faster than the $k_{2}$ value of Grx (Table 3). Thus, efficient Grx-catalyzed protein glutathionylation (e.g., for redox signaling) should only occur if the GR concentration is lower than the Grx concentration. Further quantitative data on GR, Grx, and GSSG transporters are necessary to decipher the exact fate of GSSG on oxidative challenge.

It is interesting to note that a hypothetical temporary depletion of NADPH on oxidative challenge will have a direct effect on the activity of GR, whereas the activity of Grx is not affected. When the GSSG concentration rises and GR stays inactive, Grx could glutathionylate a number of proteins. Such a metabolic flux should occur in GR-deficient cells, which are presumably viable because (selected) glutathionylated proteins are also substrates of the Trx/TrxR system as demonstrated in vitro $(79,139)$. A similar situation might occur in the secretory pathway of yeast, which lacks GR but harbors ScGrx6 and ScGrx7 $(132,184)$. Whether these enzymes catalyze glutathionylations or deglutathionylations should depend on the ratio between GSSG and GSH (Fig. 2). Whether specific PDI isoforms exert similar glutathione-dependent functions on oxidative protein folding in mammals and other eukaryotes requires more quantitative and qualitative data in vivo (Modified Cysteine Residues section) (8, 170, 209, 272). 
In summary, a general accumulation of glutathionylated proteins during oxidative challenge is unlikely to occur in vivo and would necessitate a permanent depletion of NADPH. Nonenzymatic GSSG-dependent glutathionylations are outcompeted by enzymatic glutathionylations when Grx are present. Enzymatically active Grx prevent or immediately reverse glutathionylations at millimolar GSH concentrations. GSSG-dependent protein glutathionylations require special conditions such as (i) high local GSSG concentrations (e.g., when GR or GSSG transporters are absent or inactive) or (ii) kinetic uncoupling mechanisms (e.g., to transfer the glutathione moiety from an inactive Grx isoform to a specific transducer).

\section{Kinetic competitions for radicals}

The substrate $\mathrm{O}_{2}{ }^{\bullet-}$ of superoxide dismutase is one of the most important radicals in biology. Is a nonenzymatic reaction between $\mathrm{O}_{2}{ }^{\bullet-}$ and GSH of any physiological relevance? The reaction rate of superoxide dismutase ranges from $5 \times 10^{-8}$ to $6 \times 10^{-6} \mathrm{M} / \mathrm{s}$ at a hypothetical $\mathrm{O}_{2}^{\bullet-}$ concentration of $0.1 \mathrm{n} M$ (using the calculated concentration for cytosolic superoxide dismutase between 0.23 and $31 \mu M$ from Table 2 and the rate constant from Table 3 ). At a GSH concentration of $13 \mathrm{~m} M(212)$, the enzymatic reaction of superoxide dismutase is four to six orders of magnitude faster than the nonenzymatic reaction with GSH. Thus, there is no way that GSH has any relevance for $\mathrm{O}_{2}{ }^{\bullet-}$ removal in the cytosol. Such a reaction might only play a role in a compartment that is (i) devoid of superoxide dismutase, (ii) contains only low concentrations of competing flavo-, heme-, or iron-sulfur cluster proteins, and (iii) has a $\mathrm{pH}$ value above 6 (otherwise the spontaneous disproportionation of $\mathrm{O}_{2}{ }^{\bullet-}$ is faster).

However, GSH might play a role in scavenging other radicals that react with any available electron donor in a diffusion-controlled manner. The rate constants of radical reactions and the high GSH concentration obviously increase the likelihood for the formation of the thiyl radical GS ${ }^{\bullet}$. From there on one can go through many potential reactions on paper. Whether this "paper chemistry" is really relevant in vivo, or whether $\mathrm{GS}^{\bullet}$ is just another link in a detrimental chain reaction, might depend on the presence and concentration of other compounds such as $\mathrm{NO}^{\bullet}$, ascorbate, and maybe Grx $(38,95,97,147)$. For example, GSNO is sometimes suggested to be formed by $\mathrm{GS}^{\bullet}$ and $\mathrm{NO}^{\bullet}$. However, even at a high $\mathrm{NO}^{\bullet}$ concentration, the $\mathrm{GS}^{\bullet}$-dependent formation of GSNO is questionable because of a competition with the $\mathrm{O}_{2}^{\bullet}$ - dependent formation of peroxynitrite (Reactive Oxygen and Nitrogen Species section). The rate constant for the reaction of $\mathrm{NO}^{\bullet}$ with $\mathrm{GS}^{\bullet}$ is about one order of magnitude smaller than for the reaction with $\mathrm{O}_{2}^{\bullet-}$ (38). Whether the metabolic flux is now directed toward the formation of peroxynitrite or GSNO highly depends on the steady-state concentrations of $\mathrm{GS}^{\bullet}$ and $\mathrm{O}_{2}^{\bullet-}$. Although there appear to be no quantitative data on the steady-state concentration of GS ${ }^{\bullet}$, I would be surprised if it is 10 times higher than the concentration of $\mathrm{O}_{2}{ }^{\bullet-}$. The detection of $\mathrm{GS}^{\bullet}$ by sensitive spin traps required, for example, the continuous treatment of neuro-

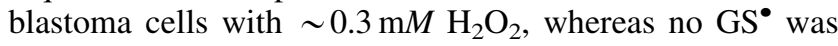
trapped in unstressed controls (155).

In summary, a GSH-dependent detoxification of radicals and the $\mathrm{NO}^{\bullet}$-dependent formation of GSNO are presumably of little physiological relevance and would require highly specialized reaction conditions because of unfavorable kinetic competitions. However, when iron ions are liberated from damaged iron-sulfur clusters during oxidative challenge (Modified Cysteine Residues section), GSH could contribute electrons to detrimental Fenton reactions (197). This might lead to local glutathionylations and the formation of $\mathrm{O}_{2}{ }^{\bullet-}, \mathrm{H}_{2} \mathrm{O}_{2}$, and ${ }^{\bullet} \mathrm{OH}$. In such a scenario, nonenzymatic single-electron exchanges with GSH would rather enhance the formation of harmful radicals instead of scavenging them as an "antioxidant".

\section{Mother Nature Invented Glutathione: But Why So Much?}

\section{Hypothesis I: high GSH concentrations are crucial for redox homeostasis}

This imprecise hypothesis subsumes numerous parameters, including enzymatic and nonenzymatic reactions between multiple partners. As outlined in the previous sections, nonenzymatic reactions of $\mathrm{GSH}$ with $\mathrm{O}_{2}{ }^{\bullet-}, \mathrm{H}_{2} \mathrm{O}_{2}$, and disulfides are too slow and cannot compete with enzymes even at millimolar GSH concentrations. Enzymatic reactions with $\mathrm{O}_{2}{ }^{\bullet-}$ and $\mathrm{H}_{2} \mathrm{O}_{2}$ also occur without a glutathione system, and glutathione-dependent hydroperoxidases are rather the exception than the rule. Furthermore, such enzymes work with ping-pong mechanisms and their catalytic efficiency is constant and does not depend on high GSH concentrations. One might argue that apparent substrate saturations play a role. However, nanomolar hydroperoxide concentrations and the established rate constants do not necessitate millimolar GSH concentrations to maintain the hydroperoxidases in a reduced state. This should also be the case for nanomolar GSSG concentrations and the Grx-catalyzed reduction of disulfides, even though these reactions are reversible. A common argument is that high GSH concentrations are necessary to fully reduce redox proteins such as Grx at equilibrium, because-in contrast to dithiol reductants such as dihydrolipoate or Trxthe half-cell reduction potential $E_{\mathrm{GSH}}^{\prime}$ not only depends on the standard $E^{o \prime}{ }_{\mathrm{GSH}}$ value $\left(-0.24 \mathrm{~V}\right.$ at $\mathrm{pH} 7.0$ and $\left.25^{\circ} \mathrm{C}\right)$ and the [GSH]/[GSSG] ratio but also on the total concentration of glutathione $(10,101)$. However, metabolism is not at equilibrium and the reversibility of the reduction of disulfide substrates (e.g., of ribonucleotide reductase) should remain unproblematic even at lower glutathione concentrations as long as the $(\mathrm{GSH})^{2} / \mathrm{GSSG}$ ratio is maintained and the metabolic flux is sufficiently high. Both aspects are ensured by the rapid GR-dependent removal of GSSG and the high, substrate concentration-independent catalytic efficiency of Grx. The same principle should apply to the GSH/GSNO couple as long as there is an efficient GSNOR-dependent removal of GSNO.

The only situation that appears to necessitate a higher GSH concentration for redox homeostasis is the extreme oxidative challenge. The more GSH available, the more oxidants can be immediately buffered resulting in a temporary increase of GSSG. The question is whether such challenges are of general relevance and really reflect a basic principle in biology. For example, deletion of GR in yeast and harsh treatment

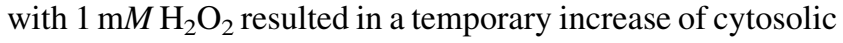
GSSG with a peak concentration of $140 \mu M$. The same treatment resulted in wild-type cells in a minuscule temporary change of the $(\mathrm{GSH})^{2} / \mathrm{GSSG}$ ratio (192). Thus, even under extreme conditions, the buffer capacity of the GSH pool was hardly ever utilized. One might argue that the 
situation is different in other organisms or subcellular compartments (e.g., in human cells or in the secretory pathway) and that different enzyme repertoires and transport processes will affect the glutathione fluxes. This is certainly true for other organisms. For example, exogenous $\mathrm{H}_{2} \mathrm{O}_{2}$ concentrations between 10 and $100 \mu M$ yielded minor and major temporary changes of the $(\mathrm{GSH})^{2} / \mathrm{GSSG}$ ratio in HeLa cells (112), indicating that not only the Trx/TrxR system but also the glutathione system responded to the challenge in contrast to yeast. However, it is unlikely that requirements in the secretory pathway or other subcellular compartments dictate the high cytosolic GSH concentration in eukaryotes, in particular, taking into account that millimolar glutathione concentrations are also found in bacteria.

In summary, the presence of alternative hydroperoxidases and electron donor systems, as well as the kinetic patterns and activities of Prx, GPx, Grx, and GR, raises the question whether millimolar GSH concentrations are really necessary for redox homeostasis. Even under physiological oxidative challenge, the buffer capacity of the GSH system might be hardly ever used depending on the organism and genetic background.

\section{Hypothesis II: high GSH concentrations are crucial for detoxifications}

This hypothesis subsumes the removal of heavy metals, xenobiotics, and endogenous harmful metabolites such as 2-oxoaldehydes, formaldehyde, or 4-hydroxy-2-nonenal (Fig. 1). Depending on the toxin, a few molecules might be sufficient to alter the genome or to poison the organism. Furthermore, a high GSH concentration might be completely irrelevant for most of the life span (or under axenic laboratory conditions) but becomes immediately essential once the organism is exposed. This selection pressure might have favored permanent millimolar glutathione concentrations at an early time point in the course of evolution, in particular, if we consider that the corresponding enzymes often have sequential kinetic patterns so that the catalytic efficiencies increase with higher GSH concentrations. Please note that $K_{\mathrm{m}}{ }^{\text {app }}$ values of GST isoforms usually reflect a real substrate affinity. Thus, high GSH concentrations also help to scavenge the toxin by lowering the $K_{\mathrm{m}}{ }^{\text {app }}$ value.

Among the candidate detoxification systems and substrates that could necessitate high glutathione concentrations, glyoxalases deal with a very basic chemical challenge: the removal of glycolysis-derived methylglyoxal. However, we can exclude these enzymes and 2-oxoaldehydes from the list because (i) glyoxalases are often nonessential, (ii) high GSH concentrations inhibit Glo2, and (iii) some organisms have methylglyoxal reductase or other GSH-independent enzymes that can also do the job $(60,61,129,256)$. We can also exclude the activities of GSNOR and GSH-dependent formaldehyde dehydrogenases because these enzymes are often missing in glutathione-utilizing pro- and eukaryotes. The best candidates are indeed the numerous GST isoforms. They are the most widespread and diverse glutathionedependent enzymes and they are able to remove potentially deadly mutagens and poisons $(6,30,60,117)$. Among the numerous GST and MAPEG members, we can exclude the specialized isoforms that contribute to amino acid catabolism or to steroid and eicosanoid biosynthesis (Fig. 1) (60, 117, $135,176)$. For the remaining vast majority of isoforms, we encounter the dilemma of how to quantitatively address the relevance of millimolar GSH concentrations for detoxification processes without knowing the identity and compartmentspecific concentrations of the relevant enzyme-substrate couples in real ecosystems.

\section{Hypothesis III: high GSH concentrations are crucial for iron metabolism}

The hypothesis is counterintuitive because nonenzymatic reactions between GSH and free iron ions could promote harmful Fenton reactions. However, biochemical systems are adopted to limit free iron ions. Furthermore, genetic studies in yeast support hypothesis III $(153,194,214,241)$. Best candidates for an important link between iron and glutathione metabolism are evolutionarily conserved Grx isoforms that are able to bind iron-sulfur clusters (Orphan Proteins and Unknown Metabolites and Substrates section). The stability of these clusters was shown to not only depend on the presence $(17,161,164,228,302)$ but also on the concentration of reduced GSH in vitro (183). However, nothing is known about the steady-state concentrations of Grx-bound $\left[\mathrm{Fe}_{2} \mathrm{~S}_{2}(\mathrm{GS})_{2}\right]$ clusters and many rate constants are missing to support the hypothesis. We only know that the cluster transfer from Grx has an intermediate rate constant, as has been reported for poplar chloroplast monothiol GrxS14 and ferredoxin (Table 3) (17). On the one hand, the Grx-bound cluster has to be accessible and should not be bound too tightly to facilitate the critical transfer between proteins. On the other hand, the cluster should be shielded from $\mathrm{O}_{2}{ }^{\bullet-}$ and $\mathrm{H}_{2} \mathrm{O}_{2}$. This presumably reflects a dual function of glutathione, which might be easily stripped off during the cluster transfer and also shields the iron ions. Both parameters should depend on the Grx isoform and function. Thus, a quantitative analysis of the relevance of glutathione for iron-sulfur cluster metabolism boils down to potential kinetic competitions between $\mathrm{GS}^{-}$, $\mathrm{O}_{2}^{\bullet-}, \mathrm{H}_{2} \mathrm{O}_{2}$ and donor and acceptor proteins regarding their cluster interactions. Almost all relevant rate constants of these processes seem to be unknown. For example, whether millimolar GSH concentrations are necessary to shift the equilibrium from the unprotected to the protected cluster species depends on the rate constants for $\mathrm{GS}^{-}$binding and dissociation. In summary, many more rate constants and concentrations are necessary to quantitatively address the relevance of millimolar GSH concentrations for iron metabolism.

\section{Concluding Remarks}

Recent discoveries have challenged the traditional view of glutathione metabolism that was predominantly based on concepts of redox homeostasis and oxidative stress. The focus has clearly shifted from antioxidant defense to the compartmentalization of glutathione-dependent pathways, redox regulation, and the relevance of glutathione for iron metabolism. So far, there appears to be no unambiguous explanation for the millimolar concentration of GSH, and the glutathione puzzle remains incomplete. It still comprises numerous missing pieces, including compartment-specific transporters, substrates, and enzymes as well as crucial quantitative data regarding concentrations, rate constants, and enzyme kinetic patterns. I tried to emphasize the importance of each of these parameters and provided examples how to use them to compare the rates of potentially 
competing reactions with hydroperoxides, disulfides, or radicals. Such a quantitative approach could be also helpful to unravel the relevance of the other functions of glutathione, which can differ significantly among organisms, cell types, and subcellular compartments. The presented model on uncoupling mechanisms might be useful to address fundamental aspects of iron-sulfur cluster biogenesis, redox sensing, and oxidative protein folding. Future qualitative and, in particular, quantitative analyses will certainly reveal novel unexpected insights on glutathione metabolism and tell us whether we were on the right way or just guessing at numbers and figures.

\section{Acknowledgments}

I thank the Deutsche Forschungsgemeinschaft (DFG) for support in the frame of the SPP1710 Priority Programme "Dynamics of Thiol-based Redox Switches in Cellular Physiology" (grant DE 1431/8-1) and for funding of my position in the frame of the Heisenberg program (grant DE 1431/9-1). I also thank my colleagues and friends who proofread the manuscript and Michel Toledano for the invitation to contribute this review. I apologize to all colleagues whose relevant work was not cited here.

\section{References}

1. Akerboom TP, Bilzer M, and Sies H. The relationship of biliary glutathione disulfide efflux and intracellular glutathione disulfide content in perfused rat liver. $J$ Biol Chem 257: 4248-4252, 1982.

2. Akoachere M, Iozef R, Rahlfs S, Deponte M, Mannervik B, Creighton DJ, Schirmer H, and Becker K. Characterization of the glyoxalases of the malarial parasite Plasmodium falciparum and comparison with their human counterparts. Biol Chem 386: 41-52, 2005.

3. Alfonso-Prieto M, Vidossich P, and Rovira C. The reaction mechanisms of heme catalases: an atomistic view by ab initio molecular dynamics. Arch Biochem Biophys 525: 121-130, 2012.

4. Allen EM and Mieyal JJ. Protein-thiol oxidation and cell death: regulatory role of glutaredoxins. Antioxid Redox Signal 17: 1748-1763, 2012.

5. Allocati N, Federici L, Masulli M, and Di Ilio C. Glutathione transferases in bacteria. FEBS J 276: 58-75, 2009.

6. Ames BN, Profet M, and Gold LS. Nature's chemicals and synthetic chemicals: comparative toxicology. Proc Natl Acad Sci U S A 87: 7782-7786, 1990.

7. Antonenkov VD and Hiltunen JK. Peroxisomal membrane permeability and solute transfer. Biochim Biophys Acta 1763: 1697-1706, 2006.

8. Appenzeller-Herzog $\mathrm{C}$ and Ellgaard L. The human PDI family: versatility packed into a single fold. Biochim Biophys Acta 1783: 535-548, 2008.

9. Armeni T, Cianfruglia L, Piva F, Urbanelli L, Luisa Caniglia M, Pugnaloni A, and Principato G. S-D-Lactoylglutathione can be an alternative supply of mitochondrial glutathione. Free Radic Biol Med 67: 451-459, 2014.

10. Aslund F, Berndt KD, and Holmgren A. Redox potentials of glutaredoxins and other thiol-disulfide oxidoreductases of the thioredoxin superfamily determined by direct protein-protein redox equilibria. J Biol Chem 272: 30780 30786, 1997.

11. Aslund F, Ehn B, Miranda-Vizuete A, Pueyo C, and Holmgren A. Two additional glutaredoxins exist in Escher- ichia coli: glutaredoxin 3 is a hydrogen donor for ribonucleotide reductase in a thioredoxin/glutaredoxin 1 double mutant. Proc Natl Acad Sci U S A 91: 9813-9817, 1994.

12. Atamna $H$ and Ginsburg $H$. The malaria parasite supplies glutathione to its host cell-investigation of glutathione transport and metabolism in human erythrocytes infected with Plasmodium falciparum. Eur J Biochem 250: 670679, 1997.

13. Atkins P and De Paula J. Atkins' Physical Chemistry, 8th ed. Oxford, United Kingdom: Oxford University Press, 2006.

14. Avery AM and Avery SV. Saccharomyces cerevisiae expresses three phospholipid hydroperoxide glutathione peroxidases. J Biol Chem 276: 33730-33735, 2001.

15. Bachhawat AK, Thakur A, Kaur J, and Zulkifli M. Glutathione transporters. Biochim Biophys Acta 1830: 31543164, 2013.

16. Bai M, Zhou JM, and Perrett S. The yeast prion protein Ure2 shows glutathione peroxidase activity in both native and fibrillar forms. J Biol Chem 279: 50025-50030, 2004.

17. Bandyopadhyay S, Gama F, Molina-Navarro MM, Gualberto JM, Claxton R, Naik SG, Huynh BH, Herrero E, Jacquot JP, Johnson MK, and Rouhier N. Chloroplast monothiol glutaredoxins as scaffold proteins for the assembly and delivery of [2Fe-2S] clusters. EMBO J 27: 1122-1133, 2008.

18. Banhegyi G, Lusini L, Puskas F, Rossi R, Fulceri R, Braun L, Mile V, di Simplicio P, Mandl J, and Benedetti A. Preferential transport of glutathione versus glutathione disulfide in rat liver microsomal vesicles. $J$ Biol Chem 274: 12213-12216, 1999.

19. Barrand MA, Winterberg M, Ng F, Nguyen M, Kirk K, and Hladky SB. Glutathione export from human erythrocytes and Plasmodium falciparum malaria parasites. Biochem J 448: 389-400, 2012.

20. Barreto L, Garcera A, Jansson K, Sunnerhagen P, and Herrero E. A peroxisomal glutathione transferase of Saccharomyces cerevisiae is functionally related to sulfur amino acid metabolism. Eukaryot Cell 5: 1748-1759, 2006.

21. Bedard K and Krause KH. The NOX family of ROSgenerating NADPH oxidases: physiology and pathophysiology. Physiol Rev 87: 245-313, 2007.

22. Begas P, Liedgens L, Moseler A, Meyer AJ, and Deponte M. Glutaredoxin catalysis requires two distinct glutathione interaction sites. Nat Commun 8: 14835, 2017.

23. Begas P, Staudacher V, and Deponte M. Systematic reevaluation of the bis(2-hydroxyethyl)disulfide (HEDS) assay reveals an alternative mechanism and activity of glutaredoxins. Chem Sci 6: 3788-3796, 2015.

24. Benhar M, Forrester MT, and Stamler JS. Protein denitrosylation: enzymatic mechanisms and cellular functions. Nat Rev Mol Cell Biol 10: 721-732, 2009.

25. Bermingham-McDonogh O, Gralla EB, and Valentine JS. The copper, zinc-superoxide dismutase gene of Saccharomyces cerevisiae: cloning, sequencing, and biological activity. Proc Natl Acad Sci U S A 85: 4789-4793, 1988.

26. Bien M, Longen S, Wagener N, Chwalla I, Herrmann JM, and Riemer J. Mitochondrial disulfide bond formation is driven by intersubunit electron transfer in Erv1 and proofread by glutathione. Mol Cell 37: 516-528, 2010.

27. Birk J, Meyer M, Aller I, Hansen HG, Odermatt A, Dick TP, Meyer AJ, and Appenzeller-Herzog C. Endoplasmic reticulum: reduced and oxidized glutathione revisited. $J$ Cell Sci 126: 1604-1617, 2013.

28. Bisswanger H. Enzymkinetik. Weinheim, Deutschland: Wiley-VCH, 2000. 
29. Bito A, Haider M, Hadler I, and Breitenbach M. Identification and phenotypic analysis of two glyoxalase II encoding genes from Saccharomyces cerevisiae, GLO2 and GLO4, and intracellular localization of the corresponding proteins. J Biol Chem 272: 21509-21519, 1997.

30. Board PG and Menon D. Glutathione transferases, regulators of cellular metabolism and physiology. Biochim Biophys Acta 1830: 3267-3288, 2013.

31. Bonnichsen RK, Chance B, and Theorell H. Catalase activity. Acta Chem Scand 1: 685-709, 1947.

32. Bourbouloux A, Shahi P, Chakladar A, Delrot S, and Bachhawat AK. Hgtlp, a high affinity glutathione transporter from the yeast Saccharomyces cerevisiae. J Biol Chem 275: 13259-13265, 2000.

33. Brautigam L, Jensen LD, Poschmann G, Nystrom S, Bannenberg S, Dreij K, Lepka K, Prozorovski T, Montano SJ, Aktas O, Uhlen P, Stuhler K, Cao Y, Holmgren A, and Berndt C. Glutaredoxin regulates vascular development by reversible glutathionylation of sirtuin 1. Proc Natl Acad Sci U S A 110: 20057-20062, 2013.

34. Brigelius-Flohe $\mathrm{R}$ and Flohe L. Basic principles and emerging concepts in the redox control of transcription factors. Antioxid Redox Signal 15: 2335-2381, 2011.

35. Brigelius-Flohe R and Maiorino M. Glutathione peroxidases. Biochim Biophys Acta 1830: 3289-3303, 2013.

36. Bulleid NJ and Ellgaard L. Multiple ways to make disulfides. Trends Biochem Sci 36: 485-492, 2011.

37. Can B, Kulaksiz Erkmen G, Dalmizrak O, Ogus IH, and Ozer N. Purification and characterisation of rat kidney glutathione reductase. Protein J 29: 250-256, 2010.

38. Carballal S, Bartesaghi S, and Radi R. Kinetic and mechanistic considerations to assess the biological fate of peroxynitrite. Biochim Biophys Acta 1840: 768-780, 2014.

39. Castro H, Teixeira F, Romao S, Santos M, Cruz T, Florido M, Appelberg R, Oliveira P, Ferreira-da-Silva F, and Tomas AM. Leishmania mitochondrial peroxiredoxin plays a crucial peroxidase-unrelated role during infection: insight into its novel chaperone activity. PLoS Pathog 7: e1002325, 2011.

40. Castro L, Rodriguez M, and Radi R. Aconitase is readily inactivated by peroxynitrite, but not by its precursor, nitric oxide. J Biol Chem 269: 29409-29415, 1994.

41. Cha MK, Choi YS, Hong SK, Kim WC, No KT, and Kim IH. Nuclear thiol peroxidase as a functional alkylhydroperoxide reductase necessary for stationary phase growth of Saccharomyces cerevisiae. J Biol Chem 278: 24636-24643, 2003.

42. Chae HZ, Kim IH, Kim K, and Rhee SG. Cloning, sequencing, and mutation of thiol-specific antioxidant gene of Saccharomyces cerevisiae. J Biol Chem 268: 1681516821, 1993.

43. Chance B, Sies H, and Boveris A. Hydroperoxide metabolism in mammalian organs. Physiol Rev 59: 527-605, 1979.

44. Chang LY, Slot JW, Geuze HJ, and Crapo JD. Molecular immunocytochemistry of the CuZn superoxide dismutase in rat hepatocytes. J Cell Biol 107: 2169-2179, 1988.

45. Chapple SJ, Cheng X, and Mann GE. Effects of 4hydroxynonenal on vascular endothelial and smooth muscle cell redox signaling and function in health and disease. Redox Biol 1: 319-331, 2013.

46. Cho CS, Yoon HJ, Kim JY, Woo HA, and Rhee SG. Circadian rhythm of hyperoxidized peroxiredoxin II is determined by hemoglobin autoxidation and the $20 \mathrm{~S}$ proteasome in red blood cells. Proc Natl Acad Sci U S A 111: 12043-12048, 2014.

47. Choi JH, Lou W, and Vancura A. A novel membranebound glutathione S-transferase functions in the stationary phase of the yeast Saccharomyces cerevisiae. J Biol Chem 273: 29915-29922, 1998.

48. Chong YT, Koh JL, Friesen H, Duffy SK, Cox MJ, Moses A, Moffat J, Boone C, and Andrews BJ. Yeast proteome dynamics from single cell imaging and automated analysis. Cell 161: 1413-1424, 2015.

49. Chouchani ET, Hurd TR, Nadtochiy SM, Brookes PS, Fearnley IM, Lilley KS, Smith RA, and Murphy MP. Identification of S-nitrosated mitochondrial proteins by $\mathrm{S}$ nitrosothiol difference in gel electrophoresis (SNODIGE): implications for the regulation of mitochondrial function by reversible S-nitrosation. Biochem J 430: 4959, 2010.

50. Cohen G, Fessl F, Traczyk A, Rytka J, and Ruis H. Isolation of the catalase A gene of Saccharomyces cerevisiae by complementation of the cta1 mutation. Mol Gen Genet 200: 74-79, 1985.

51. Coleman JD, Prabhu KS, Thompson JT, Reddy PS, Peters JM, Peterson BR, Reddy CC, and Vanden Heuvel JP. The oxidative stress mediator 4-hydroxynonenal is an intracellular agonist of the nuclear receptor peroxisome proliferator-activated receptor-beta/delta (PPARbeta/delta). Free Radic Biol Med 42: 1155-1164, 2007.

52. Collinson EJ and Grant CM. Role of yeast glutaredoxins as glutathione S-transferases. J Biol Chem 278: 22492 22497, 2003.

53. Collinson EJ, Wheeler GL, Garrido EO, Avery AM, Avery SV, and Grant CM. The yeast glutaredoxins are active as glutathione peroxidases. J Biol Chem 277: 16712-16717, 2002.

54. Comini MA. Measurement and meaning of cellular thiol:disufhide redox status. Free Radic Res 50: 246-271, 2016.

55. Cordell PA, Futers TS, Grant PJ, and Pease RJ. The human hydroxyacylglutathione hydrolase (HAGH) gene encodes both cytosolic and mitochondrial forms of glyoxalase II. J Biol Chem 279: 28653-28661, 2004.

56. Couturier J, Przybyla-Toscano J, Roret T, Didierjean C, and Rouhier N. The roles of glutaredoxins ligating Fe-S clusters: sensing, transfer or repair functions? Biochim Biophys Acta 1853: 1513-1527, 2015.

57. Dalziel K. Initial steady state velocities in the evaluation of enzyme-coenzyme-substrate reaction mechanisms. Acta Chem Scand 11: 1706-1723, 1957.

58. Dardalhon M, Kumar C, Iraqui I, Vernis L, Kienda G, Banach-Latapy A, He T, Chanet R, Faye G, Outten CE, and Huang ME. Redox-sensitive YFP sensors monitor dynamic nuclear and cytosolic glutathione redox changes. Free Radic Biol Med 52: 2254-2265, 2012.

59. Delaunay A, Pflieger D, Barrault MB, Vinh J, and Toledano MB. A thiol peroxidase is an $\mathrm{H} 2 \mathrm{O} 2$ receptor and redoxtransducer in gene activation. Cell 111: 471-481, 2002.

60. Deponte M. Glutathione catalysis and the reaction mechanisms of glutathione-dependent enzymes. Biochim Biophys Acta 1830: 3217-3266, 2013.

61. Deponte M. Glyoxalase diversity in parasitic protists. Biochem Soc Trans 42: 473-478, 2014.

62. Deponte $\mathrm{M}$ and Becker K. Biochemical characterization of Toxoplasma gondii 1-Cys peroxiredoxin 2 with mechanistic similarities to typical 2-Cys Prx. Mol Biochem Parasitol 140: 87-96, 2005. 
63. Deponte M, Becker K, and Rahlfs S. Plasmodium falciparum glutaredoxin-like proteins. Biol Chem 386: 33-40, 2005.

64. Deponte M and Hell K. Disulphide bond formation in the intermembrane space of mitochondria. J Biochem 146: 599-608, 2009.

65. Deponte $\mathrm{M}$ and Lillig CH. Enzymatic control of cysteinyl thiol switches in proteins. Biol Chem 396: 401-413, 2015.

66. Deponte M, Rahlfs S, and Becker K. Peroxiredoxin systems of protozoal parasites. Subcell Biochem 44: 219-229, 2007.

67. Deponte M, Sturm N, Mittler S, Harner M, Mack H, and Becker K. Allosteric coupling of two different functional active sites in monomeric Plasmodium falciparum glyoxalase I. J Biol Chem 282: 28419-28430, 2007.

68. Derakhshan B, Wille PC, and Gross SS. Unbiased identification of cysteine S-nitrosylation sites on proteins. Nat Protoc 2: 1685-1691, 2007.

69. Djuika CF, Fiedler S, Schnolzer M, Sanchez C, Lanzer M, and Deponte M. Plasmodium falciparum antioxidant protein as a model enzyme for a special class of glutaredoxin/glutathione-dependent peroxiredoxins. Biochim Biophys Acta 1830: 4073-4090, 2013.

70. Djuika CF, Huerta-Cepas J, Przyborski JM, Deil S, Sanchez CP, Doerks T, Bork P, Lanzer M, and Deponte M. Prokaryotic ancestry and gene fusion of a dual localized peroxiredoxin in malaria parasites. Microbial Cell 2: 513, 2015.

71. Doulias PT, Greene JL, Greco TM, Tenopoulou M, Seeholzer SH, Dunbrack RL, and Ischiropoulos H. Structural profiling of endogenous S-nitrosocysteine residues reveals unique features that accommodate diverse mechanisms for protein S-nitrosylation. Proc Natl Acad Sci U S A 107: 16958-16963, 2010.

72. Draculic T, Dawes IW, and Grant CM. A single glutaredoxin or thioredoxin gene is essential for viability in the yeast Saccharomyces cerevisiae. Mol Microbiol 36: 1167 1174, 2000.

73. Eckers E, Bien M, Stroobant V, Herrmann JM, and Deponte M. Biochemical characterization of dithiol glutaredoxin 8 from Saccharomyces cerevisiae: the catalytic redox mechanism redux. Biochemistry 48: 1410-1423, 2009.

74. Edskes HK, Gray VT, and Wickner RB. The [URE3] prion is an aggregated form of Ure $2 p$ that can be cured by overexpression of Ure2p fragments. Proc Natl Acad Sci U S A 96: 1498-1503, 1999.

75. Eisenstein RS. Iron regulatory proteins and the molecular control of mammalian iron metabolism. Annu Rev Nutr 20: 627-662, 2000.

76. Elbaz-Alon Y, Morgan B, Clancy A, Amoako TN, Zalckvar E, Dick TP, Schwappach B, and Schuldiner M. The yeast oligopeptide transporter Opt2 is localized to peroxisomes and affects glutathione redox homeostasis. FEMS Yeast Res 14: 1055-1067, 2014.

77. Elgan TH and Berndt KD. Quantifying Escherichia coli glutaredoxin-3 substrate specificity using ligand-induced stability. J Biol Chem 283: 32839-32847, 2008.

78. Endo T, Yamano K, and Kawano S. Structural basis for the disulfide relay system in the mitochondrial intermembrane space. Antioxid Redox Signal 13: 1359-1373, 2010.

79. Fernandes AP, Fladvad M, Berndt C, Andresen C, Lillig CH, Neubauer P, Sunnerhagen M, Holmgren A, and VlamisGardikas A. A novel monothiol glutaredoxin (Grx4) from Escherichia coli can serve as a substrate for thioredoxin reductase. J Biol Chem 280: 24544-24552, 2005.
80. Fernando MR, Lechner JM, Lofgren S, Gladyshev VN, and Lou MF. Mitochondrial thioltransferase (glutaredoxin 2) has GSH-dependent and thioredoxin reductasedependent peroxidase activities in vitro and in lens epithelial cells. FASEB J 20: 2645-2647, 2006.

81. Ferrer-Sueta G and Radi R. Chemical biology of peroxynitrite: kinetics, diffusion, and radicals. ACS Chem Biol 4: 161-177, 2009.

82. Fielden EM, Roberts PB, Bray RC, Lowe DJ, Mautner GN, Rotilio G, and Calabrese L. Mechanism of action of superoxide dismutase from pulse radiolysis and electron paramagnetic resonance. Evidence that only half the active sites function in catalysis. Biochem $J$ 139: 49-60, 1974.

83. Finkemeier I, Goodman M, Lamkemeyer P, Kandlbinder A, Sweetlove LJ, and Dietz KJ. The mitochondrial type II peroxiredoxin $\mathrm{F}$ is essential for redox homeostasis and root growth of Arabidopsis thaliana under stress. J Biol Chem 280: 12168-12180, 2005.

84. Fischer M, Horn S, Belkacemi A, Kojer K, Petrungaro C, Habich M, Ali M, Kuttner V, Bien M, Kauff F, Dengjel J, Herrmann JM, and Riemer J. Protein import and oxidative folding in the mitochondrial intermembrane space of intact mammalian cells. Mol Biol Cell 24: 2160-2170, 2013.

85. Fleming $\mathrm{T}$ and Nawroth PP. Reactive metabolites as a cause of late diabetic complications. Biochem Soc Trans 42: 439-442, 2014.

86. Flint DH, Tuminello JF, and Emptage MH. The inactivation of $\mathrm{Fe}-\mathrm{S}$ cluster containing hydro-lyases by superoxide. J Biol Chem 268: 22369-22376, 1993.

87. Flohe L. The fairytale of the GSSG/GSH redox potential. Biochim Biophys Acta 1830: 3139-3142, 2013.

88. Flohe L, Gunzler W, Jung G, Schaich E, and Schneider F. [Glutathione peroxidase. II. Substrate specificity and inhibitory effects of substrate analogues]. Hoppe Seylers $Z$ Physiol Chem 352: 159-169, 1971.

89. Flohe L, Loschen G, Gunzler WA, and Eichele E. Glutathione peroxidase, V. The kinetic mechanism. Hoppe Seylers Z Physiol Chem 353: 987-999, 1972.

90. Flohe L, Toppo S, Cozza G, and Ursini F. A comparison of thiol peroxidase mechanisms. Antioxid Redox Signal 15: 763-780, 2011.

91. Forman HJ, Maiorino M, and Ursini F. Signaling functions of reactive oxygen species. Biochemistry 49: 835842, 2010.

92. Forrester MT, Thompson JW, Foster MW, Nogueira L, Moseley MA, and Stamler JS. Proteomic analysis of Snitrosylation and denitrosylation by resin-assisted capture. Nat Biotechnol 27: 557-559, 2009.

93. Fridovich I. Superoxide dismutases. An adaptation to a paramagnetic gas. J Biol Chem 264: 7761-7764, 1989.

94. Fuss JO, Tsai CL, Ishida JP, and Tainer JA. Emerging critical roles of Fe-S clusters in DNA replication and repair. Biochim Biophys Acta 1853: 1253-1271, 2015.

95. Gallogly MM, and Mieyal JJ. Mechanisms of reversible protein glutathionylation in redox signaling and oxidative stress. Curr Opin Pharmacol 7: 381-391, 2007.

96. Gallogly MM, Starke DW, Leonberg AK, Ospina SM, and Mieyal JJ. Kinetic and mechanistic characterization and versatile catalytic properties of mammalian glutaredoxin 2: implications for intracellular roles. Biochemistry 47: 11144-11157, 2008.

97. Gallogly MM, Starke DW, and Mieyal JJ. Mechanistic and kinetic details of catalysis of thiol-disulfide exchange 
by glutaredoxins and potential mechanisms of regulation. Antioxid Redox Signal 11: 1059-1081, 2009.

98. Garcia-Gimenez JL, Markovic J, Dasi F, Queval G, Schnaubelt D, Foyer CH, and Pallardo FV. Nuclear glutathione. Biochim Biophys Acta 1830: 3304-3316, 2013.

99. Gellert M, Venz S, Mitlohner J, Cott C, Hanschmann EM, and Lillig $\mathrm{CH}$. Identification of a dithiol-disulfide switch in collapsin response mediator protein 2 (CRMP2) that is toggled in a model of neuronal differentiation. $J$ Biol Chem 288: 35117-35125, 2013.

100. Ghaemmaghami S, Huh WK, Bower K, Howson RW, Belle A, Dephoure N, O'Shea EK, and Weissman JS. Global analysis of protein expression in yeast. Nature 425: 737-741, 2003.

101. Gilbert HF. Thiol/disulfide exchange equilibria and disulfide bond stability. Methods Enzymol 251: 8-28, 1995.

102. Giustarini D, Dalle-Donne I, Milzani A, Fanti P, and Rossi R. Analysis of GSH and GSSG after derivatization with N-ethylmaleimide. Nat Protoc 8: 1660-1669, 2013.

103. Godoy JR, Funke M, Ackermann W, Haunhorst P, Oesteritz S, Capani F, Elsasser HP, and Lillig CH. Redox atlas of the mouse. Immunohistochemical detection of glutaredoxin-, peroxiredoxin-, and thioredoxin-family proteins in various tissues of the laboratory mouse. Biochim Biophys Acta 1810: 2-92, 2011.

104. Gort AS and Imlay JA. Balance between endogenous superoxide stress and antioxidant defenses. $J$ Bacteriol 180: 1402-1410, 1998.

105. Grant CM. Role of the glutathione/glutaredoxin and thioredoxin systems in yeast growth and response to stress conditions. Mol Microbiol 39: 533-541, 2001.

106. Grant CM, Collinson LP, Roe JH, and Dawes IW. Yeast glutathione reductase is required for protection against oxidative stress and is a target gene for yAP-1 transcriptional regulation. Mol Microbiol 21: 171-179, 1996.

107. Grant CM, Perrone G, and Dawes IW. Glutathione and catalase provide overlapping defenses for protection against hydrogen peroxide in the yeast Saccharomyces cerevisiae. Biochem Biophys Res Commun 253: 893-898, 1998.

108. Gravina SA and Mieyal JJ. Thioltransferase is a specific glutathionyl mixed disulfide oxidoreductase. Biochemistry 32: 3368-3376, 1993.

109. Greetham D and Grant CM. Antioxidant activity of the yeast mitochondrial one-Cys peroxiredoxin is dependent on thioredoxin reductase and glutathione in vivo. Mol Cell Biol 29: 3229-3240, 2009.

110. Greetham D, Kritsiligkou P, Watkins RH, Carter Z, Parkin $\mathrm{J}$, and Grant CM. Oxidation of the yeast mitochondrial thioredoxin promotes cell death. Antioxid Redox Signal 18: 376-385, 2013.

111. Gupta V and Carroll KS. Sulfenic acid chemistry, detection and cellular lifetime. Biochim Biophys Acta 1840: 847-875, 2014.

112. Gutscher M, Pauleau AL, Marty L, Brach T, Wabnitz GH, Samstag Y, Meyer AJ, and Dick TP. Real-time imaging of the intracellular glutathione redox potential. Nat Methods 5: 553-559, 2008.

113. Hall A, Nelson K, Poole LB, and Karplus PA. Structurebased insights into the catalytic power and conformational dexterity of peroxiredoxins. Antioxid Redox Signal 15: 795-815, 2011.

114. Han YH, Kim SU, Kwon TH, Lee DS, Ha HL, Park DS, Woo EJ, Lee SH, Kim JM, Chae HB, Lee SY, Kim BY, Yoon do Y, Rhee SG, Fibach E, and Yu DY. Peroxir- edoxin II is essential for preventing hemolytic anemia from oxidative stress through maintaining hemoglobin stability. Biochem Biophys Res Commun 426: 427-432, 2012.

115. Hatahet F, Boyd D, and Beckwith J. Disulfide bond formation in prokaryotes: history, diversity and design. Biochim Biophys Acta 1844: 1402-1414, 2014.

116. Hausladen A and Fridovich I. Superoxide and peroxynitrite inactivate aconitases, but nitric oxide does not. $J$ Biol Chem 269: 29405-29408, 1994.

117. Hayes JD, Flanagan JU, and Jowsey IR. Glutathione transferases. Anпu Rev Pharmacol Toxicol 45: 51-88, 2005.

118. Hentze MW, Muckenthaler MU, Galy B, and Camaschella C. Two to tango: regulation of Mammalian iron metabolism. Cell 142: 24-38, 2010.

119. Herrero E, Ros J, Belli G, and Cabiscol E. Redox control and oxidative stress in yeast cells. Biochim Biophys Acta 1780: 1217-1235, 2008.

120. Hildebrandt T, Knuesting J, Berndt C, Morgan B, and Scheibe R. Cytosolic thiol switches regulating basic cellular functions: GAPDH as an information hub? Biol Chem 396: 523-537, 2015.

121. Hiller N, Fritz-Wolf K, Deponte M, Wende W, Zimmermann H, and Becker K. Plasmodium falciparum glutathione S-transferase-structural and mechanistic studies on ligand binding and enzyme inhibition. Protein Sci 15: 281-289, 2006.

122. Hirrlinger J, Konig J, Keppler D, Lindenau J, Schulz JB, and Dringen R. The multidrug resistance protein MRP1 mediates the release of glutathione disulfide from rat astrocytes during oxidative stress. J Neurochem 76: 627636, 2001.

123. Huh WK, Falvo JV, Gerke LC, Carroll AS, Howson RW, Weissman JS, and O'Shea EK. Global analysis of protein localization in budding yeast. Nature 425: 686-691, 2003.

124. Hwang C, Sinskey AJ, and Lodish HF. Oxidized redox state of glutathione in the endoplasmic reticulum. Science 257: 1496-1502, 1992.

125. Imlay JA. Cellular defenses against superoxide and hydrogen peroxide. Annu Rev Biochem 77: 755-776, 2008.

126. Imlay JA. The molecular mechanisms and physiological consequences of oxidative stress: lessons from a model bacterium. Nat Rev Microbiol 11: 443-454, 2013.

127. Imlay JA and Fridovich I. Assay of metabolic superoxide production in Escherichia coli. J Biol Chem 266: 69576965, 1991.

128. Inoue $\mathrm{Y}$ and Kimura $\mathrm{A}$. Identification of the structural gene for glyoxalase I from Saccharomyces cerevisiae. J Biol Chem 271: 25958-25965, 1996.

129. Inoue Y, Maeta K, and Nomura W. Glyoxalase system in yeasts: structure, function, and physiology. Semin Cell Dev Biol 22: 278-284, 2011.

130. Inoue Y, Matsuda T, Sugiyama K, Izawa S, and Kimura A. Genetic analysis of glutathione peroxidase in oxidative stress response of Saccharomyces cerevisiae. J Biol Chem 274: 27002-27009, 1999.

131. Iwai K, Naganuma A, and Kuge S. Peroxiredoxin Ahp1 acts as a receptor for alkylhydroperoxides to induce disulfide bond formation in the Cad1 transcription factor. $J$ Biol Chem 285: 10597-10604, 2010.

132. Izquierdo A, Casas $\mathrm{C}$, Muhlenhoff U, Lillig $\mathrm{CH}$, and Herrero E. Saccharomyces cerevisiae Grx6 and Grx7 are monothiol glutaredoxins associated with the early secretory pathway. Eukaryot Cell 7: 1415-1426, 2008. 
133. Jaffrey SR, Erdjument-Bromage H, Ferris CD, Tempst $P$, and Snyder SH. Protein S-nitrosylation: a physiological signal for neuronal nitric oxide. Nat Cell Biol 3: 193-197, 2001.

134. Jakobsson PJ, Mancini JA, Riendeau D, and FordHutchinson AW. Identification and characterization of a novel microsomal enzyme with glutathione-dependent transferase and peroxidase activities. J Biol Chem 272: 22934-22939, 1997.

135. Jakobsson PJ, Morgenstern R, Mancini J, FordHutchinson A, and Persson B. Common structural features of MAPEG-a widespread superfamily of membrane associated proteins with highly divergent functions in eicosanoid and glutathione metabolism. Protein Sci 8: 689-692, 1999.

136. Jang HH, Lee KO, Chi YH, Jung BG, Park SK, Park JH, Lee JR, Lee SS, Moon JC, Yun JW, Choi YO, Kim WY, Kang JS, Cheong GW, Yun DJ, Rhee SG, Cho MJ, and Lee SY. Two enzymes in one; two yeast peroxiredoxins display oxidative stress-dependent switching from a peroxidase to a molecular chaperone function. Cell 117: 625-635, 2004.

137. Jarvis RM, Hughes SM, and Ledgerwood EC. Peroxiredoxin 1 functions as a signal peroxidase to receive, transduce, and transmit peroxide signals in mammalian cells. Free Radic Biol Med 53: 1522-1530, 2012.

138. Johansson AS and Mannervik B. Human glutathione transferase A3-3, a highly efficient catalyst of doublebond isomerization in the biosynthetic pathway of steroid hormones. J Biol Chem 276: 33061-33065, 2001.

139. Johansson $\mathrm{C}$, Lillig $\mathrm{CH}$, and Holmgren A. Human mitochondrial glutaredoxin reduces S-glutathionylated proteins with high affinity accepting electrons from either glutathione or thioredoxin reductase. J Biol Chem 279: 7537-7543, 2004.

140. Johnson RM, Goyette G, Jr., Ravindranath Y, and Ho YS. Hemoglobin autoxidation and regulation of endogenous $\mathrm{H} 2 \mathrm{O} 2$ levels in erythrocytes. Free Radic Biol Med 39: 1407-1417, 2005.

141. Johnson WM, Golczak M, Choe K, Currran PL, Gorelenkova Miller O, Yao C, Wang W, Lin J, Milkovic NM, Ray A, Ravindranath V, Zhu X, Wilson MA, WilsonDelfosse AL, Chen SG, and Mieyal JJ. Regulation of DJ-1 by glutaredoxin 1 in vivo-implications for Parkinson's disease. Biochemistry 55: 4512-4532, 2016.

142. Jones CM, Lawrence A, Wardman P, and Burkitt MJ. Electron paramagnetic resonance spin trapping investigation into the kinetics of glutathione oxidation by the superoxide radical: re-evaluation of the rate constant. Free Radic Biol Med 32: 982-990, 2002.

143. Kehr S, Jortzik E, Delahunty C, Yates JR, 3rd, Rahlfs S, and Becker K. Protein S-glutathionylation in malaria parasites. Antioxid Redox Signal 15: 2855-2865, 2011.

144. Kelner MJ and Montoya MA. Structural organization of the human glutathione reductase gene: determination of correct cDNA sequence and identification of a mitochondrial leader sequence. Biochem Biophys Res Commun 269: 366-368, 2000.

145. Keyer K and Imlay JA. Inactivation of dehydratase [4Fe-4S] clusters and disruption of iron homeostasis upon cell exposure to peroxynitrite. J Biol Chem 272: 27652-27659, 1997.

146. Kim IH, Kim K, and Rhee SG. Induction of an antioxidant protein of Saccharomyces cerevisiae by $\mathrm{O} 2, \mathrm{Fe} 3+$, or $2-$ mercaptoethanol. Proc Natl Acad Sci U S A 86: 6018$6022,1989$.
147. Kirsch M, Lehnig M, Korth HG, Sustmann R, and de Groot $\mathrm{H}$. Inhibition of peroxynitrite-induced nitration of tyrosine by glutathione in the presence of carbon dioxide through both radical repair and peroxynitrate formation. Chemistry 7: 3313-3320, 2001.

148. Knockenhauer KE and Schwartz TU. The nuclear pore complex as a flexible and dynamic gate. Cell 164: 11621171, 2016.

149. Kodali VK and Thorpe C. Oxidative protein folding and the quiescin-sulfhydryl oxidase family of flavoproteins. Antioxid Redox Signal 13: 1217-1230, 2010.

150. Kojer K, Bien M, Gangel H, Morgan B, Dick TP, and Riemer J. Glutathione redox potential in the mitochondrial intermembrane space is linked to the cytosol and impacts the Mia40 redox state. EMBO J 31: 3169-3182, 2012.

151. Kojer K, Peleh V, Calabrese G, Herrmann JM, and Riemer J. Kinetic control by limiting glutaredoxin amounts enables thiol oxidation in the reducing mitochondrial intermembrane space. Mol Biol Cell 26: 195-204, 2015.

152. Kulak NA, Pichler G, Paron I, Nagaraj N, and Mann M. Minimal, encapsulated proteomic-sample processing applied to copy-number estimation in eukaryotic cells. Nat Methods 11: 319-324, 2014.

153. Kumar C, Igbaria A, D’Autreaux B, Planson AG, Junot C, Godat E, Bachhawat AK, Delaunay-Moisan A, and Toledano MB. Glutathione revisited: a vital function in iron metabolism and ancillary role in thiol-redox control. EMBO J 30: 2044-2056, 2011.

154. Kussmaul L and Hirst J. The mechanism of superoxide production by NADH:ubiquinone oxidoreductase (complex I) from bovine heart mitochondria. Proc Natl Acad Sci U S A 103: 7607-7612, 2006.

155. Kwak HS, Yim HS, Chock PB, and Yim MB. Endogenous intracellular glutathionyl radicals are generated in neuroblastoma cells under hydrogen peroxide oxidative stress. Proc Natl Acad Sci U S A 92: 4582-4586, 1995.

156. Le Moan N, Clement G, Le Maout S, Tacnet F, and Toledano MB. The Saccharomyces cerevisiae proteome of oxidized protein thiols: contrasted functions for the thioredoxin and glutathione pathways. J Biol Chem 281: 10420-10430, 2006.

157. Lee J, Spector D, Godon C, Labarre J, and Toledano MB. A new antioxidant with alkyl hydroperoxide defense properties in yeast. J Biol Chem 274: 4537-4544, 1999.

158. Lee JY, Yang JG, Zhitnitsky D, Lewinson O, and Rees DC. Structural basis for heavy metal detoxification by an Atm1-type ABC exporter. Science 343: 1133-1136, 2014.

159. Lee TH, Kim SU, Yu SL, Kim SH, Park DS, Moon HB, Dho SH, Kwon KS, Kwon HJ, Han YH, Jeong S, Kang SW, Shin HS, Lee KK, Rhee SG, and Yu DY. Peroxiredoxin II is essential for sustaining life span of erythrocytes in mice. Blood 101: 5033-5038, 2003.

160. Leichert LI, Gehrke F, Gudiseva HV, Blackwell T, Ilbert M, Walker AK, Strahler JR, Andrews PC, and Jakob U. Quantifying changes in the thiol redox proteome upon oxidative stress in vivo. Proc Natl Acad Sci U S A 105: 8197-8202, 2008.

161. Li H, Mapolelo DT, Dingra NN, Naik SG, Lees NS, Hoffman BM, Riggs-Gelasco PJ, Huynh BH, Johnson MK, and Outten CE. The yeast iron regulatory proteins Grx3/4 and Fra2 form heterodimeric complexes containing a $[2 \mathrm{Fe}-2 \mathrm{~S}]$ cluster with cysteinyl and histidyl ligation. Biochemistry 48: 9569-9581, 2009. 
162. Li ZS, Szczypka M, Lu YP, Thiele DJ, and Rea PA. The yeast cadmium factor protein (YCF1) is a vacuolar glutathione S-conjugate pump. J Biol Chem 271: 6509-6517, 1996.

163. Lillig $\mathrm{CH}$, Berndt $\mathrm{C}$, and Holmgren A. Glutaredoxin systems. Biochim Biophys Acta 1780: 1304-1317, 2008.

164. Lillig $\mathrm{CH}$, Berndt $\mathrm{C}$, Vergnolle O, Lonn ME, Hudemann $\mathrm{C}$, Bill E, and Holmgren A. Characterization of human glutaredoxin 2 as iron-sulfur protein: a possible role as redox sensor. Proc Natl Acad Sci U S A 102: 8168-8173, 2005.

165. Little $\mathrm{C}$ and O'Brien PJ. Mechanism of peroxideinactivation of the sulphydryl enzyme glyceraldehyde-3phosphate dehydrogenase. Eur J Biochem 10: 533-538, 1969.

166. Lopreiato R, Facchin S, Sartori G, Arrigoni G, Casonato S, Ruzzene M, Pinna LA, and Carignani G. Analysis of the interaction between piD261/Bud32, an evolutionarily conserved protein kinase of Saccharomyces cerevisiae, and the Grx4 glutaredoxin. Biochem J 377: 395-405, 2004.

167. Lu SC. Glutathione synthesis. Biochim Biophys Acta 1830: 3143-3153, 2013.

168. Luikenhuis S, Perrone G, Dawes IW, and Grant CM. The yeast Saccharomyces cerevisiae contains two glutaredoxin genes that are required for protection against reactive oxygen species. Mol Biol Cell 9: 1081-1091, 1998.

169. Luo M, Jiang YL, Ma XX, Tang YJ, He YX, Yu J, Zhang RG, Chen Y, and Zhou CZ. Structural and biochemical characterization of yeast monothiol glutaredoxin Grx6. $J$ Mol Biol 398: 614-622, 2010.

170. Maiorino M, Bosello-Travain V, Cozza G, Miotto G, Roveri A, Toppo S, Zaccarin M, and Ursini F. Understanding mammalian glutathione peroxidase 7 in the light of its homologs. Free Radic Biol Med 83: 352-360, 2015.

171. Maiorino M, Scapin M, Ursini F, Biasolo M, Bosello V, and Flohe L. Distinct promoters determine alternative transcription of gpx-4 into phospholipid-hydroperoxide glutathione peroxidase variants. J Biol Chem 278: $34286-$ 34290, 2003.

172. Maiorino M, Ursini F, Bosello V, Toppo S, Tosatto SC, Mauri P, Becker K, Roveri A, Bulato C, Benazzi L, De Palma A, and Flohe L. The thioredoxin specificity of Drosophila GPx: a paradigm for a peroxiredoxin-like mechanism of many glutathione peroxidases. $\mathrm{J} \mathrm{Mol} \mathrm{Biol}$ 365: 1033-1046, 2007.

173. Malik SI, Hussain A, Yun BW, Spoel SH, and Loake GJ. GSNOR-mediated de-nitrosylation in the plant defence response. Plant Sci 181: 540-544, 2011.

174. Manta B, Hugo M, Ortiz C, Ferrer-Sueta G, Trujillo M, and Denicola A. The peroxidase and peroxynitrite reductase activity of human erythrocyte peroxiredoxin 2 . Arch Biochem Biophys 484: 146-154, 2009.

175. Martinez-Ruiz A, Araujo IM, Izquierdo-Alvarez A, Hernansanz-Agustin P, Lamas S, and Serrador JM. Specificity in S-nitrosylation: a short-range mechanism for $\mathrm{NO}$ signaling? Antioxid Redox Signal 19: 1220-1235, 2013.

176. Martinez Molina D, Eshaghi S, and Nordlund P. Catalysis within the lipid bilayer-structure and mechanism of the MAPEG family of integral membrane proteins. Curr Opin Struct Biol 18: 442-449, 2008.

177. Martins AM, Mendes P, Cordeiro C, and Freire AP. In situ kinetic analysis of glyoxalase I and glyoxalase II in Saccharomyces cerevisiae. Eur J Biochem 268: 3930-3936, 2001.
178. Massey V. Activation of molecular oxygen by flavins and flavoproteins. J Biol Chem 269: 22459-22462, 1994.

179. Mattevi A. To be or not to be an oxidase: challenging the oxygen reactivity of flavoenzymes. Trends Biochem Sci 31: 276-283, 2006.

180. McLaggan D, Rufino H, Jaspars M, and Booth IR. Glutathione-dependent conversion of N-ethylmaleimide to the maleamic acid by Escherichia coli: an intracellular detoxification process. Appl Environ Microbiol 66: 1393 1399, 2000

181. McLellan AC, Phillips SA, and Thornalley PJ. The assay of S-D-lactoylglutathione in biological systems. Anal Biochem 211: 37-43, 1993.

182. Meinecke M, Cizmowski C, Schliebs W, Kruger V, Beck $\mathrm{S}$, Wagner R, and Erdmann R. The peroxisomal importomer constitutes a large and highly dynamic pore. Nat Cell Biol 12: 273-277, 2010.

183. Mesecke N, Mittler S, Eckers E, Herrmann JM, and Deponte M. Two novel monothiol glutaredoxins from Saccharomyces cerevisiae provide further insight into ironsulfur cluster binding, oligomerization, and enzymatic activity of glutaredoxins. Biochemistry 47: 1452-1463, 2008.

184. Mesecke N, Spang A, Deponte M, and Herrmann JM. A novel group of glutaredoxins in the cis-Golgi critical for oxidative stress resistance. Mol Biol Cell 19: 2673-2680, 2008.

185. Mesecke N, Terziyska N, Kozany C, Baumann F, Neupert W, Hell K, and Herrmann JM. A disulfide relay system in the intermembrane space of mitochondria that mediates protein import. Cell 121: 1059-1069, 2005.

186. Messner KR and Imlay JA. The identification of primary sites of superoxide and hydrogen peroxide formation in the aerobic respiratory chain and sulfite reductase complex of Escherichia coli. J Biol Chem 274: 10119-10128, 1999.

187. Mieyal JJ, Gallogly MM, Qanungo S, Sabens EA, and Shelton MD. Molecular mechanisms and clinical implications of reversible protein S-glutathionylation. Antioxid Redox Signal 10: 1941-1988, 2008.

188. Molina MM, Belli G, de la Torre MA, RodriguezManzaneque MT, and Herrero E. Nuclear monothiol glutaredoxins of Saccharomyces cerevisiae can function as mitochondrial glutaredoxins. J Biol Chem 279: 51923 51930, 2004.

189. Montero D, Tachibana C, Rahr Winther J, and Appenzeller-Herzog C. Intracellular glutathione pools are heterogeneously concentrated. Redox Biol 1: 508-513, 2013.

190. Moore RB, Mankad MV, Shriver SK, Mankad VN, and Plishker GA. Reconstitution of $\mathrm{Ca}(2+)$-dependent $\mathrm{K}+$ transport in erythrocyte membrane vesicles requires a cytoplasmic protein. J Biol Chem 266: 18964-18968, 1991.

191. Morel F, Rauch C, Petit E, Piton A, Theret N, Coles B, and Guillouzo A. Gene and protein characterization of the human glutathione S-transferase kappa and evidence for a peroxisomal localization. J Biol Chem 279: 16246-16253, 2004.

192. Morgan B, Ezerina D, Amoako TN, Riemer J, Seedorf M, and Dick TP. Multiple glutathione disulfide removal pathways mediate cytosolic redox homeostasis. Nat Chem Biol 9: 119-125, 2013.

193. Morgan B, Van Laer K, Owusu TN, Ezerina D, PastorFlores D, Amponsah PS, Tursch A, and Dick TP. Real- 
time monitoring of basal $\mathrm{H} 2 \mathrm{O} 2$ levels with peroxiredoxinbased probes. Nat Chem Biol 12: 437-443, 2016.

194. Muhlenhoff U, Molik S, Godoy JR, Uzarska MA, Richter N, Seubert A, Zhang Y, Stubbe J, Pierrel F, Herrero E, Lillig CH, and Lill R. Cytosolic monothiol glutaredoxins function in intracellular iron sensing and trafficking via their bound ironsulfur cluster. Cell Metab 12: 373-385, 2010.

195. Muller EG. A glutathione reductase mutant of yeast accumulates high levels of oxidized glutathione and requires thioredoxin for growth. Mol Biol Cell 7: 1805-1813, 1996.

196. Muller S. Role and Regulation of glutathione metabolism in Plasmodium falciparum. Molecules 20: 10511-10534, 2015.

197. Munday R. Toxicity of thiols and disulphides: involvement of free-radical species. Free Radic Biol Med 7: 659673, 1989.

198. Nagy P. Kinetics and mechanisms of thiol-disulfide exchange covering direct substitution and thiol oxidationmediated pathways. Antioxid Redox Signal 18: 16231641, 2013.

199. Nagy P and Ashby MT. Reactive sulfur species: kinetics and mechanisms of the oxidation of cysteine by hypohalous acid to give cysteine sulfenic acid. J Am Chem Soc 129: 14082-14091, 2007.

200. Nelson KJ, Klomsiri C, Codreanu SG, Soito L, Liebler DC, Rogers LC, Daniel LW, and Poole LB. Use of dimedone-based chemical probes for sulfenic acid detection methods to visualize and identify labeled proteins. Methods Enzymol 473: 95-115, 2010.

201. Netto LE, de Oliveira MA, Tairum CA, and da Silva Neto JF. Conferring specificity in redox pathways by enzymatic thiol/disulfide exchange reactions. Free Radic Res 50: 206-245, 2016.

202. Nicholls P. Classical catalase: ancient and modern. Arch Biochem Biophys 525: 95-101, 2012.

203. Nickel C, Rahlfs S, Deponte M, Koncarevic S, and Becker K. Thioredoxin networks in the malarial parasite Plasmodium falciparum. Antioxid Redox Signal 8: 1227-1239, 2006.

204. Nordlund P and Reichard P. Ribonucleotide reductases. Annu Rev Biochem 75: 681-706, 2006.

205. Ogino N, Miyamoto T, Yamamoto S, and Hayaishi O. Prostaglandin endoperoxide E isomerase from bovine vesicular gland microsomes, a glutathione-requiring enzyme. J Biol Chem 252: 890-895, 1977.

206. Ogura Y. Catalase activity at high concentration of hydrogen peroxide. Arch Biochem Biophys 57: 288-300, 1955.

207. Ogusucu R, Rettori D, Munhoz DC, Netto LE, and Augusto O. Reactions of yeast thioredoxin peroxidases I and II with hydrogen peroxide and peroxynitrite: rate constants by competitive kinetics. Free Radic Biol Med 42: 326-334, 2007.

208. Ohdate $\mathrm{T}$ and Inoue Y. Involvement of glutathione peroxidase 1 in growth and peroxisome formation in Saccharomyces cerevisiae in oleic acid medium. Biochim Biophys Acta 1821: 1295-1305, 2012.

209. Okumura M, Kadokura H, and Inaba K. Structures and functions of protein disulfide isomerase family members involved in proteostasis in the endoplasmic reticulum. Free Radic Biol Med 83: 314-322, 2015.

210. Osawa H, Stacey G, and Gassmann W. ScOPT1 and AtOPT4 function as proton-coupled oligopeptide trans- porters with broad but distinct substrate specificities. Biochem J 393: 267-275, 2006.

211. Oshino N, Chance B, Sies H, and Bucher T. The role of $\mathrm{H} 2 \mathrm{O} 2$ generation in perfused rat liver and the reaction of catalase compound I and hydrogen donors. Arch Biochem Biophys 154: 117-131, 1973.

212. Ostergaard H, Tachibana C, and Winther JR. Monitoring disulfide bond formation in the eukaryotic cytosol. $J$ Cell Biol 166: 337-345, 2004.

213. Ott C, Jacobs K, Haucke E, Navarrete Santos A, Grune T, and Simm A. Role of advanced glycation end products in cellular signaling. Redox Biol 2: 411-429, 2014.

214. Outten CE and Albetel AN. Iron sensing and regulation in Saccharomyces cerevisiae: ironing out the mechanistic details. Curr Opin Microbiol 16: 662-668, 2013.

215. Outten CE and Culotta VC. Alternative start sites in the Saccharomyces cerevisiae GLR1 gene are responsible for mitochondrial and cytosolic isoforms of glutathione reductase. J Biol Chem 279: 7785-7791, 2004.

216. Outten CE, Falk RL, and Culotta VC. Cellular factors required for protection from hyperoxia toxicity in Saccharomyces cerevisiae. Biochem J 388: 93-101, 2005.

217. Ozyamak E, Black SS, Walker CA, Maclean MJ, Bartlett $\mathrm{W}$, Miller S, and Booth IR. The critical role of Slactoylglutathione formation during methylglyoxal detoxification in Escherichia coli. Mol Microbiol 78: 15771590, 2010.

218. Park JW, Piszczek G, Rhee SG, and Chock PB. Glutathionylation of peroxiredoxin I induces decamer to dimers dissociation with concomitant loss of chaperone activity. Biochemistry 50: 3204-3210, 2011.

219. Park SG, Cha MK, Jeong W, and Kim IH. Distinct physiological functions of thiol peroxidase isoenzymes in Saccharomyces cerevisiae. J Biol Chem 275: 5723-5732, 2000.

220. Parsonage D, Karplus PA, and Poole LB. Substrate specificity and redox potential of AhpC, a bacterial peroxiredoxin. Proc Natl Acad Sci U S A 105: 8209-8214, 2008.

221. Pedrajas JR, Kosmidou E, Miranda-Vizuete A, Gustafsson JA, Wright AP, and Spyrou G. Identification and functional characterization of a novel mitochondrial thioredoxin system in Saccharomyces cerevisiae. J Biol Chem 274: 6366-6373, 1999.

222. Pedrajas JR, Miranda-Vizuete A, Javanmardy N, Gustafsson JA, and Spyrou G. Mitochondria of Saccharomyces cerevisiae contain one-conserved cysteine type peroxiredoxin with thioredoxin peroxidase activity. $J$ Biol Chem 275: 16296-16301, 2000.

223. Pedrajas JR, Porras P, Martinez-Galisteo E, Padilla CA, Miranda-Vizuete A, and Barcena JA. Two isoforms of Saccharomyces cerevisiae glutaredoxin 2 are expressed in vivo and localize to different subcellular compartments. Biochem J 364: 617-623, 2002.

224. Peltoniemi MJ, Karala AR, Jurvansuu JK, Kinnula VL, and Ruddock LW. Insights into deglutathionylation reactions. Different intermediates in the glutaredoxin and protein disulfide isomerase catalyzed reactions are defined by the gamma-linkage present in glutathione. $J$ Biol Chem 281: 33107-33114, 2006.

225. Peralta D, Bronowska AK, Morgan B, Doka E, Van Laer K, Nagy P, Grater F, and Dick TP. A proton relay enhances $\mathrm{H} 2 \mathrm{O} 2$ sensitivity of GAPDH to facilitate metabolic adaptation. Nat Chem Biol 11: 156-163, 2015. 
226. Peskin AV, Pace PE, Behring JB, Paton LN, Soethoudt M, Bachschmid MM, and Winterbourn CC. Glutathionylation of the active site cysteines of peroxiredoxin 2 and recycling by glutaredoxin. J Biol Chem 291: 3053-3062, 2016.

227. Petrova VY, Drescher D, Kujumdzieva AV, and Schmitt MJ. Dual targeting of yeast catalase A to peroxisomes and mitochondria. Biochem J 380: 393-400, 2004.

228. Picciocchi A, Saguez C, Boussac A, Cassier-Chauvat C, and Chauvat F. CGFS-type monothiol glutaredoxins from the cyanobacterium Synechocystis PCC6803 and other evolutionary distant model organisms possess a glutathioneligated [2Fe-2S] cluster. Biochemistry 46: 15018-15026, 2007.

229. Prohaska JR and Ganther HE. Glutathione peroxidase activity of glutathione-s-transferases purified from rat liver. Biochem Biophys Res Commun 76: 437-445, 1976.

230. Puigpinos J, Casas C, and Herrero E. Altered intracellular calcium homeostasis and endoplasmic reticulum redox state in Saccharomyces cerevisiae cells lacking Grx6 glutaredoxin. Mol Biol Cell 26: 104-116, 2015.

231. Pujol-Carrion N, Belli G, Herrero E, Nogues A, and de la Torre-Ruiz MA. Glutaredoxins Grx3 and Grx4 regulate nuclear localisation of Aft1 and the oxidative stress response in Saccharomyces cerevisiae. J Cell Sci 119: 4554-4564, 2006.

232. Rabbani N and Thornalley PJ. Glyoxalase in diabetes, obesity and related disorders. Semin Cell Dev Biol 22: 309-317, 2011.

233. Rabbani N and Thornalley PJ. Measurement of methylglyoxal by stable isotopic dilution analysis LC-MS/MS with corroborative prediction in physiological samples. Nat Protoc 9: 1969-1979, 2014.

234. Rabenstein DL, and Millis KK. Nuclear magnetic resonance study of the thioltransferase-catalyzed glutathione/ glutathione disulfide interchange reaction. Biochim Biophys Acta 1249: 29-36, 1995.

235. Rahlfs S, Nickel C, Deponte M, Schirmer RH, and Becker K. Plasmodium falciparum thioredoxins and glutaredoxins as central players in redox metabolism. Redox Rep 8: 246250, 2003.

236. Reeves SA, Parsonage D, Nelson KJ, and Poole LB. Kinetic and thermodynamic features reveal that Escherichia coli BCP is an unusually versatile peroxiredoxin. Biochemistry 50: 8970-8981, 2011.

237. Reisz JA, Bechtold E, King SB, Poole LB, and Furdui CM. Thiol-blocking electrophiles interfere with labeling and detection of protein sulfenic acids. FEBS $J$ 280: 6150-6161, 2013.

238. Rhee SG, Chae HZ, and Kim K. Peroxiredoxins: a historical overview and speculative preview of novel mechanisms and emerging concepts in cell signaling. Free Radic Biol Med 38: 1543-1552, 2005.

239. Riemer J, Bulleid N, and Herrmann JM. Disulfide formation in the ER and mitochondria: two solutions to a common process. Science 324: 1284-1287, 2009.

240. Rodriguez-Manzaneque MT, Ros J, Cabiscol E, Sorribas A, and Herrero E. Grx5 glutaredoxin plays a central role in protection against protein oxidative damage in Saccharomyces cerevisiae. Mol Cell Biol 19: 8180-8190, 1999.

241. Rodriguez-Manzaneque MT, Tamarit J, Belli G, Ros J, and Herrero E. Grx5 is a mitochondrial glutaredoxin required for the activity of iron/sulfur enzymes. Mol Biol Cell 13: 1109-1121, 2002.
242. Rouhier N, Gelhaye E, Sautiere PE, Brun A, Laurent P, Tagu D, Gerard J, de Fay E, Meyer Y, and Jacquot JP. Isolation and characterization of a new peroxiredoxin from poplar sieve tubes that uses either glutaredoxin or thioredoxin as a proton donor. Plant Physiol 127: 1299-1309, 2001.

243. Rouhier N, Villarejo A, Srivastava M, Gelhaye E, Keech O, Droux M, Finkemeier I, Samuelsson G, Dietz KJ, Jacquot JP, and Wingsle G. Identification of plant glutaredoxin targets. Antioxid Redox Signal 7: 919-929, 2005.

244. Sato M, Sato K, and Nakano A. Endoplasmic reticulum quality control of unassembled iron transporter depends on Rer1p-mediated retrieval from the golgi. Mol Biol Cell 15: 1417-1424, 2004.

245. Schaedler TA, Thornton JD, Kruse I, Schwarzlander M, Meyer AJ, van Veen HW, and Balk J. A conserved mitochondrial ATP-binding cassette transporter exports glutathione polysulfide for cytosolic metal cofactor assembly. J Biol Chem 289: 23264-23274, 2014.

246. Schuppe-Koistinen I, Moldeus P, Bergman T, and Cotgreave IA. S-thiolation of human endothelial cell glyceraldehyde-3phosphate dehydrogenase after hydrogen peroxide treatment. Eur J Biochem 221: 1033-1037, 1994.

247. Schutte LD, Baumeister S, Weis B, Hudemann C, Hanschmann EM, and Lillig CH. Identification of potential protein dithiol-disulfide substrates of mammalian Grx2. Biochim Biophys Acta 1830: 4999-5005, 2013.

248. Schwarzlander M, Dick TP, Meyer AJ, and Morgan B. Dissecting redox biology using fluorescent protein sensors. Antioxid Redox Signal 24: 680-712, 2016.

249. Seaver LC and Imlay JA. Hydrogen peroxide fluxes and compartmentalization inside growing Escherichia coli. J Bacteriol 183: 7182-7189, 2001.

250. Segel I. Enzyme Kinetics: Behavior and Analysis of Rapid Equilibrium and Steady State Enzyme Systems. New York: John Wiley \& Sons, Inc., 1993.

251. Shenton D and Grant CM. Protein S-thiolation targets glycolysis and protein synthesis in response to oxidative stress in the yeast Saccharomyces cerevisiae. Biochem J 374: 513-519, 2003.

252. Sies $\mathrm{H}$. Role of metabolic $\mathrm{H} 2 \mathrm{O} 2$ generation: redox signaling and oxidative stress. J Biol Chem 289: 8735-8741, 2014.

253. Sies $\mathrm{H}$ and Chance B. The steady state level of catalase compound I in isolated hemoglobin-free perfused rat liver. FEBS Lett 11: 172-176, 1970.

254. Sobotta MC, Barata AG, Schmidt U, Mueller S, Millonig G, and Dick TP. Exposing cells to H2O2: a quantitative comparison between continuous low-dose and one-time highdose treatments. Free Radic Biol Med 60: 325-335, 2013.

255. Sobotta MC, Liou W, Stocker S, Talwar D, Oehler M, Ruppert T, Scharf AN, and Dick TP. Peroxiredoxin-2 and STAT3 form a redox relay for $\mathrm{HO}$ signaling. Nat Chem Biol 11: 64-70, 2014.

256. Sousa Silva M, Gomes RA, Ferreira AE, Ponces Freire A, and Cordeiro C. The glyoxalase pathway: the first hundred years... and beyond. Biochem J 453: 1-15, 2013.

257. Spickett CM. The lipid peroxidation product 4-hydroxy-2nonenal: advances in chemistry and analysis. Redox Biol 1: 145-152, 2013.

258. Srinivasan U, Mieyal PA, and Mieyal JJ. pH profiles indicative of rate-limiting nucleophilic displacement in thioltransferase catalysis. Biochemistry 36: 3199-3206, 1997.

259. Srinivasan V, Pierik AJ, and Lill R. Crystal structures of nucleotide-free and glutathione-bound mitochondrial ABC transporter Atm1. Science 343: 1137-1140, 2014. 
260. Staab CA, Hellgren M, and Hoog JO. Medium- and shortchain dehydrogenase/reductase gene and protein families: dual functions of alcohol dehydrogenase 3: implications with focus on formaldehyde dehydrogenase and $\mathrm{S}$ nitrosoglutathione reductase activities. Cell Mol Life Sci 65: 3950-3960, 2008.

261. Staudacher V, Djuika CF, Koduka J, Schlossarek S, Kopp J, Buchler M, Lanzer M, and Deponte M. Plasmodium falciparum antioxidant protein reveals a novel mechanism for balancing turnover and inactivation of peroxiredoxins. Free Radic Biol Med 85: 228-236, 2015.

262. Stearman R, Yuan DS, Yamaguchi-Iwai Y, Klausner RD, and Dancis A. A permease-oxidase complex involved in high-affinity iron uptake in yeast. Science 271: 15521557, 1996.

263. Stone JR and Yang S. Hydrogen peroxide: a signaling messenger. Antioxid Redox Signal 8: 243-270, 2006.

264. Sturm N, Jortzik E, Mailu BM, Koncarevic S, Deponte M, Forchhammer K, Rahlfs S, and Becker K. Identification of proteins targeted by the thioredoxin superfamily in Plasmodium falciparum. PLoS Pathog 5: e1000383, 2009.

265. Sturtz LA, Diekert K, Jensen LT, Lill R, and Culotta VC. A fraction of yeast $\mathrm{Cu}, \mathrm{Zn}$-superoxide dismutase and its metallochaperone, CCS, localize to the intermembrane space of mitochondria. A physiological role for SOD1 in guarding against mitochondrial oxidative damage. $J$ Biol Chem 276: 38084-38089, 2001.

266. Szajewski RP and Whitesides GM. Rate constants and equilibrium constants for thiol-disulfide interchange reactions involving oxidized glutathione. J Am Chem Soc 102: 2011-2026, 1980.

267. Takanishi CL, Ma LH, and Wood MJ. A genetically encoded probe for cysteine sulfenic acid protein modification in vivo. Biochemistry 46: 14725-14732, 2007.

268. Tang Y, Zhang J, Yu J, Xu L, Wu J, Zhou CZ, and Shi Y. Structure-guided activity enhancement and catalytic mechanism of yeast grx8. Biochemistry 53: 2185-2196, 2014.

269. Terziyska N, Grumbt B, Kozany C, and Hell K. Structural and functional roles of the conserved cysteine residues of the redox-regulated import receptor Mia40 in the intermembrane space of mitochondria. J Biol Chem 284: 1353-1363, 2009.

270. Thornalley PJ. The glyoxalase system: new developments towards functional characterization of a metabolic pathway fundamental to biological life. Biochem J 269: 1-11, 1990.

271. Thornalley PJ and Rabbani N. Glyoxalase in tumourigenesis and multidrug resistance. Semin Cell Dev Biol 22: 318-325, 2011.

272. Toledano MB, Delaunay-Moisan A, Outten CE, and Igbaria A. Functions and cellular compartmentation of the thioredoxin and glutathione pathways in yeast. Antioxid Redox Signal 18: 1699-1711, 2013.

273. Toppo S, Flohe L, Ursini F, Vanin S, and Maiorino M. Catalytic mechanisms and specificities of glutathione peroxidases: variations of a basic scheme. Biochim Biophys Acta 1790: 1486-1500, 2009.

274. Trotter EW and Grant CM. Overlapping roles of the cytoplasmic and mitochondrial redox regulatory systems in the yeast Saccharomyces cerevisiae. Eukaryot Cell 4: 392-400, 2005.

275. Trujillo M, Clippe A, Manta B, Ferrer-Sueta G, Smeets A, Declercq JP, Knoops B, and Radi R. Pre-steady state kinetic characterization of human peroxiredoxin 5: taking advantage of Trp84 fluorescence increase upon oxidation. Arch Biochem Biophys 467: 95-106, 2007.

276. Turell L, Botti H, Carballal S, Ferrer-Sueta G, Souza JM, Duran R, Freeman BA, Radi R, and Alvarez B. Reactivity of sulfenic acid in human serum albumin. Biochemistry 47: 358-367, 2008.

277. Uchida M, Sun Y, McDermott G, Knoechel C, Le Gros MA, Parkinson D, Drubin DG, and Larabell CA. Quantitative analysis of yeast internal architecture using soft Xray tomography. Yeast 28: 227-236, 2011.

278. Urade Y, Ujihara M, Horiguchi Y, Igarashi M, Nagata A, Ikai K, and Hayaishi O. Mast cells contain spleen-type prostaglandin D synthetase. J Biol Chem 265: 371-375, 1990.

279. Urscher M, Alisch R, and Deponte M. The glyoxalase system of malaria parasites-Implications for cell biology and general glyoxalase research. Semin Cell Dev Biol 22: 262-270, 2011.

280. Urscher $\mathrm{M}$ and Deponte $\mathrm{M}$. Plasmodium falciparum glyoxalase II: Theorell-Chance product inhibition patterns, rate-limiting substrate binding via $\operatorname{Arg}(257) /$ Lys(260), and unmasking of acid-base catalysis. Biol Chem 390: 1171-1183, 2009.

281. Urscher M, Przyborski JM, Imoto M, and Deponte M. Distinct subcellular localization in the cytosol and apicoplast, unexpected dimerization and inhibition of Plasmodium falciparum glyoxalases. Mol Microbiol 76: 92-103, 2010.

282. Ursini F, Heim S, Kiess M, Maiorino M, Roveri A, Wissing J, and Flohe L. Dual function of the selenoprotein PHGPx during sperm maturation. Science 285: 13931396, 1999.

283. Vall-Llaura N, Reverter-Branchat G, Vived C, Weertman N, Rodriguez-Colman MJ, and Cabiscol E. Reversible glutathionylation of Sir2 by monothiol glutaredoxins Grx3/4 regulates stress resistance. Free Radic Biol Med 96: 45-56, 2016.

284. Wachter A, Wolf S, Steininger H, Bogs J, and Rausch T. Differential targeting of GSH1 and GSH2 is achieved by multiple transcription initiation: implications for the compartmentation of glutathione biosynthesis in the Brassicaceae. Plant J 41: 15-30, 2005.

285. Wallace MA, Liou LL, Martins J, Clement MH, Bailey S, Longo VD, Valentine JS, and Gralla EB. Superoxide inhibits $4 \mathrm{Fe}-4 \mathrm{~S}$ cluster enzymes involved in amino acid biosynthesis. Cross-compartment protection by $\mathrm{CuZn}$-superoxide dismutase. J Biol Chem 279: 32055-32062, 2004.

286. Wang L, Wang X, and Wang CC. Protein disulfideisomerase, a folding catalyst and a redox-regulated chaperone. Free Radic Biol Med 83: 305-313, 2015.

287. Wang M, Weiss M, Simonovic M, Haertinger G, Schrimpf $\mathrm{SP}$, Hengartner MO, and von Mering C. PaxDb, a database of protein abundance averages across all three domains of life. Mol Cell Proteomics 11: 492-500, 2012.

288. Wang Y, Armando AM, Quehenberger O, Yan C, and Dennis EA. Comprehensive ultra-performance liquid chromatographic separation and mass spectrometric analysis of eicosanoid metabolites in human samples. $J$ Chromatogr A 1359: 60-69, 2014.

289. Waszczak C, Akter S, Eeckhout D, Persiau G, Wahni K, Bodra N, Van Molle I, De Smet B, Vertommen D, Gevaert K, De Jaeger G, Van Montagu M, Messens J, and Van Breusegem F. Sulfenome mining in Arabidopsis thaliana. Proc Natl Acad Sci U S A 111: 11545-11550, 2014. 
290. Wendler A, Irsch T, Rabbani N, Thornalley PJ, and Krauth-Siegel RL. Glyoxalase II does not support methylglyoxal detoxification but serves as a general trypanothione thioesterase in African trypanosomes. $\mathrm{Mol}$ Biochem Parasitol 163: 19-27, 2009.

291. Weydert CJ and Cullen JJ. Measurement of superoxide dismutase, catalase and glutathione peroxidase in cultured cells and tissue. Nat Protoc 5: 51-66, 2010.

292. Wickner RB. [URE3] as an altered URE2 protein: evidence for a prion analog in Saccharomyces cerevisiae. Science 264: 566-569, 1994.

293. Winterbourn CC. The challenges of using fluorescent probes to detect and quantify specific reactive oxygen species in living cells. Biochim Biophys Acta 1840: 730 738, 2014.

294. Winterbourn CC and Hampton MB. Thiol chemistry and specificity in redox signaling. Free Radic Biol Med 45: 549-561, 2008.

295. Winterbourn CC and Metodiewa D. Reactivity of biologically important thiol compounds with superoxide and hydrogen peroxide. Free Radic Biol Med 27: 322-328, 1999.

296. Winther JR and Thorpe C. Quantification of thiols and disulfides. Biochim Biophys Acta 1840: 838-846, 2014.

297. Wolfe KH and Shields DC. Molecular evidence for an ancient duplication of the entire yeast genome. Nature 387: 708-713, 1997.

298. Wong CM, Siu KL, and Jin DY. Peroxiredoxin-null yeast cells are hypersensitive to oxidative stress and are genomically unstable. J Biol Chem 279: 23207-23213, 2004.

299. Wood ZA, Poole LB, and Karplus PA. Peroxiredoxin evolution and the regulation of hydrogen peroxide signaling. Science 300: 650-653, 2003.

300. Zaffagnini M, Bedhomme M, Marchand $\mathrm{CH}$, Couturier JR, Gao XH, Rouhier N, Trost P, and Lemaire SP. Glutaredoxin s12: unique properties for redox signaling. Antioxid Redox Signal 16: 17-32, 2012.

301. Zahedi Avval F and Holmgren A. Molecular mechanisms of thioredoxin and glutaredoxin as hydrogen donors for Mammalian s phase ribonucleotide reductase. J Biol Chem 284: 8233-8240, 2009.

302. Zhang B, Bandyopadhyay S, Shakamuri P, Naik SG, Huynh BH, Couturier J, Rouhier N, and Johnson MK. Monothiol glutaredoxins can bind linear [Fe3S4]+ and [Fe4S4]2+ clusters in addition to [Fe2S2]2+ clusters: spectroscopic characterization and functional implications. J Am Chem Soc 135: 15153-15164, 2013.
Address correspondence to: Prof. Marcel Deponte Department of Parasitology Ruprecht-Karls University Im Neuenheimer Feld 324

Heidelberg D-69120

Germany

E-mail: marcel.deponte@gmx.de

Date of first submission to ARS Central, April 19, 2017; date of acceptance, May 22, 2017.

\begin{tabular}{|c|}
\hline 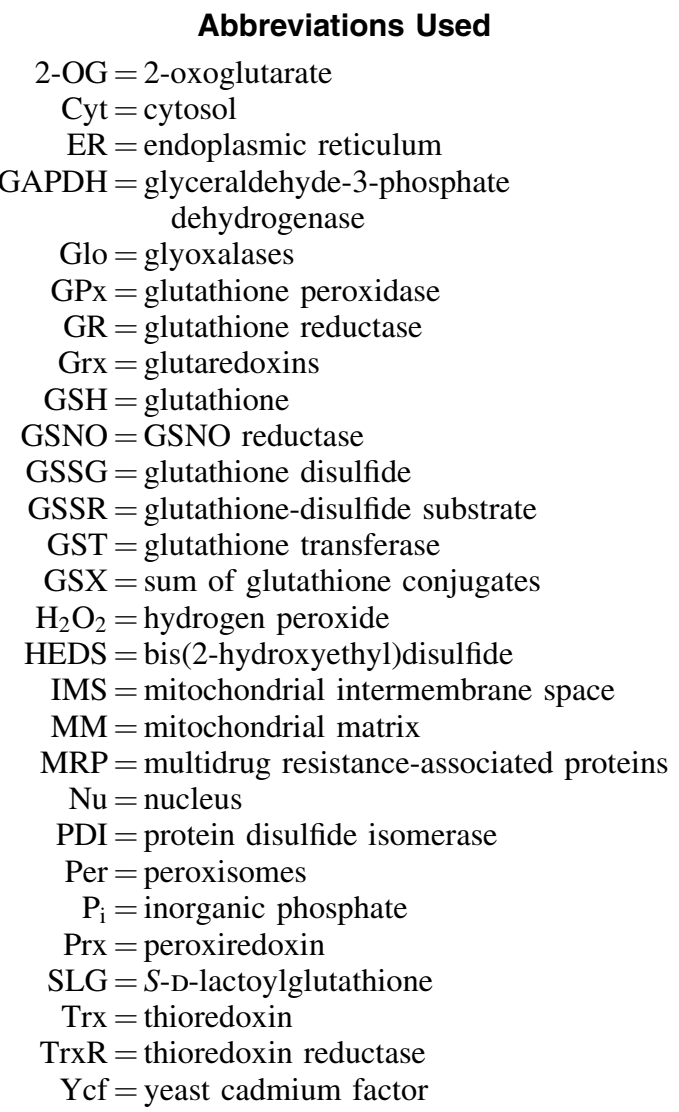 \\
\hline
\end{tabular}

